International Scientific-Technical and Production Journal

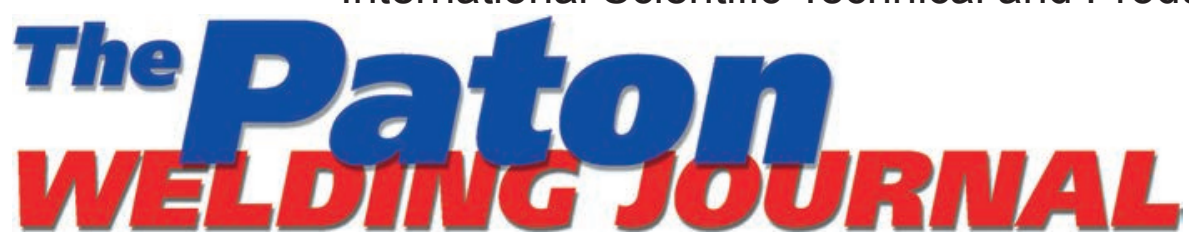

English Translation of the Monthly «Avtomatychne Zvaryuvannya»

(Avtomaticheskaya Svarka/Automatic Welding) Journal Published in Ukrainian and Russian Since 1948

\section{EDITORIAL BOARD}

E.O. Paton Electric Welding Institute, Kyiv, Ukraine: B.E. Paton (Editor-in-Chief),

S.I. Kuchuk-Yatsenko (Deputy Editor-in-Chief),

V.M. Lipodaev (Deputy Editor-in-Chief),

O.M. Berdnikova, Yu.S. Borisov,

V.V. Knysh, I.V. Krivtsun, Yu.M. Lankin,

L.M. Lobanov, S.Yu. Maksimov,

M.O. Pashchin, V.D. Poznyakov,

I.O. Ryabtsev, K.A. Yushchenko; V.V. Dmitrik, NTUU

«Kharkiv Polytechnic Institute», Kharkiv, Ukraine; V.V. Kvasnitsky, NTUU

«Igor Sikorsky Kyiv Polytechnic Institute», Kyiv, Ukraine;

E.P. Chvertko, NTUU

«Igor Sikorsky Kyiv Polytechnic Institute», Kyiv, Ukraine;

M.M. Student, Karpenko Physico-Mechanical Institute, Lviv, Ukraine;

M. Zinigrad, Ariel University, Israel;

Ya. Pilarczyk, Welding Institute, Gliwice, Poland;

U. Reisgen, Welding and Joining Institute, Aachen, Germany

\section{Founders}

E.O. Paton Electric Welding Institute International Association «Welding» Publisher

International Association «Welding» Translators

A.O. Fomin, I.M. Kutianova Editor

N.G. Khomenko

Electron galley

D.I. Sereda, T.Yu. Snegiryova Address

E.O. Paton Electric Welding Institute International Association «Welding»

11 Kazimir Malevich Str. (former Bozhenko), 03150, Kyiv, Ukraine

Tel.:/Fax: (38044) 2008277

E-mail: journal@paton.kiev.ua

www://patonpublishinghouse.com/eng/journals/tpwj

State Registration Certificate
KV 4790 of 09.01 .2001 KV 4790 of 09.01 .2001
ISSN 0957-798X

DOI: http://dx.doi.org/10.15407/tpwj Subscriptions

12 issues per year, back issues available. $\$ 384$, subscriptions for the printed (hard copy) version, air postage and packaging included.

$\$ 312$, subscriptions for the electronic version (sending issues of Journal in pdf format or providing access to IP addresses).

Institutions with current subscriptions on printed version

can purchase online access to the electronic versions of any back issues that they have not subscribed to.

Issues of the Journal (more than two years old)

are available at a substantially reduced price.

All rights reserved.

This publication and each of the articles contained herein are protected by copyright.

Permission to reproduce material contained in this journal must be obtained in writing from the Publisher.

\section{CONTENTS}

\section{SCIENTIFIC AND TECHNICAL}

Lashchenko G.I. Welding production in the economy of Ukraine

Lobanov L.M., Asnis E.A., Piskun N.V., Vrzhizhevsky E.L., Milenin A.S. and Velikoivanenko E.A. Investigation of stress-strain state of welded

joints of the system TiAl intermetallics

Krektuleva R.A., Saraev YU.N., SEMENCHUK V.M. and Cherepanov R.O.

Self-organization of thermal processes in welding sheet low-alloyed

steel

Borisov Yu.S., Voinarovych S.G., Kyslytsia A.N., Kuzmych-Yanchuk E.K. and Kaliuzhnyi S.N. Investigation of electrical and thermal characteristics of plasmatron for microplasma spraying of coatings from powder

materials

Boi U. and Krivtsun I.V. Processes of nonconsumable electrode welding with welding current modulation (Review). Part 1. Peculiarities of burning of nonstationary arcs with refractory cathode

Ivanov V.P., Leshchynskyi L.K. and Shcherbakov S.V. Modeling the technology of deposition of a layer of variable chemical composition

\section{INDUSTRIAL}

Drimal D., Kasencak M., Kolenic F., Kramarcik A. and Kovac L.

Pecularities of electron beam welding of hot-rolled aluminum-lithium

alloys

Knysh V.V., Osadchuk S.O., Solovei S.O., Nyrkova L.I. and Rybakov A.O. Procedure of accelerated corrosion testing for modeling the long-term effect of moderate climate atmosphere on welded joints

\section{BRIEF INFORMATION}

Nesterenkov V., Khrypko K. and Lukyanov V. Multipurpose electron beam welding machine

CALENDAR OF NOVEMBER 53 


\title{
WELDING PRODUCTION IN THE ECONOMY OF UKRAINE
}

\author{
G.I. LASHCHENKO \\ STC «E.O. Paton Electric Welding Institute of the NAS of Ukraine» \\ 11 Kazymyr Malevich Str., 03150, Kyiv, Ukraine. E-mail: office@stc-paton.com
}

\begin{abstract}
The growth in volumes of production and consumption of structural materials continues to be an important component in the development of modern economy. For stabilization and growth of the Ukrainian economy, it is necessary to dramatically increase the consumption of rolled metal with an emphasis on industrial construction, implementation of large-scale infrastructure projects, heavy, power and transport engineering. Moreover, the processes of welding, cutting, surfacing and coating are the most preferred and widespread means for creating a wide range of competitive products. In the near term, it remains vitally important for Ukraine to maintain different power, processing, mining, agricultural, defence equipment and infrastructure facilities in order to extend their service life through the use of innovative welding and metal treatment technologies. 9 Ref., 2 Figures.
\end{abstract}

Ke y words : welding production, national economy, metal consumption, industry of Ukraine, machine building and innovative technologies, small business

Role of welding in the development of the national economy. The highly-developed material production is the basis of modern civilization. A large role here is played by structural materials. At first, the $20^{\text {th }}$ century was called the «cast iron age», since the melting of cast iron in the world exceeded the production of steel, and in 1913 it amounted to $78.5 \mathrm{mln} \mathrm{t}$ (steel — $72.4 \mathrm{mln} \mathrm{t}$ ). By the end of the $20^{\text {th }}$ century, steel production reached $800 \mathrm{mln} \mathrm{t}$, and the production of cast iron — about 500 mln t (approximately $63 \%$ ), which allowed calling it the «steel age». In the second half of the $20^{\text {th }}$ century, such knowledge-intensive technologies of steel production as vacuum arc remelting, electron beam melting, plasma remelting, electroslag and induction melting were developed and introduced into the industry. The development of these processes was stimulated not only by the need in manufacturing civilian industry products, but to an even greater extent by the requirements of the military-industrial complex, which needed a high-quality metal to solve its problems.

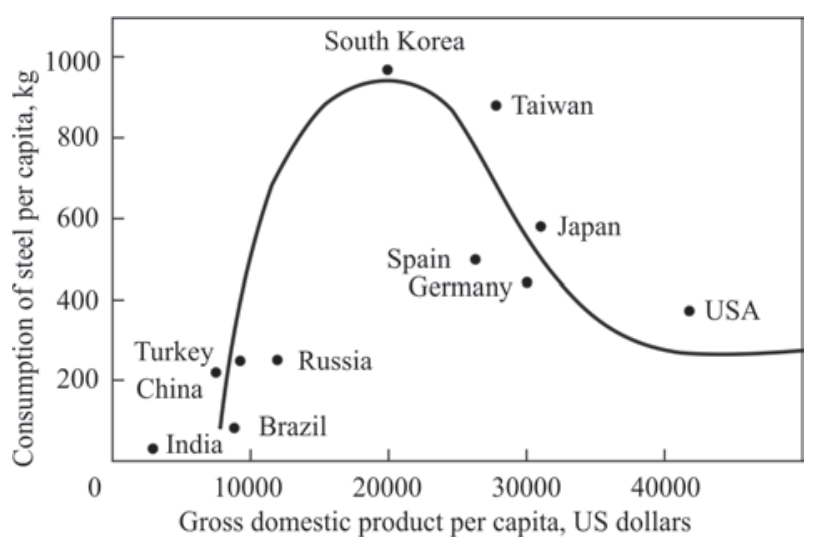

Figure 1. Curve of intensity of steel application

(c) G.I. LASHCHENKO, 2019
Analysts from the International Iron and Steel Institute (IISI) came to the firm conclusion about a direct correlation between the growth in steel consumption and the general economic level of countries with high growth rates of gross domestic product (GDP). By the end of the $20^{\text {th }}$ century and in the subsequent years in such countries as the USA, Germany, and Japan, the annual consumption of rolled steel was maintained at the level of 420-590 kg/person. In Ukraine, in 2007 the own consumption of rolled steel amounted to approximately $25 \%$ of the industrial, i.e. $8.7 \mathrm{mln} \mathrm{t}$, and the specific consumption of rolled products reached approximately $190 \mathrm{~kg} /$ person. In Russia, this indicator was at the level of $250 \mathrm{~kg} /$ person. For many countries, an increase in domestic steel consumption is an essential condition for building a highly-developed economy (Figure 1) [1]. Therefore, the dynamic development of the Ukrainian economy is impossible without a significant increase in metal consumption. At the same time, in connection with the intensification of the deindustrialization process in the Ukrainian economy, in 2013 the specific consumption of rolled steel decreased to about $140 \mathrm{~kg} /$ person.

Although steel holds a leading position in the world market (93\% by weight of the total production of structural materials), its positions are pressed by aluminum, plastics and polymers; composites and ceramics are being introduced into production. Alloys based on nonferrous metals ( $\mathrm{Al}, \mathrm{Cu}, \mathrm{Ni}, \mathrm{Mg}, \mathrm{Ti})$ and plastics amount to about $7 \%$ of the group of structural materials. In the group of nonferrous metals and plastics, dominating positions are occupied by aluminum (38 \%) and plastics (23\%) [2].

Starting from the second half of the $20^{\text {th }}$ century, the demand for steel was satisfied not only due to the growth of the physical volume, but to a significant ex- 
tent due to its quality. The increase in strength and other service characteristics of steel contributed to the stabilization of its consumption (by weight). A certain effect on steel consumption was also caused by the expansion in the use of aluminum and plastics.

Over the past 20 years, more than 1000 new grades of steels for different purposes have appeared on the world market, the range of rolled steel has expanded significantly, including with different coatings. Unfortunately, amid the situation in the world, achievements of Ukrainian metallurgists look very modest.

In advanced countries with the developed economy, the main consumers of steel are industrial and civil engineering, shipbuilding, heavy and power engineering, automotive, transport engineering and pipeline transport. For most of these countries, automotive and shipbuilding industries are the locomotives of the modern economy.

The industrial use of aluminum is caused by its low density $\left(2.7 \mathrm{~g} / \mathrm{cm}^{3}\right)$, which is approximately three times less than that of steel, increased cold resistance, corrosion resistance in oxidizing environments and in air.

Aluminum and its alloys are characterized by a low melting point (the melting point of pure aluminum is $660^{\circ} \mathrm{C}$ ), high thermal and electrical conductivity, increased linear expansion coefficient as compared to steel, and a lower elasticity modulus.

Aluminum alloys are widely used in many branches of machine building, as well as in civil and industrial construction [3]. Moreover, in aircraft vehicles, the share of structural materials from aluminum alloys occupies up to $80 \%$ of their weight. In the last decade, a special attention has been paid to the use of aluminum alloys in automobile, carriage and shipbuilding. A significant part of aluminum products in the form of ultra thin rolled metal and foil goes to the production of containers and packaging.

In 2003, the average consumption of aluminum and its alloys per capita was the following: in Ukraine - $2.0 \mathrm{~kg}$, in Russia - $2.5 \mathrm{~kg}$, in Western Europe — $19.8 \mathrm{~kg}$, in Germany — $27.1 \mathrm{~kg}$, in Japan $27.9 \mathrm{~kg}$ and in the USA - $29.2 \mathrm{~kg}$ [3]. The growth in the consumption of aluminum alloys in different countries is usually associated with the release of new products. It should be noted that as to the values of ratio of strength and yield to density, high-strength aluminum alloys are significantly superior to cast iron, low-carbon and low-alloy steels, pure titanium and are only inferior to high-alloy steels of higher strength and titanium alloys.

It is considered, that a factor restraining the volume of aluminum production is its cost, determined by a high energy consumption of metallurgical production of aluminum.
According to [3] in 2003, a domestic demand for aluminum products in Ukraine amounted to about 360 thou t per year. The main consumers were construction industry (275-280 thou t) and aerospace industry (52 thou t). The rest was the manufacture of cable products and packaging foil.

In the world practice, titanium alloys of different strength groups have also gained an industrial application [2]. The group of low-strength alloys includes alloys with a tensile strength of up to 750-800 MPa; medium-strength alloys have a strength of 11001200 MPa without a heat treatment; high-strength titanium alloys after strengthening heat treatment (hardening and subsequent aging) can have a strength of more than $1400 \mathrm{MPa}$.

The main advantages of titanium and its alloys include:

- high corrosion resistance in many natural, biological and technological environments, where the use of traditional steels and alloys is impossible or requires additional methods of protection;

- higher or equivalent specific strength and fatigue life in comparison with corrosion-resistant steels and alloys;

- ecological cleanness and a good biological compatibility with living tissues, which allows the successful use of titanium and its alloys for the manufacture of endoprostheses.

Due to its unique properties, titanium finds its application as a structural material for the construction of submarines, aircrafts, rockets and space vehicles, automobiles, small coastal vessels as well as in the production of consumer goods. Titanium alloys are used for the manufacture of heat exchange equipment of NPP, hydrofoils, propellers, stressed elements of the bottom part of offshore platforms, drill pipes, etc.

Among the new rapidly growing applications of titanium, it is worth noting the construction of liquefied gas plants and regasification terminals (up to 250 tons of rolled titanium per a unit). In general, the manufacture of titanium products in the form of rolled ingots, slabs, forgings is considered a very promising area of production, taking into account the global increase in demand for these products [4].

It should be noted that in Ukraine 16 deposits of titanium ores of different degree of credibility were explored and 14 are in operation (see B. Sobolev. Stockholm Syndrome of Ukrainian Titanium. ZN.UA - 2018. - No. 17). According to the data of the US Geological Survey, in Ukraine $1 \%$ of the world's reserves of ilmenite and $5 \%$ of rutile are concentrated, and this is the main raw material for the production of titanium. According to different sources, the indicator of the share of Ukraine in the explored reserves of titanium ores is $20 \%$. 
Ukraine has all the elements of the titanium production chain by Kroll process from extraction of ores (ilmenite, rutile) to rolling of finished metal and producing strength, nonmagnetic pipes and other products. In addition, in Zaporozhye a specialized Institute of Titanium operates. Also, Zaporozhye Titanium-Magnesium Plant (ZTMK), production of pigments at the «Sumykhimprom» and at the «Crimea Titan» as well as electron beam melting of finished titanium slabs and billets at three Kiev enterprises should be mentioned. Among the latter, the Antares plant should be distinguished with a capacity of 5 thou $t$ of titanium slabs per year, which is about $7 \%$ of the world production of these products. Four electron beam furnaces finished in 2000-2016 together with ZTMK are able to melt over a half of the titanium sponge into a high-quality commercial metal. The Scientific and Production Center «Titan» at the E.O. Paton Electric Welding Institute can melt 3 thou t of titanium billets per year and roll them into pipes to strengthen oil wells. The Transcarpathian Metallurgical Plant (town of Vyshkovo, Transcarpathian region) produces up to 3600 tons of titanium powders per year. Recently, all three enterprises are held hostage by a one monopolist, which is ZTMK, and mostly stand idle.

The global consumption of rolled titanium is approximately 135 thou t per year.

The Russian corporation «VSMPO-Avisma» annually produces about 30 thou $t$ of finished rolled titanium and its alloys, including about 10-12 thou t for its own consumption (the main consumers are military-industrial complex and aerospace industry). The dependence of Boeing Company on Russian supplies of rolled titanium amounts to $45 \%$, that of EADS is about 60 \%, Bombardier, Embrayer, Pratt \& Whitney, Rolls-Royce - to almost $100 \%$.

Ukraine so far supplies mainly titanium ore concentrate to the world markets. Thus, according to the data of the State Customs Committee and the State Statistics Service, 295 thou t were shipped in 2015, 463 thou $t$ in 2016, and 583 thou $t$ in 2017, of which about $35 \%$ of the mentioned concentrate were shipped directly from the Russian Federation. At the same time, during 2003-2017 the average selling price of ilmenite concentrate amounted to not more than 20 US dollars per ton. At the same time, from a one ton of concentrate about $200 \mathrm{~kg}$ of metallic titanium can be produced, the price of which in the mentioned period ranged from 5 to 40 US dollars per kilogram. If Ukraine had the corresponding production capacities of rolled titanium, then it would not lose from 625 to $5000 \%$ of profitability. The processing of rolled metal into the end products such as medical prostheses, sports equipment or spectacle frames would provide an added value from 600 to $1200 \%$.
According to the estimates of experts, to create the own production of rolled titanium in Ukraine with a capacity equal to Russian, about 2.5 bln US dollars are required. There are companies and people throughout the world interested in that, but to attract them, the purposeful work of the government and other state structures is needed.

In material production, different technologies for shaping of metal products (stamping, bending, casting, forging, welding, etc.) are used. At the same time, many years of world experience testifies to the many advantages of using welding technologies [5].

However, it should be noted that welding is only a definite technological method for producing permanent joints and therefore, it cannot be an independent production by itself, or end in any production process. It should be considered as a means to achieve another goal - producing welded structures or directly products. The manufacture of welded structures represents a complex production process, consisting of a whole range of interrelated operations that differ in their nature, duration and purpose. Here, different technologies are used. At the stage of preparing rolled metal, straightening and cleaning dominate. In the process of manufacturing parts for welded structures, different technologies of cutting, bending and stamping are used. The assembly and welding operations are performed based on the application of different welding techniques and methods and postweld treatment is carried out using the technological processes that reduce stress-strain state and improve the structural and physicomechanical characteristics of welded joints.

The abovementioned package of works is generally considered as welding production, which is necessarily organized taking into account the characteristics and nature of a product manufactured by the relevant branch (machine building, automobile, shipbuilding, aerospace, etc.).

Recently, the term "welding production» is interpreted more widely [6]. The composition of welding production includes research centers, leading research and development works on new welding technologies, equipment and materials; industrial enterprises producing welded structures, main and auxiliary welding equipment, welding consumables, means for industrial and environmental protection; a network of organizations providing communication between the developers and consumers of welding equipment; system for training engineering and working personnel, consisting of educational establishments of the IIV accreditation levels and vocational schools.

Welding production in its development covered a path from performing a separate welding operation, which has an auxiliary character (rewelding of defects 
of casting and forging parts, repair of worn parts, etc.), to performing complex operations at the modern workplaces, sections, workshops, plants-welding centers, formed by technological, subject or mixed principles.

More than a half of the gross national product of industrialized countries is created by welding and related technologies. In this case, up to 2/3 of the global consumption of rolled steel goes to the production of welded structures and erections, and the thickness of welded parts ranges from micrometers to meters, the mass of welded structures - from fractions of a gram to hundreds and thousands of tons [1].

Welding and related technologies make it possible to create original designs of modern cars, aircrafts, ships, locomotives and wagons, apparatuses and installations for chemical industry and power engineering, provide a high reliability of pipeline transport, many types of building constructions, electronic means and devices, including those operating in extreme conditions, rocket and space engineering, etc.

The widespread use of welded structures (WS) is predetermined by the possibility of:

- combining the advantages of a composite structure in production with the advantages of monolithic structures in operation;

- expanding the selection of more rational design solutions when creating high-quality and reliable structures;

- using dissimilar materials in structures that are most suitable for the operating conditions of different elements, which makes it possible to fully use the properties of materials, reduce the weight and metal consumption of structures;

- reducing production costs by improving the technology of parts manufacturing.

Depending on the purpose of welded structures and the requirements specified to them, certain structural materials are used.

Welding production played a key role in the formation of an industrial society, which is especially vividly illustrated on the example of the USSR [7].

At this stage, the main driving factor of development was the opportunities provided by welding technologies in creating new types of products and increasing the scale of their production.

Postindustrial society originated from the industrial society and was formed on its basis. Therefore, the tasks solved by welding production in the postindustrial period are partially preserved. This refers to the creation of new types of products and the increase in their output volumes. However, the task of the first priority is providing a high quality of products with new consumer characteristics, including the quality of welding products themselves, i.e., welded structures.
On the one hand, welding production, being one of the elements of a postindustrial society, participates in its formation by providing its products, and on the other hand it uses the achievements of a postindustrial society for its development. At the same time, the increase in the knowledge-intensive technologies in welding production contributes to the improvement of quality of products, their efficiency and competitiveness. According to the American and German Welding Societies, the processes of welding, cutting and coating in the future also will be the most preferable and widespread methods to create a wide range of competitive materials and products.

Welding production, most of which is concentrated in the structure of machine building enterprises, fully experienced negative processes in the country's economy that have taken place in recent years. At the same time, in Ukraine there are several potential directions for increasing metal consumption.

At the facilities of basic industries in Ukraine (ferrous and nonferrous metallurgy, machine building, power, coal mining, oil and gas industries, etc.) $36 \mathrm{mln} t$ of load-carrying metal structures are in service [8]. The diagram of the fund of metal structures being in service is shown in Figure 2. The majority of metal structures are the structures of buildings and erections (about $60 \%$ ), metal sheet erections (mainly steel tanks), electrical grid facilities (masts, power transmission towers), as well as bridges. The basis of the metal fund being in service consists of metal structures put into operation in 1950-1983, i.e. they served 33-66 years.

According to the carried out studies [8], the physical wear of metal structures at the time of their failure amounts to $35-40 \%$. Regarding industrial buildings, this means that the average service life is $40-50$ years. According to the estimates of experts, by 2001, $7-8 \%$ of the existing metal fund was already at the

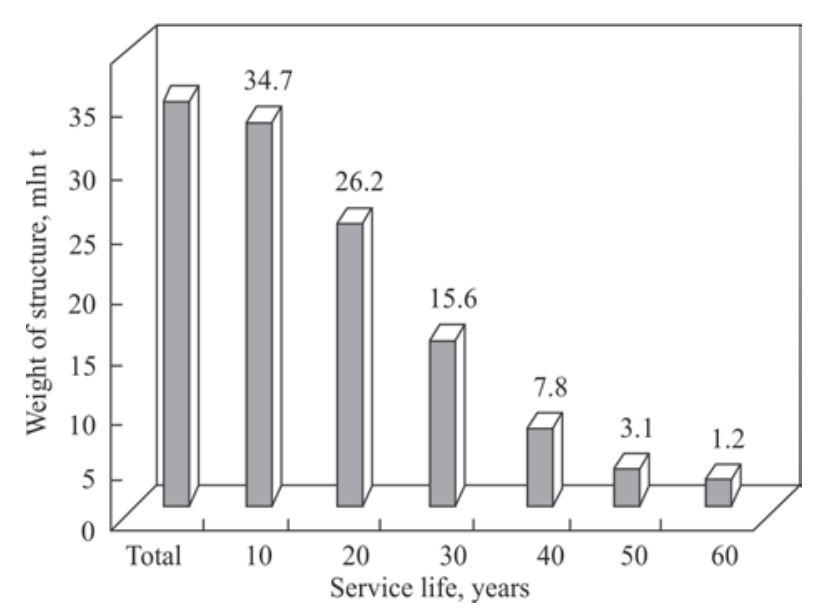

Figure 2. Diagram of fund of metal structures being in service in Ukraine 
ending stage of its service life. In the last years the situation has worsened. The lack of financies for the replacement of structures forces owners to extend the life of structures, the physical wear of which reaches 35-40\%, which often leads to accidents and the material damage is tens of times higher than the cost of their restoration and replacement.

Today it can be stated that more than $25 \%$ (3 mln t) of the existing metal fund of building structures needs urgent replacement [9]. Technically, this task does not cause great difficulties, since Ukraine has the production facilities capable of producing up to 450 thou t of metal structures for different purposes annually. But for this purpose, a state program of works with related financial resources should be developed.

According to the data of «Ukravtodor», about $10 \mathrm{mln}$ t of rolled metal produced by domestic metallurgical plants will be needed only for the reconstruction of principal roads.

Significant volumes of rolled steel (at least $2 \mathrm{mln} \mathrm{t}$ during 5 years) are required to restore the rolling stock of railways. Such railway car building works of Ukraine as PJSC «Kryukovsky Railway Car Building Works», PJSC «Azovvagonmash» and PJSC «Dneprovagonmash» still have some opportunities for the annual production of 15-20 thou of new cars.

A huge metal fund has been accumulated in the gas transportation system (GTS) of Ukraine, the total length of which is 37.6 thou $\mathrm{km}$; including the length of main gas pipelines - 22.2 thou $\mathrm{km}$. As a part of the GTS, 81 compressor stations are operating with 765 gas pumping units with a total capacity of $5.6 \mathrm{mln} \mathrm{kW}$.

The aging of the main funds of GTS not only reduces the reliability of its operation, but is also fraught with sudden destructions, accidents and it endangers the life and health of the working personnel and people living in the areas where the gas pipelines are laid. At the same time, gas-pumping units of GTS are obsolete, energy-consuming, which leads to excessive gas consumption for own needs, which in 2006 amounted to 4.6 bln $\mathrm{m}^{3}$.

Over the years of independence of Ukraine, thanks to the efforts of scientists and specialists of the E.O. Paton Electric Welding Institute and other organizations, the diagnostic methods and repair technologies were developed that help to extend the life of pipelines and other critical technical systems and facilities. However, the problem of degradation of the linear part of pipelines cannot be solved only by the use of repair technologies. Replacement of pipes on long sections of the GTS with new pipes of modern steel is inevitable. Fundamental proposals were also prepared for the modernization of gas compressor stations of GTS using the scientific and production potential of the domestic enterprises «Zorya-Mashproekt» (Nikolaev),
OJSC «M.V. Frunze Sumy Machine Building Scientific Production Association», JSC Motor-Sich (Zaporozhye), possessing advanced technologies of electron beam welding, brazing, thermal spraying, etc.

In the meantime, the fate of the Ukrainian GTS is in a «suspended» state. Although NAK has not been purchasing Russian gas for Ukrainian consumers since the autumn of 2015, the obligations of transporting the gas of «Gazprom» through our transportation systems are fulfilled properly. Thus, «Ukrtransgaz» supplied the following volumes of Russian gas to consumers: in 2017 - 93.5, in 2016 - 82.2, in 2015 - 67.1, in $2014-62.2$ bln $\mathrm{m}^{3}$. In 2019, the contract between «Naftogaz» of Ukraine and «Gazprom» on the transit of natural gas to the EU is ending. Russia continues to push an idea of constructing an alternative «Nord Stream-2».

For Ukraine, the important issue is even not the amount of profit from transit (more than 2 bln dollars/ year), but the guaranteed volumes of gas that allow loading pipelines and preserving the GTS. It is possible to solve this problem by cooperation with a European partner - operator of the gas transportation system, who in the future together with «Naftogaz» of Ukraine will conduct negotiations with «Gazprom» on the supply of gas to the EU.

In December 2017, the Government of Ukraine officially began the procedure of selecting an international partner for the joint management of the Ukrainian GTS. By the autumn of 2018, Germany and other European countries agreed to the construction of the «Nord Stream-2» gas pipeline. Most likely it will be built in any case. Therefore, the issue of transportation of gas to Europe via Ukrainian pipelines has become even more acute. Many decisions on this issue depend on the positions of the USA, EU and Russia and on our government as well, although to a lesser extent. Certain prospects for increasing metal consumption in Ukraine are associated with an increase in the use of renewable energy (wind, solar, biogas and biofuel), which should form the basis of our energy strategy. The question is, first of all, about the creation of wind power plants and pumped storage units, and in the long term - the construction of a Pan-Eurasian energy system.

Other directions can also be mentioned. For example, according to the American entrepreneur Elon Musk, out of 11 branches of the superhigh-speed ground transport Hyperloop 5, branches can go through the territory of Ukraine, three of which are drawn through Kyiv: the first will connect China, Europe and Canada, the second - Asia, the Middle East, Europe and North Africa, and the third - Spain and China. By means of such a transport, it will be possible to get from Dnipo and Kryvyi Rih to India, and from Kharkiv, Donetsk or Odessa to America. This is not fiction, however not a day of tomorrow as well. 
For the next 5-7 years it remains vitally important for Ukraine to maintain different energy processing, mining, agricultural, defense equipment and infrastructure facilities in order to extend their service life. These works can only be performed basing on welding and related technologies.

Therefore, repair technologies based on welding, surfacing, spraying and thermal cutting will continue to be in demand both in the short and medium term. The domestic welding production has a corresponding potential for repair works. Here the initiative of small business can also be involved. This is convinced by numerous examples of active participation of small businesses in the modernization and repair of military equipment. However, such work should be systematic and appropriately organized with the involvement of specialists from the «big» business, having a sufficient level of knowledge and experience. Especially innovative technologies are needed.

If we talk about welding production in Ukraine in terms of equipment and materials, the existing production capacities of Ukrainian manufacturers allow satisfying domestic needs for a group of goods of electric welding equipment and welding materials, as well as deliver products to foreign markets [6].

The further sustainable development of markets for welding equipment and materials is possible with the active transfer of high welding technologies and other innovations. Welding production suffers from a disease typical for the whole Ukrainian industry: elimination of sectoral science and most of the experimental production units, which are the necessary links for implementation of research and development results in industrial volumes.

In the former times, the potential of sectoral science was determined not only by the presence of sectoral research institutes, but also by the functioning of key and medium-sized enterprises which had their own design bureaus and well-equipped factory laboratories. For example, many years ago the Kakhovka plant of electric welding equipment created a branch of the experimental design bureau, which provided a significant acceleration in the introduction of new welding equipment into production and today this enterprise is a modern engineering centre. Unfortunately, today in Ukrainian mechanical engineering not many such examples still exist.

But, according to the opinion of the author of this article, not everything is so hopeless. These functions should be taken over by a small business. Such a process is already underway in Ukraine. Here are some examples.
For instance, the research and production company "VISP» (Kyiv) has been present for almost 15 years on the Ukrainian market and has established itself as a reliable developer and supplier of welding equipment (installations, machines, rotators, manipulators), equipment for plasma and arc spraying, different means of automation and other products. «VISP» closely cooperates with the PWI of the NASU in the field of technology for arc welding of stationary pipe joints, surfacing of copper, including the friction stir method. The joint works are also carried out with the Institute of Metal Physics and other institutes of the NAS of Ukraine.

«Navko-Tech» LLC (Kyiv) performs technological works, designs and manufactures specialized equipment for automatic welding of rectilinear and circumferential welds, installations for surfacing of cylindrical, conical and plane surfaces and welding complexes based on industrial robots Fanuc.

«Steel Work» LLC (Kryvyi Rih) specializes in protecting industrial equipment from destructive factors at enterprises of the mining, metallurgical, cement, coal and other industries using innovative welding technologies.

The companies mentioned above and many other companies make a tangible practical contribution to the development of domestic welding production. The further fate of the Ukrainian welding production largely depends on changes in the structure of the domestic economy, production strategy of the country and some other factors.

1. Bernadsky, V.N., Makovetskaya, O.K. (2008) State-of-the-art and perspective of modern market of welding engineering. PWI survey information, 2 [in Russian].

2. Lashchenko, G.I. (2012) Modern technologies of welding production. Kiev, Ekotekhnologiya [in Russian].

3. Ishchenko, A.Ya., Labur, T.M., Bernadsky, V.N. et al. (2006) Aluminium and its alloys in modern structures. Kiev, Ekotekhnologiya [in Russian].

4. Akhonin, S.V. (2018) Tendencies of development of special electrometallurgy of titanium in Ukraine. The Paton Welding J., 11-12, 134-139.

5. Paton, B.E. (1999) Problems of welding at the turn of the century. Avtomatich. Svarka, 1, 4-14 [in Russian].

6. Mazur, A.A., Lipodaev, V.N., Pustovojt, S.V., Petruk, V.S. (2017) State-of-the-art of welding equipment and consumables market in Ukraine. The Paton Welding. J., 11, 31-37.

7. (1981) Welding in USSR. Vol. 1: Development of welding engineering and science. Technological processes, welding materials and equipment. Moscow, Nauka [in Russian].

8. Shimanovsky, A.V., Gordeev, V.N., Ogloblya, A.N. et al. (2001) Technological state of building structures in Ukraine. The Paton Welding J., 9, 33-38.

9. Lashchenko, G.I. (2009) Welding production and national economy. Svarshchik, 1, 34-39 [in Russian]. 


\title{
INVESTIGATION OF STRESS-STRAIN STATE OF WELDED JOINTS OF THE SYSTEM TiAI INTERMETALLICS*
}

\author{
L.M. LOBANOV, E.A. ASNIS, N.V. PISKUN, E.L. \\ VRZHIZHEVSKY, A.S. MILENIN and E.A. VELIKOIVANENKO \\ E.O. Paton Electric Welding Institute of the NAS of Ukraine \\ 11 Kazymyr Malevych Str., 03150, Kyiv, Ukraine. E-mail: office@paton.kiev.ua
}

\begin{abstract}
In the work, stress state of welded joints of intermetallic of the TiAl system was investigated. The influence of stress state of weld on cold cracks formation was determined. A mathematical model was created and computational experiments were carried out to determine residual welding stresses in welded joint. Using the methods of optical and electron microscopy, the structure of welded joints of intermetallic of titanium-aluminum system was studied. At the same time, the relationship between the cooling rate of the material after the end of welding process and the structure of welded joint was established. Based on the results of numerical experiments and metallographic examinations, a technology for welding of intermetallic alloy with a subsequent local heat treatment was developed, which allows producing defect-free welded joints. 7 Ref., 4 Figures.
\end{abstract}

Ke y w o rds : intermetallic, electron beam welding, stresses, cold cracks, local heat treatment

Intermetallic alloys of the system TiAl are considered to be promising materials in the production of aircraft engine turbines and other products of aerospace engineering, as well as for automotive industry and power generating turbines in heat power plants. They are distinguished by a high strength, heat resistance, creep and corrosion resistance at high temperatures. However, with all mentioned advantages, they are characterized by a low ductility at room temperatures, which leads to significant difficulties in producing different semi-finished products. Therefore, the successful production of TiAl system alloys depends on achieving a suitable combination of ductility at a room temperature, strength, fatigue strength, creep, fracture toughness, as well as oxidation and corrosion resistance. The required mechanical properties are closely related to such factors as chemical composition, microstructure and technology of treatment. One of the ways to increase ductility is alloying with elements that can influence the formation of the structure during cooling of the alloy [1]. The industrial implementation of these alloys also depends on the development of technology for their joining. From intermetallics, a wide range of products can be manufactured, a part of which are welded assemblies; therefore, the development of technology for welding intermetallics of the system TiAl is very relevant [2].
Electron beam welding (EBW) is one of the most promising methods for producing welded joints of the mentioned materials [3]. In the process of producing welded joints of TiAl system intermetallics, their essential defect is cold cracks in the welds, which occur at the temperatures below $700{ }^{\circ} \mathrm{C}$, when the material passes from a viscous to a brittle state. The brittleness of a weld in the state after welding, in its turn, is determined by its structure and, at the increment of welding stresses during cooling, leads to the appearance of defects such as cold cracks, the source of which are microcracks, dislocations, etc.

The aim of this work was to study the stress-strain state of welded joints of TiAl system intermetallics and to develop the technology of welding that allows producing defect-free welded joints.

To calculate the value of welding stresses, it is necessary to take into account the thermal effect on the metal being welded, which is determined by heat input during welding. The most important characteristic of heat input is the fact, that it determines the rate of cooling the metal and, therefore, affects the microstructure of weld and heat-affected zone. Since EBW proceeds at a high energy concentration, the formed HAZ has insignificant sizes of $1 \mathrm{~mm}$ [4].

Welding of specimens of intermetallic alloy of the TiAl system (Ti-44Al-5Nb-3Cr-1.5Zr) with a size of

\footnotetext{
${ }^{*}$ Published on the materials of the report presented at the International Conference «Innovative Technologies and Engineering in Welding and Related Technologies — POLYWELD 2019», NTUU «Igor Sikorsky Kyiv Polytechnic Institute». ${ }^{* *}$ In the work I.L. Bogaichuk, G.F. Rozynka, I.I. Statkevich and T.G. Taranova participated.
} 
$30 \times 100 \mathrm{~mm}$ and a thickness of $3 \mathrm{~mm}$ was carried out at a heat input of $2500 \mathrm{~J} / \mathrm{cm}$.

The TiAl system intermetallic welds produced by EBW at the specified heat input of welding had transverse cold through cracks passing through the weld into the heat-affected zone and the base material.

The initiation of cold cracks during welding occurs at the cooling stage as a result of growing stresses. To calculate the stress state, a mathematical model was created, on the basis of which computational experiments were carried out.

For welded plates with a thickness of $3 \mathrm{~mm}$, EBW proceeds in the mode of key hole penetration. Therefore, the temperature field can be considered uniform across the thickness [5]. The kinetics of temperatures can be described using the following non-stationary heat conductivity equation:

$$
\begin{gathered}
c \gamma(T) \frac{\partial T}{\partial t}=\nabla[\lambda(T) \nabla T]- \\
-\frac{\alpha\left(T-T_{0}\right)+\varepsilon_{0} \sigma_{S F} \cdot\left(T^{4}-T_{0}^{4}\right)}{\delta}+q,
\end{gathered}
$$

where $c \gamma, \lambda$ are temperature-dependent volumetric heat capacity and thermal conductivity of metal, respectively; $T$ is the temperature of the structure at the moment of time $t$ at the point with coordinates $(x, y)$; $\alpha_{T}$ is the coefficient of surface heat transfer to the rigging (bench support); $\varepsilon_{0}$ is the degree of blackness of plates surface; $\sigma_{\mathrm{SB}}$ is the Stefan-Boltzmann constant; $T_{0}$ is the ambient temperature); $q$ is the heat flux from the source of welding heating in the considered area of the surface, which in the case of key hole penetration in EBW can be described as

$$
q=\frac{\eta U I}{\pi \delta K_{s}} \exp \left(-\frac{x^{2}+y^{2}}{K_{s}}\right),
$$

where $\eta$ is the efficiency of the source of welding heating; $U$ is the accelerating voltage on the electron beam gun; $I$ is the welding current; $K_{s}$ is the coefficient of energy flux concentration in the electron beam.

The boundary conditions for the thermal conductivity equation (1) for the considered case of EBW in vacuum have the following form:

$$
\begin{gathered}
-\lambda(T) \frac{\partial T}{\partial n}= \\
=\left\{\begin{array}{l}
\alpha_{T}\left(T-T_{C}\right), \text { in the area of contact } \\
\text { with rigging } \\
\varepsilon_{0} \sigma_{S F}\left(T^{4}-T_{C}^{4}\right), \text { on free surfaces }
\end{array},\right.
\end{gathered}
$$

where $n$ is the normal to the surface of the structure.

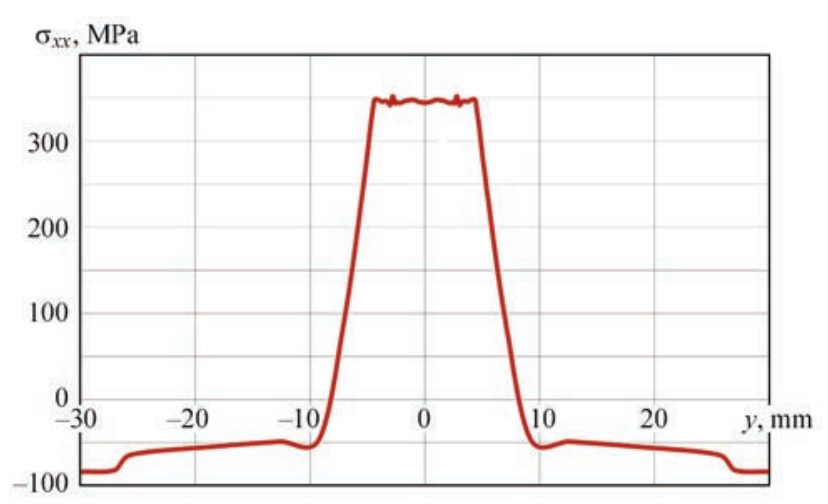

Figure 1. Distribution of longitudinal stresses along the weld length (unsupported welding)

Figure 1 shows the distribution of residual welding stresses along the length of the plates produced using a computational experiment.

The highest level of residual stresses - $330 \mathrm{MPa}$ is observed in the center of the weld, which is also confirmed by the data obtained by the method of $\mathrm{X}$-ray diffraction analysis - $335 \mathrm{MPa}$. On the base material, the stresses transfer from tensile into compressive. The welding stresses arising during cooling of the specimen in combination with the brittle structure of the weld metal, lead, in its turn, to the appearance of such defects as cold cracks.

Metallographic examinations of the structure and fracture surface in the weld are shown in Figure 2. The microstructure of the weld in Figure 2, $a$ consists of $\gamma$-TiAL and $\alpha_{2}-\mathrm{TI}_{3} \mathrm{Al}$-phases. The weld has a hardness of 5100-5300 MPa. According to fractographic investigations (Figure 2, b), it is seen that destruction of welded specimens is observed in the elastic region by a transcrystalline fracture. On the fracture surface, sections with different structures are observed. In the weld metal, the propagation of the main crack proceeded stepwise.

The mentioned structure has a low ductility. At a high cooling rate of the weld metal $-500{ }^{\circ} \mathrm{C} / \mathrm{s}$, the conditions for forming metastable phases are created, which increase the tendency of the metal to cold cracking. A large role in the formation of cracks is played by residual welding stresses and, especially, by their growth during cooling as a result of a high temperature gradient. In order to prevent cold cracks, it is necessary to provide a delayed cooling rate with a decrease in the temperature gradient and, accordingly, in the level of stress state [6]. Reducing the stress state is an important factor for prevention of the cold cracking. For this purpose it is necessary to conduct heat treatment of welded joints.

In view of the fact that cracks are formed immediately after welding, there is no possibility to perform heat treatment in a stationary furnace. The most 


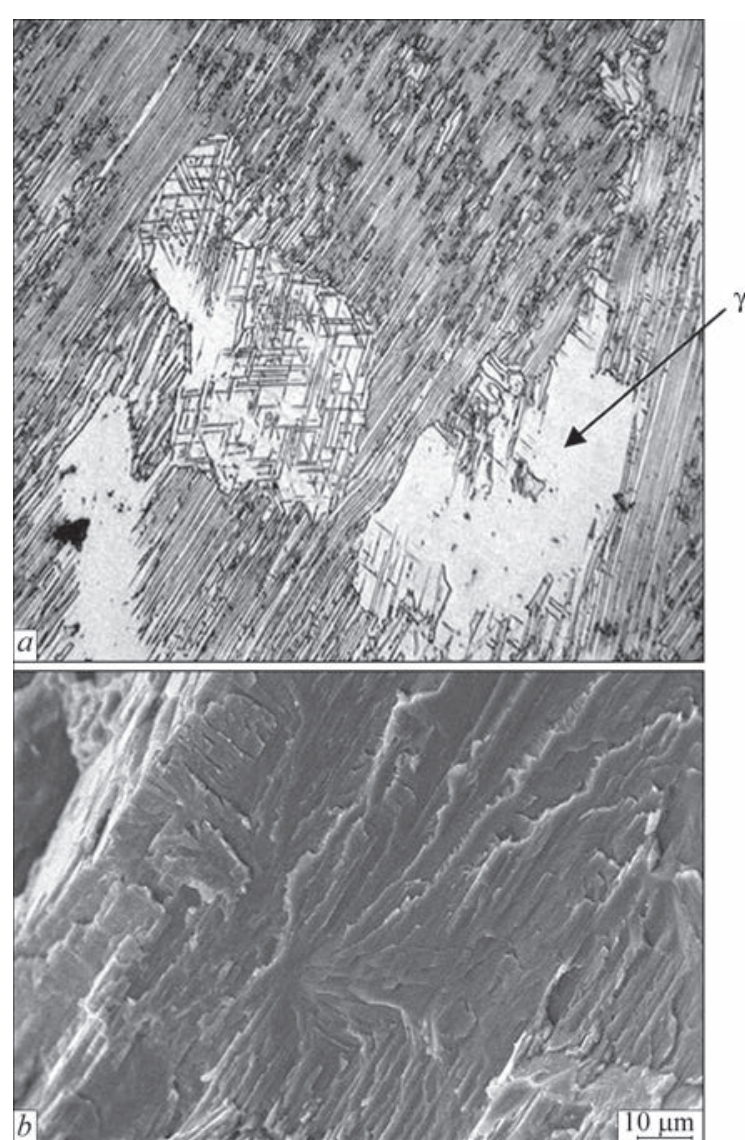

Figure 2. Microstructure of weld metal ( $a$ ) and fracture surface of the weld $(b)$ produced by EBW

rational is local heat treatment (LHT) with an electron beam. We developed LHT of welded joints of the TiAl system intermetallic with an adjustable cooling rate. This process is carried out as follows: immediately after welding, the electron beam is directed to the middle of the weld and with the help of a special computer program it is deployed to the desired configuration in one and the other direction from the middle to the end of the weld. In this case, the beam remains stationary, and the welding current is reduced by $1 / 3$.

Due to a decrease in the welding current, the heat input in the LHT process decreases to $1700 \mathrm{~J} / \mathrm{cm}$,

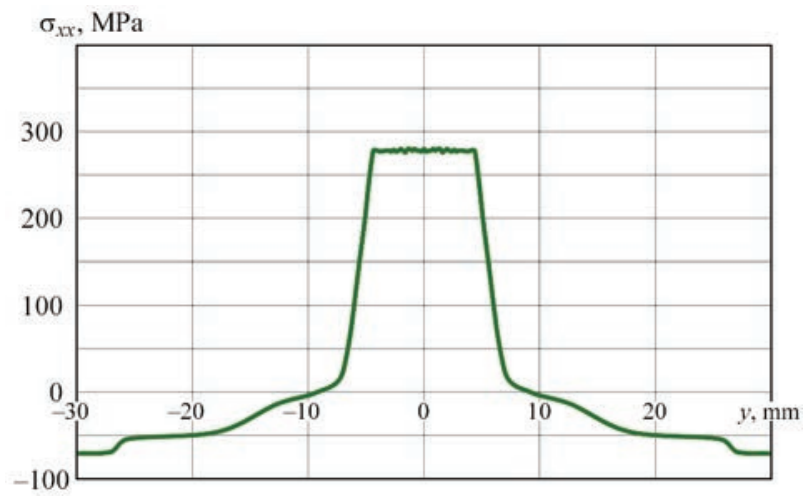

Figure 3. Distribution of longitudinal stresses along the weld length after LHT which is 1.5 times lower as compared to the same value during welding.

The period of the mentioned heat treatment is 5 minutes. At the same time, the investigations showed that the temperature of the welded joint is maintained up to $950{ }^{\circ} \mathrm{C}$. The cooling rate in this case is reduced to $30^{\circ} \mathrm{C} / \mathrm{s}$. In this regard, the temperature gradient decreases and, accordingly, the welding residual stresses are reduced to $260 \mathrm{MPa}$. In this case, cold cracks in the welds are practically not formed. Figure 3 shows the stress state of the weld after LHT.

The developed technological scheme of EBW and heat treatment allows reducing the level of residual welding stresses by more than $25 \%$.

Metallographic examinations of the welded joint produced by EBW with the following LHT (Figure 4, a) showed that the weld metal has a three-component structure: matrix of the $\gamma$-TiAl phase, colonies of $\left(\gamma-\mathrm{TiAl}+\alpha_{2}-\mathrm{Ti}_{3} \mathrm{Al}\right)$-phases and precipitations of residual $\beta_{0}$ (B2)-phase along the boundaries of the colonies. The hardness of the weld metal is $4400-4500 \mathrm{MPa}$. It was shown [7] that such a structure slightly increases ductility and in combination with the stresses, which are lower than in the initial state, it improves crack resistance of the intermetallic weld.

Examinations of fractures of the specimens produced by the proposed scheme EBW + LHT showed that the fracture occurs according to the intercrystal-
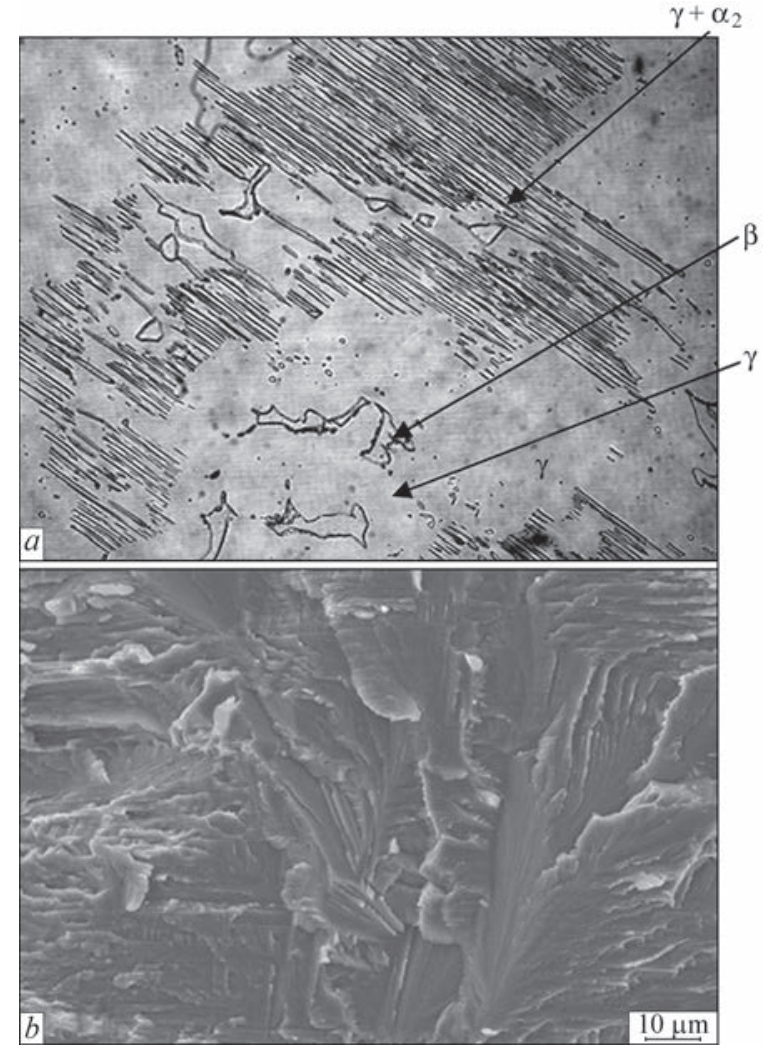

Figure 4. Microstructure $(\times 200)$ of weld metal $(a)$ and fracture surface structure $(b)$ produced by EBW with the following heat treatment 
line mechanism. Figure $4, b$ shows fractography of the weld. The fracture of the weld metal is intercrystalline. Crushing of the $\gamma$-phase is observed due to dispersed precipitations of the $\alpha_{2}$-phase. On the surface of facet fracture, the spalling facets are separated by tearing regions. That fact is predetermined by plastic shear and is a sign of ductility of the material. It can be assumed that the material resists fracture to some extent and has some ductility.

Comparing Figures 2 and 4, it can also be noted that a high heat input during welding provides coarser grain structure of weld metal as compared to heat treatment at a lower heat input.

Thus, as a result of reduction of heat input, the developed modes of local heat treatment allow slowing down the cooling rate of the weld and, thereby, creating favorable structural changes, as well as significantly reducing stress state of welded joints and practically avoiding the formation of cold cracks.

\section{Conclusions}

A mathematical model was developed and computational experiments were carried out, which allowed calculating the stress state of the intermetallic weld in the initial state after welding and LHT.

The cooling rate during application of heat treatment is $30{ }^{\circ} \mathrm{C}$ as compared to the cooling rate immediately after welding $-500^{\circ} \mathrm{C}$.

A 1.5 times decrease in heat input slows down the cooling rate of the weld, which contributes to the for- mation of a three-component structure: matrix of the $\gamma$-TiAl phase, colonies of $\left(\gamma-\mathrm{TiAl}+\alpha_{2}-\mathrm{Ti}_{3} \mathrm{Al}\right)$-phases and precipitations of residual $\beta_{0}(\mathrm{~B} 2)$-phase along the boundaries of the colonies, which allows increasing the ductility of the weld.

During the use of heat treatment, the temperature gradient decreases and, accordingly, the welding voltages decrease by more than $25 \%$.

It is shown that the use of LHT can significantly improve the structure of weld metal, reduce the value of residual welding stresses, and thereby increase the crack resistance of the weld.

1. Kartavykh, A.V., Asnis, E.A., Piskun, N.V. et al. (2015) Microstructure and mechanical properties control of c-TiAl(Nb, $\mathrm{Cr}, \mathrm{Zr}$ ) intermetallic alloy by induction float zone processing. J. of Alloy and Compounds, 643, 182-186.

2. Iliin, A.A., Kalachov, B.A., Polkin, I.S. (2009) Titanium alloys, composition, structure, properties. VILS-MATI, Moscow [in Russian].

3. (1987) Electron beam welding. Ed. by B.E. Paton. Kiev, Naukova Dumka [in Russian].

4. Rykalin, N.N. (2013) Calculations of thermal processes in welding. Moscow, Reedition of 1951 [in Russian].

5. Makhnenko, V.I. (1976) Calculation methods of investigation of kinetics of welding stresses and strains. Kiev, Naukova Dumka [in Russian].

6. Chen Guoging, Zhang Binggang, Liu Wei, Feng Jicai (2011) Crack formation and control upon the electron beam welding of TiAl-based alloys. J. of Intermetallics, 19, 1857-1863.

7. Povarova, K.B., Bannykh, O.A. (1999) Principles of creation of structural alloys based on intermetallics. Pt 1. Materialovedenie, 3, 27-33 [in Russian].

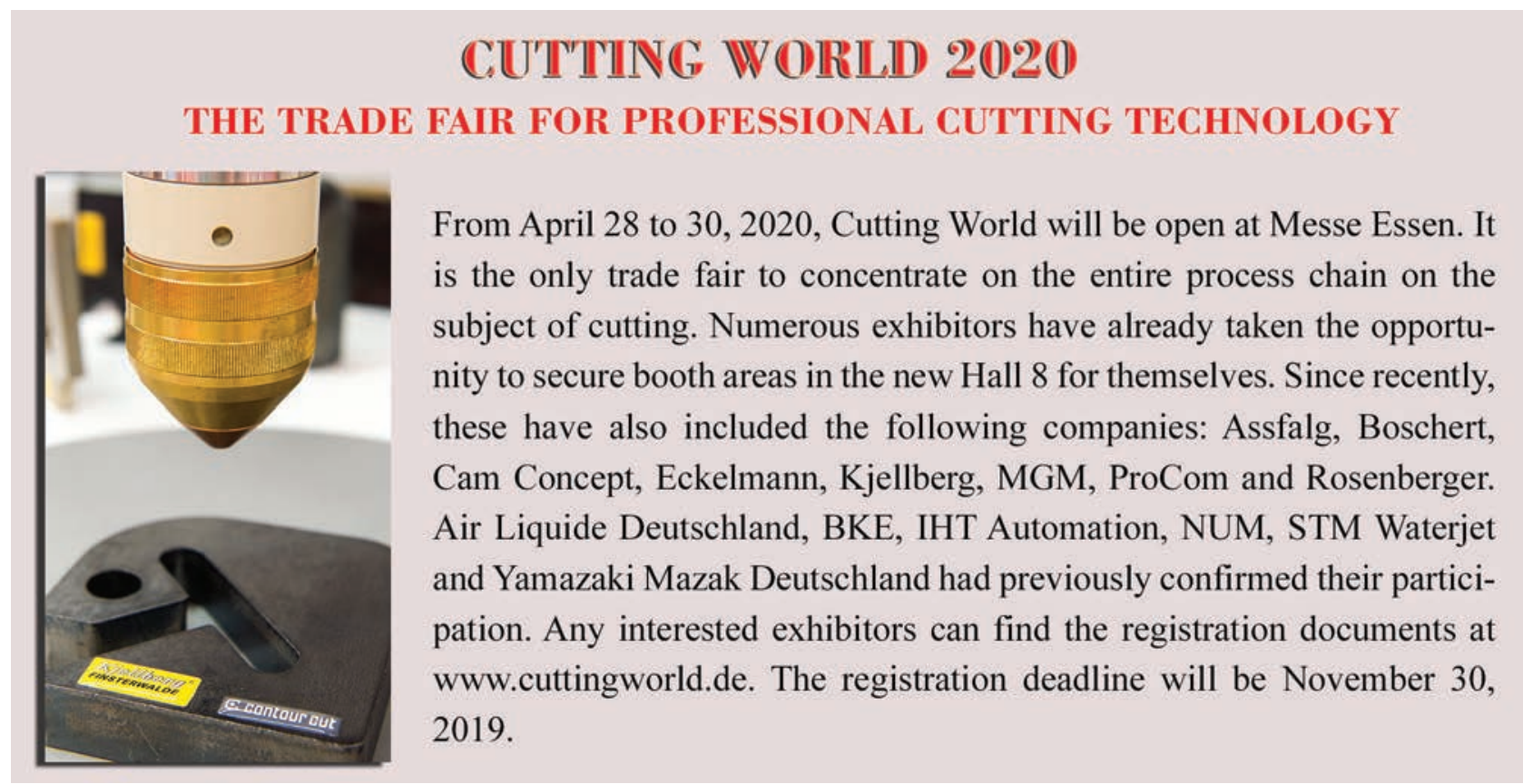




\title{
SELF-ORGANIZATION OF THERMAL PROCESSES IN WELDING SHEET LOW-ALLOYED STEEL
}

\author{
R.A. KREKTULEVA, Yu.N. SARAEV, V.M. SEMENCHUK and R.O. CHEREPANOV \\ Institute of Strength Physics and Materials Science of SB RAS \\ 2/4 Akademichesky Ave., 634050, Tomsk, RF
}

\begin{abstract}
Numerical modeling of thermal processes at weld pool formation in low-alloyed steel under the impact of the electric arc was performed. Different arcing modes are considered. A qualitative difference in propagation and dissipation of thermal energy is found, depending on the modes. Mechanisms of self-organization of thermal structures were studied, which are due to highly nonlinear thermophysical properties of low-alloyed steel, modes of thermal energy feeding into the weld pool and features of its dissipation on the boundaries. The validity of the numerical model is confirmed experimentally, that allows recommending the results of computer studies for practical application. 14 Ref., 7 Figures.
\end{abstract}

Keywords: weld, contact zone, heat flow, nonlinearity of thermophysical properties, synergism, self-organization, internal structure

In keeping with GOST 14771-76, it is recommended to weld sheet low-alloyed steels (of up to $3.5-4.0 \mathrm{~mm}$ thickness), widely applied in many branches of industry, using the so-called backing, which is fastened in the lower position of the forming welded joint. The role of backing is to contain the molten metal from flowing out of the weld pool. In technical publications, the notion that application of copper (more seldom aluminium) backing promotes removal of excess heat, due to more intensive dissipation of thermal energy, has become established. That is why it was called heat-removing or forming backing, influencing not only weld metal formation, but also its structure directly in the permanent joint zone [1-3]. The idea of copper backing application outwardly is in good agreement with the theory of self-organization of nonlinear systems, developed by the school of I.R. Prigozhin, winner of 1977 Nobel Prize in chemistry [4]. General concepts of welded joint formation from the standpoint of self-organizing systems are described in [5]. At present the above statement is ever wider applied in development of various systems of automatic regulation of welding and surfacing processes [6-8].

«Self-organization» term in modern scientific language means the process of spatiotemporal structural adjustment of the system that results in the system acquiring new properties, usually, improving its functioning in the former conditions. Three scenarios of self-organization development are possible: order-based order, chaos-based order and order-based chaos, which is also called dynamic chaos. As applied to welding technology, the self-organizing system is the welded joint proper, which was formed not chaotically (melt-solidification in any modes), but taking into account the physical nature of the metal and with strict observation of balance between the inflow of energy to the weld pool and its outflow. The importance of this parameter is shown in [9], where it is established that the rate of the change of molten metal temperature has a dominant influence on the nature of structural-phase transformations in the metal of the weld and HAZ. Correct application of this theory to welding technologies could eliminate many problems of welded joint reliability, particularly their operation under critical conditions: high and low temperatures, higher pressure, etc. Nonetheless, in the majority of the technologies still open are not only the questions of finding the mechanisms, which would bring the technological system in order, but also the issues, associated with the methods of exclusion of behaviour imposed on it, and not characteristic of good governance principles.

The objective of this work is to develop the procedure of numerical analysis of the mechanisms of self-organization of thermal processes in the weld pool in electric arc welding of sheet low-alloyed steel, and experimentally validate it in the case of welding St3 steel, using copper heat-removing backing.

Physical and mathematical statement of the problem. Formulation of research problems follows from consideration of the features of the technology of nonconsumable electrode argon-arc welding. In the weld pool zone, the substance is in four aggregative states: solid, liquid, gaseous and plasma. Different energy conversions proceed simultaneously: electromagnetic, thermal, chemical, mechanical, radiation and intra-atomic. A feature of this welding method consists in that approximately 93-95 \% of electric arc 
energy is consumed for the processes of heat-mass transfer.

The welding process is schematically shown in Figure 1. Welded samples of the same size are placed on a copper backing. The electrode moves along the butt being welded with speed $v$ (shown by an arrow). Investigations were conducted for steel samples 60 and $120 \mathrm{~mm}$ long, 20 and $40 \mathrm{~mm}$ wide, respectively, thickness was varied from 1.2 to $3.5 \mathrm{~mm}$. Dimensions of copper backing along the length were the same as those of the steel samples, or $2 \mathrm{~mm}$ longer, thickness varied from 1 to $3 \mathrm{~mm}$ with $0.5 \mathrm{~mm}$ step. The following width of the gap between the copper backing was set: $0 ; 1.0 ; 2.0 ; 3.0 ; 4.0 ; 5.0$ and $10.0 \mathrm{~mm}$. A unit on a mobile platform was used to conduct full-scale experiments. The torch with the electrode was fastened in a special holder, with the function of regulation of the extension. The platform started moving at the moment of arc striking. Design of the unit incorporates control of the length of interelectrode gap, volt-ampere characteristics of the power source and speed of welded sample displacement.

In Figure 1 planes A, B and C, crossing the sample perpendicular to the plane of electrode movement, are outlined with the purpose of further theoretical and experimental studies of structural-phase changes of the produced welded joint and checking the adequacy of model representations.

The basics of constructing a mathematical model of technological processes of welding production, including the equations of balance, equation of phase transitions and equation of the kinetics of chemical transformations, are given in work [10]. In keeping with this work, the initial system of equations modeling TIG-welding, has the following form:

$$
\begin{gathered}
\rho(T) C_{p}(T) \frac{\partial T}{\partial t}=\frac{\partial}{\partial x}\left(\lambda(T) \frac{\partial T}{\partial x}\right)+ \\
+\frac{\partial}{\partial y}\left(\lambda(T) \frac{\partial T}{\partial y}\right)+\frac{\partial}{\partial z}\left(\lambda(T) \frac{\partial T}{\partial z}\right) ; \\
L_{k} V_{k}=\lambda_{s} \frac{\partial T}{\partial n_{+0}}-\lambda, \frac{\partial T}{\partial n_{-0}} ; \\
q(r)=\frac{\eta I(t) U(t) k}{\pi e^{\left(k r^{2}\right)}} .
\end{gathered}
$$

In the presented system, equation (1) is the spatial dynamic equation of heat conductivity, (2) is the equation of phase transformations; (3) is the distribution of the plasma arc energy flow density in the zone of the source action.

The system of equations (1)-(3) is complemented by initial conditions

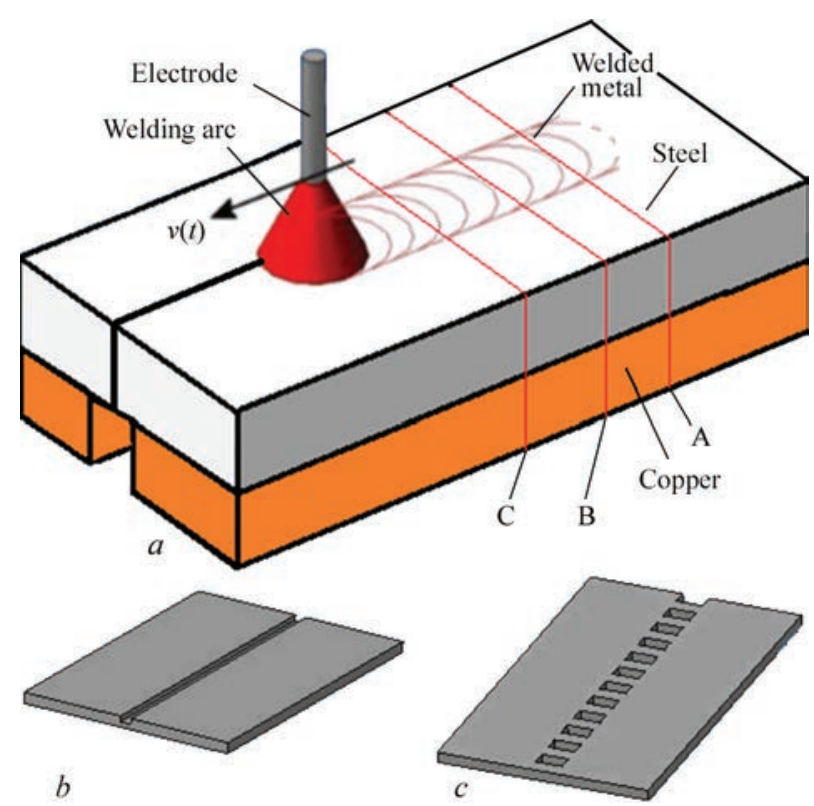

Figure 1. Sketch of welding two steel plates on copper heat-removing backing: $a$ - with a gap; $b$ - with a groove; $c$ - with perforation

$$
T(x, y, z, 0)=T_{0} .
$$

Boundary conditions are given in the following form:

- outside the region of the source action

$$
\lambda \frac{\partial T}{\partial n}=\alpha\left(T-T_{0}\right)+\varepsilon\left(T_{0}^{4}-T^{4}\right) .
$$

- in the region of the source action

$$
-\lambda \frac{\partial T}{\partial n}=\frac{\eta I U k}{\pi} \exp \left(-k r^{2}\right) ;
$$

- in the region of contact of two dissimilar materials

$$
\lambda_{1}(T) \frac{\partial T_{1}}{\partial n}=\lambda_{2}(T) \frac{\partial T_{2}}{\partial n}, \quad x, y, z \in S_{12} .
$$

The following designations were used in the system of equations (1)-(7): $T$ - temperature; $\rho(T)-$ dependence of density on temperature; $C_{p}(T)-$ dependence of heat capacity on temperature; $t$ - time; $x, y, z$ - spatial coordinates; $\lambda(T)$ - dependence of heat conductivity coefficient on temperature; $L_{k}-$ heat of phase transition (including melting, evaporation, solidification); $V_{k}$ - speed of movement of phase transition front; $n-$ vector of the normal to the interphase $( \pm$ indices below indicate different sides from the interphase); $\lambda_{s}, \lambda_{l}$ - coefficients of material heat conductivity on different sides from phase transition boundary (in particular, solid and liquid phases); $r$ - radius of the heat spot from the burning arc; $\eta$ and $k(L)$ - semi-empirical parameters, characterized by heat source power and its distribution over the heat 


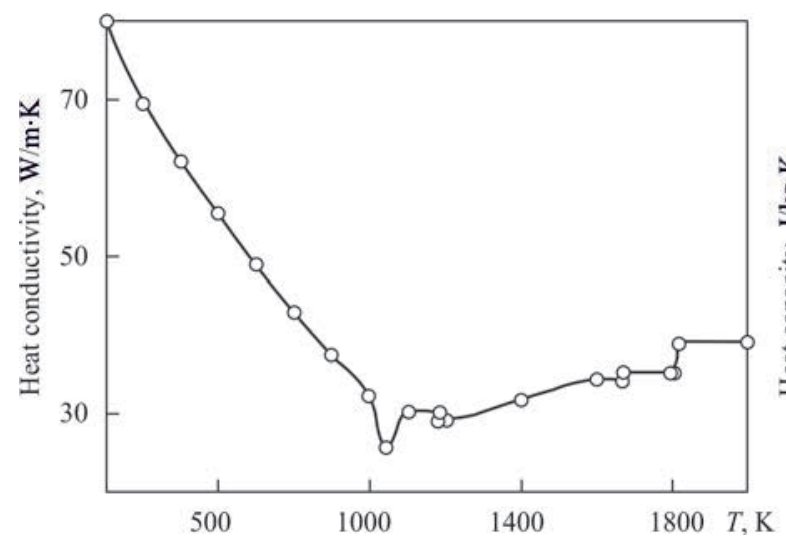

Figure 2. Thermophysical properties of iron and low-alloyed steel spot; $L$ - length of interelectrode gap; $I$ - current, $U$ - voltage of electric arc source; $\varepsilon$ - degree of blackness of the body; $\sigma=5.669 \cdot 10^{-8} \mathrm{~W} /\left(\mathrm{m}^{2} \cdot \mathrm{K}^{4}\right)$ the Stephan-Boltzmann constant; $\alpha-$ coefficient of heat exchange with the environment; $\lambda_{1}, \lambda_{2}$ - coefficients of heat conductivity of contacting materials; $S_{12}$ - area of contact of dissimilar materials. The burning arc moves along a trajectory determined by the following system of equations:

$$
\left\{\begin{array}{c}
x=x_{0}+V_{x} t, \\
y=y_{0},
\end{array}\right.
$$

where $x_{0}, y_{0}$ are the coordinates of the initial point; $V_{x}$ is the rate of heat source movement along the axis.

Mathematical model (1)-(8) is complemented by experimental dependencies [11] of thermophysical characteristics of low-alloyed steel (Figure 2), and «iron-carbon» constitution diagram [12]. Knowing the detailed temperature distribution in the volume of the samples being welded, the constitution diagram can be used to establish carbon solubility in the respective areas that will help to implicitly allow for the diffusion processes and determine the areas of structural-phase transformations (melting, incomplete melting, overheating, normalizing, etc.) in the weld zone.

The posed problem was solved numerically by the finite difference method [13]. The mesh pitch in different numerical experiments was varied from 0.2 to $0.5 \mathrm{~mm}$, depending on research objectives. Preliminary calculations showed that at correctly selected arcing modes the thermal energy of the source is localized in a narrow strip along the arc movement trajectory. This is attributable to the fact that the coefficient of heat conductivity in the considered steels in the temperature range of 1000-1300 K has a deep minimum, i.e. the rate of heat transfer beyond the boundaries of this range is low. Therefore, it is rational to confine ourselves to study of narrow strips not more than $20 \mathrm{~mm}$ wide. It was further established that the temperature field stabilizes along the length

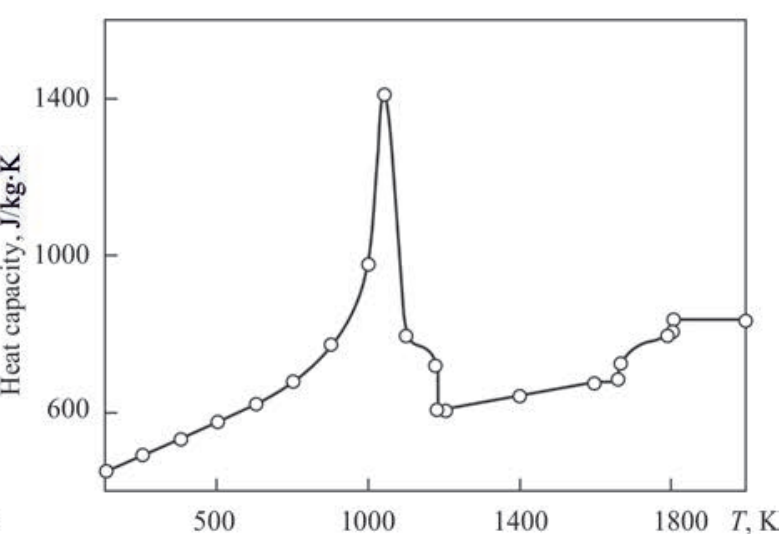

at $6 \mathrm{~mm}$ distance from the beginning of the welded joint for samples of $1.2 \mathrm{~mm}$ thickness. With increase of thickness, this distance gradually increases up to $20 \mathrm{~mm}$ for $3.5 \mathrm{~mm}$ plates. For further investigation consideration of welded steel plates was limited to dimensions of $60 \times 20 \times 2 \mathrm{~mm}$ each.

Given below are the results showing that the considered calculated model allows determination with good accuracy of not just the dimensions of the weld, but also of all the zones of structural-phase transitions in the volume, as a result of multiple thermal «heating-cooling» cycles.

Results of computer experiments on welding steel plates by a moving electric arc. It should be noted that the considered above mathematical formulation of the problem and modern level of computer engineering allow rather accurately (within experimental error of 5-7\%) predicting the arcing modes, that would provide the required characteristics of the weld and HAZ, and, furthermore, additionally derive a large scope of information, which it is impossible to obtain in direct experiments. Application of the techniques of digital visualization allowed tracing in detail all the stages of welded joint formation: heating, melting, evaporation, cooling, condensation, crystallization, phase transitions and thermodeformational changes accompanying them [13]. A systemic approach, developed in [10] was used with this purpose. Six main structural levels were identified, according to which we conducted our research:

- evaluation of the effect of heat source power on distribution of heat flow density in the burning arc flame;

- analysis of the processes of thermal energy distribution in the welded and heat-removing materials;

- determination of all the input parameters of the system, affecting the final properties of the welded joint to varying degrees;

- evaluation of inner structure of welded joint material by the results of computer modeling; 


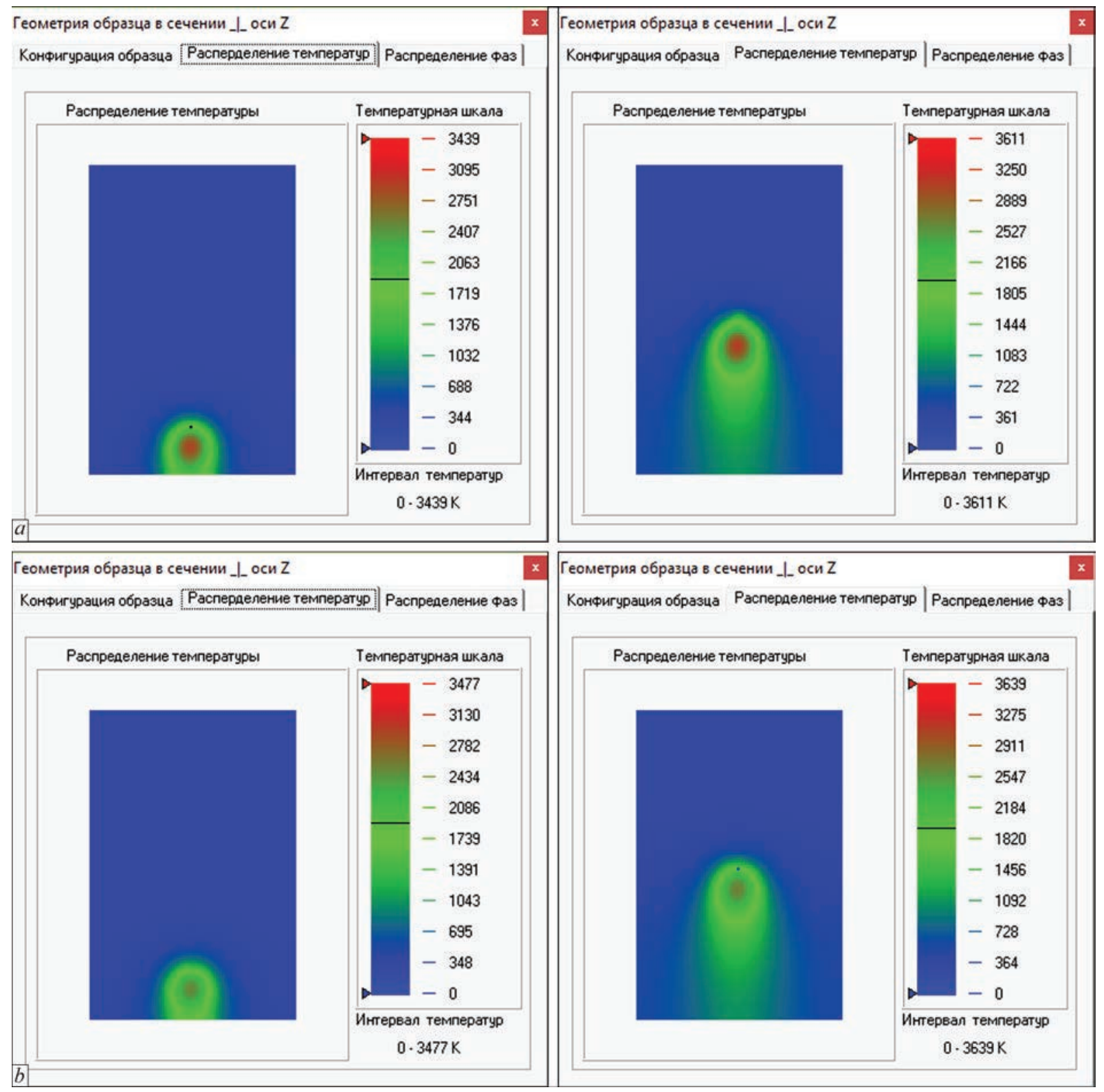

Figure 3. Formation of temperature fields at different moments of time: $a$ - on weld pool surface; $b$ - same in the zone of contact of welded samples with copper backing

- control of the processes of diffusion and structure formation at the stage of technological process design;

- determination of the criteria of rational self-organization of thermal processes in the welded joint.

The case of welding plates on a backing without a gap was initially considered. Arcing modes were established numerically, which ensured penetration of $2 \mathrm{~mm}$ thick plates to the entire depth. Figure 3 shows the temperature fields at two moments of time in two areas: on weld pool surface and in the zone of contact of the welded plates with the continuous copper backing. On the calibration temperature scale the upper value shows the maximum temperature in the sample at the given moment of time, the bar indicates temperature in the zone of contact of the two materials. One can see from the Figures, that as the heat source moves, the maximum temperatures in the zone of arc contact with the steel surface (layer thickness of about $0.2 \mathrm{~mm}$ ) increase: at the start of the welding process temperature $T=3439 \mathrm{~K}$, and by the middle of the sample $T=3611 \mathrm{~K}$. This is significantly higher than the steel melting temperature $(T=1850 \mathrm{~K})$, whereas in the zone of contact with the copper backing the temperature is close to steel melting temperature. In the selected welding modes an obvious overheating of weld pool surface is observed. Power lowering leads to incomplete penetration. The «heat-removing» backing proper turned out to be the cause for overheating. This was established proceeding from analysis of distribution of contour lines of temperatures in the sample axial section (Figure 4). One can see from the Figure that owing to high heat conductivity of copper the thermal front in it propagates faster than 


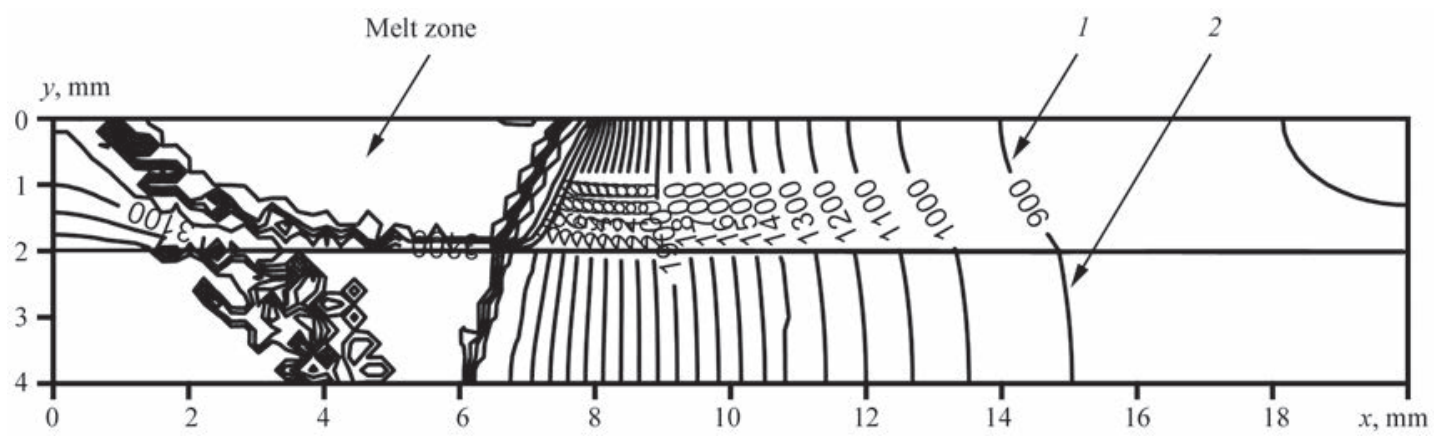

Figure 4. Map of temperature contour lines in the weld pool axial section at the $2^{\text {nd }}$ second from the beginning of welding: 1 - steel butt; 2 - copper backing

in steel. Due to that, part of the energy removed (dissipated) from the pool all the time returns from the backing to the item being welded, heating it from below. From the slope of the contour lines, one can say that initially they run almost parallel to the weld pool walls at a sharp angle to the contact zone. And then in the steel sample the contour lines gradually change their angle of inclination to obtuse one. At removal from the heat source, the bottom of the pool is heated more than its upper part.

This example shows that the main requirements of I.R. Prigozhin theory of self-organization for the welding process have been fulfilled. The nonlinearity of thermophysical properties of steel and increase of thermal energy dissipation through the zone of contact with copper are ensured. Here, an increasing overheating of the weld pool is observed as the burning arc moves forward. It is known from thermodynamics that the system entropy increases with temperature, i.e. the chaotic state of this system is enhanced.

Thus, in the considered case, the third type of self-organization is in place, namely the emergence

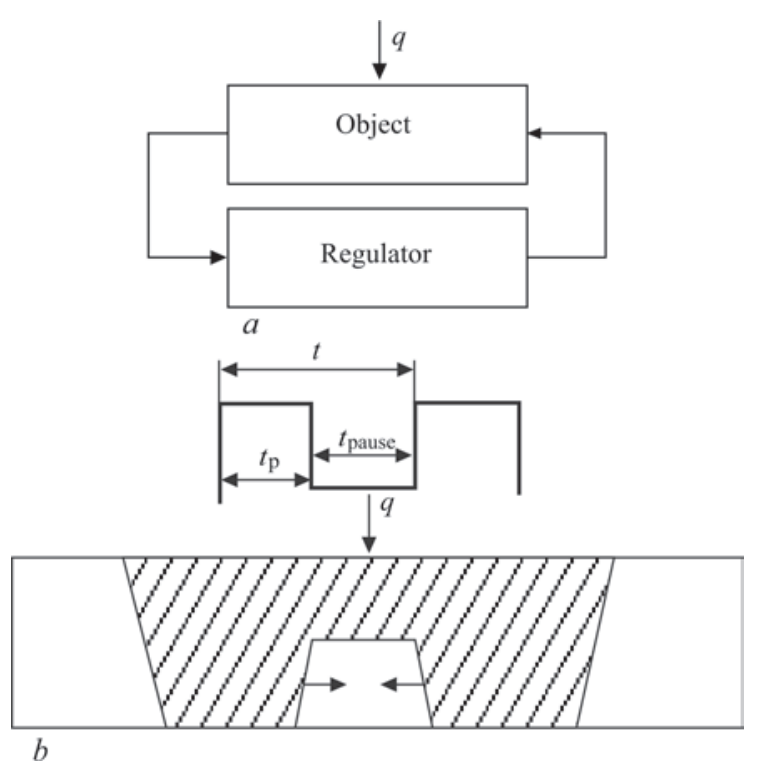

Figure 5. Block-diagram of heat distribution in the weld pool in welding on perforated copper backing and in pulsed-arc welding: $t_{\mathrm{p}}$ — pulse time; $t_{\text {pause }}$ — time during the pause and during welding of chaos from order. The initial structure of welded materials can be regarded as order. It is of interest to study in greater detail the effect of initial geometry of the copper backing in the zone of contact with the weld pool. Four different variants were considered: reduction of the thickness of the continuous backing, formation of a groove under the butt area, formation of the gap and applying perforation.

It should be noted that numerical calculations, conducted using the first two types of backing, showed that in both the cases a noticeable increase of surface temperature was observed along the weld pool length, thus increasing the nonuniformity of the temperature fields, and creating controllable dynamic chaos in the system.

The idea of application of perforated backing (see Figure, 1, c) turned out to be more productive. Copper plates of $2 \mathrm{~mm}$ thickness were used. Narrow slots of $4 \times 2 \mathrm{~mm}$ size were made every $3 \mathrm{~mm}$. Numerical calculations established that surface temperature is practically the same along the entire length of the weld pool, whereas at the weld pool bottom the temperature dependencies are of a pronounced pulsed nature (Figure 5). In this case, the obtained effect is similar to pulsed-arc welding without backing [14]. The difference is only in the fact that at pulsed-arc welding the maximum heat flow is achieved during the pulse, and in direct current welding with application of perforated backing it occurs under the perforation zone. In either case, the temperature inside the weld pool quickly equalizes, self-organization of thermal processes occurs by the type of «new order-based order». Note, however that application of perforated backing in mass production is unprofitable from the economic point of view, as it leads to an increase in technological costs.

The most rational method of self-organization by the type of «new order-based order» can be obtained in welding with application of copper backing with a gap.

During computer experiments the features of welded joint formation for all the types of backing, given above, were studied. Calculation results showed that 

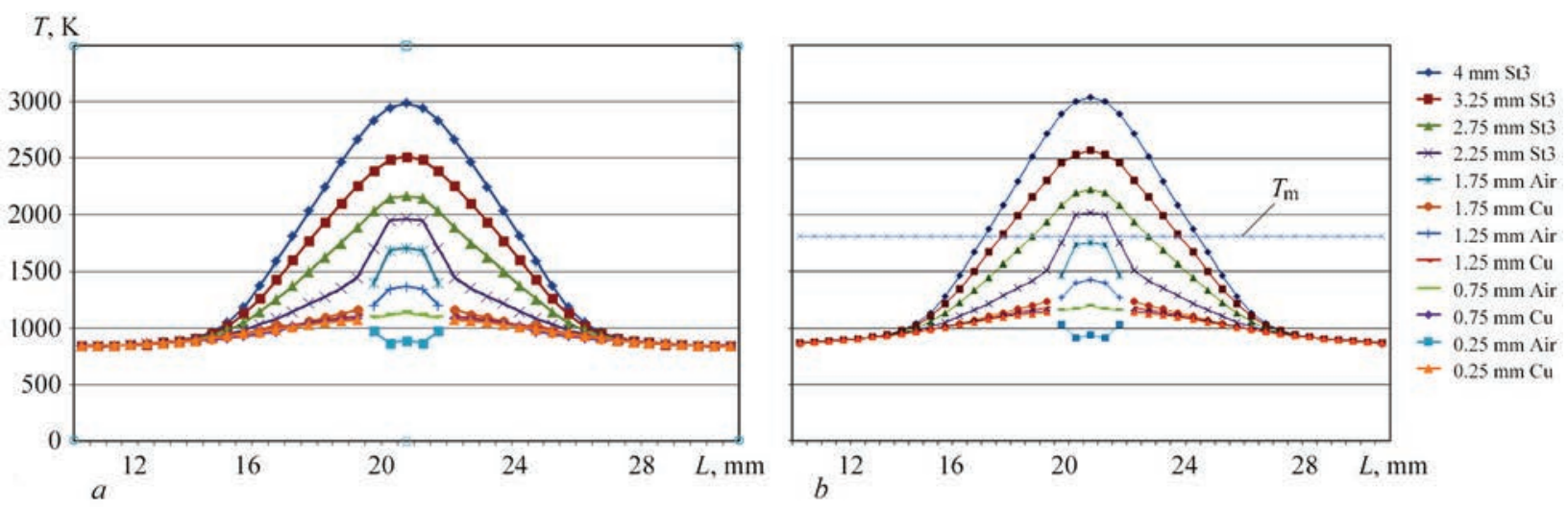

Figure 6. Temperature distribution in the cross-section at the distance of $15(a)$ and $37.5 \mathrm{~mm}(b)$ from the beginning of the weld

$2 \mathrm{~mm}$ backing also with a $2 \mathrm{~mm}$ gap turned out to be the most acceptable for welding $2 \mathrm{~mm}$ thick plates. We will illustrate it in Figure 6, which shows temperature variation by the width and depth of the welded joint in sections at 15 and $37.5 \mathrm{~mm}$ distance from the front end (sections A and C in Figure 1). Similar temperature distributions were obtained in section $\mathrm{B}$ (25 $\mathrm{mm}$ from the front end), so they are not given by virtue of identity.

These temperature distributions were calculated in the following arcing modes: power $W=1.26 \mathrm{~kW}$, interelectrode spacing $d=1.5 \mathrm{~mm}$, welding speed $v=$ $=2.8 \mathrm{~mm} / \mathrm{s}$, width of the gap between copper backing $S=2 \mathrm{~mm}$. In both the graphs the weld dimensions are practically the same in the upper and lower positions. We will explain their determination using the example in Figure 6, $b$, where one more additional horizontal line was drawn, cutting off the melting temperature $T=1850 \mathrm{~K}$ on four upper curves, which belong to the steel sample. The other curves belong to the copper backing. The width of the cut off regions is exactly what indicates the dimensions of the weld by depth: from the face side $-7.5 \mathrm{~mm}$, from the reverse side $-2.5 \mathrm{~mm}$ that corresponds to normative requirements. The dimensions of these zones can be established similarly from the width of cut-off areas, by measuring on the ordinate axis the temperatures of structural-phase transitions of low-alloyed steels (1523 K — incomplete melting, $1273 \mathrm{~K}$ - overheating, $1123 \mathrm{~K}$ - normalizing, etc.). Note that by the calculated data the maximum temperatures along the entire length of the melt pool differ by less than 100 degrees. Here, the calculated deviation of weld width is not more than $0.5 \mathrm{~mm}$ along the entire sample. Thus, it can be assumed that under these conditions, self-organization of thermal processes by the type of «new order-based order» is ensured. Correct selection of the width of the copper backing gap plays a special role here: narrow gap or its absence lead to excess heating of the weld pool as the electric arc moves, wide gap does not ensure the required heat removal from weld pool bottom and does not protect it from running out (burn-through).

Experimental verification of the validity of calculation results. In order to confirm the correctness of theoretical conclusions and validity of the developed calculation procedure, experimental studies were conducted on a welded joint of low-carbon steel St3sp(killed). Nonconsumable electrode argon-arc welding on a copper backing (with $2 \mathrm{~mm}$ gap) was performed, which completely corresponded to the computer experiment. The experiment was conducted at room temperature $(T=300 \mathrm{~K})$ with subsequent cooling of the welded joint in a natural air environment. The experimental set-up was first tested for determination of semi-empirical parameters of the model $\eta$ and $k(L)$, that yielded the following values: $\eta=$ $=0.9 ; k(L)=8$.

It was obtained experimentally that the weld width (directly the fusion zone) in the upper and lower positions coincides with the calculated value with the accuracy of up to $0.5 \mathrm{~mm}$. Metallographic studies were conducted on samples, cut out of the welded plates, located in the following zones: 15, 25 and $37.5 \mathrm{~mm}$ from the beginning of the welded joint. Structure of welded joint zones was studied with application of Olympus-GX51 microscope and SIAMS 700 applied

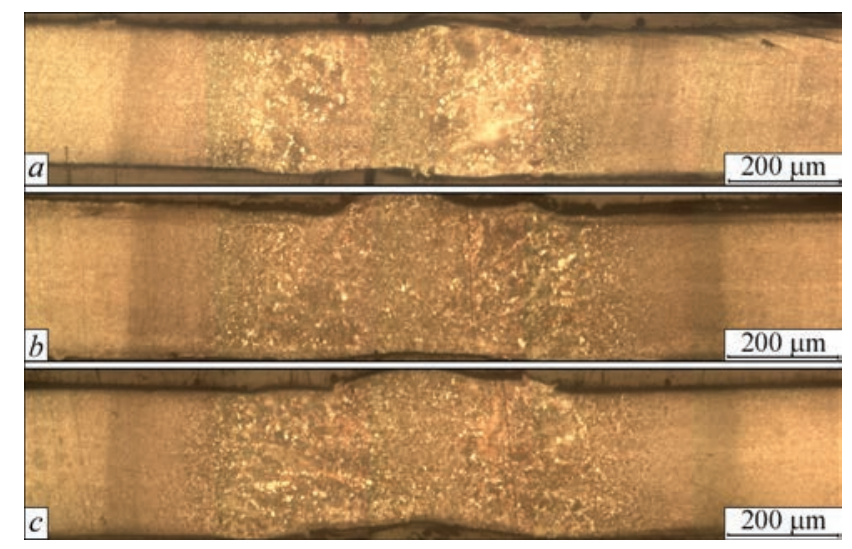

Figure 7. Macrostructure of welded joint in the cross-sections at the following distance: $a-15 ; b-25 ; c-37.5 \mathrm{~mm}$ from the beginning of the welded joint 
program package. Characteristic features of welded joint structure are given in Figure 7.

The structure uniformity by welded joint depth and width, both in the area of the weld, and in the zones of structural-phase transitions should be noted. Despite the fact that the weld width is reduced more than 2 times towards the bottom both in calculations and in the experiment, the macrostructure does not reflect it, as its dimensions practically do not change across the thickness.

This is the manifestation of one of the positive qualities of the technology of welding on heat-removing copper backing with a gap. It is, apparently, due to the effect of preheating, realized owing to rapid dissipation of thermal energy from the welding zone and its transfer through the copper backing to lower-lying layers of steel plates. Thus, control of the processes of self-organization of metallographic structures and their ordering across the welded joint thickness take place.

\section{Conclusions}

1. Numerical analysis of the dynamics of thermal processes in the weld pool in arc welding of sheet low-alloyed steel was performed, and experimental studies, confirming the validity of numerical calculations and conclusions from their analysis, were conducted.

2. It is found that in case of fulfillment of normative requirements using copper backing, two types of self-organization processes can be in place: new order-based order and dynamically controlled order-based chaos. The second type of self-organization processes has not been discussed in welding publications so far and needs additional study.

3. Mechanisms of self-organization and control of material internal structure were studied, which bring the technological system in order and which allow eliminating the imposed behaviour not inherent to good governance principles.

The work was performed using the funding from RSF 16-19-10010P project, in keeping with 2019 work plan. The authors express their sincere gratitude to Tabanov A.M. for participation in research performance.

1. Kalyuzhny, V.V. (1992) Copper backing. USSR Pat. 1745489, Int. Cl. B23K37/06, No. 4799796/08 [in Russian].

2. Chan Tuan An (1996) Formation of weld root in one-sided welding of butt joints using copper backings: Syn. Of Thesis for Cand. of Techn. Sci. Degree. Kiev [in Russian].

3. Atroshchenko, V.V., Bychkov, V.M., Nikiforov, R.V. et al. (2012) Numerical modeling of penetration shape in consumable electrode argon-arc welding on copper backing. Vestnik Ufimskogo GATU, 16, 53(8), 89-93 [in Russian].

4. Nikolis, G., Prigogine, I. (1977) Self-organization in Nonequilibrium systems: From dissipative structures to order through fluctuations. New York, John Wiley.

5. Zuev, I.V., Galkin, A.G., Bushma, V.O. (1995) Self-organisation in certain processes of welding and processing materials. J. of Advanced Materials, B2, 70-74.

6. Saraev, Yu.N., Lunev, A.G., Kiselev, A.S. et al. (2018) Complex for investigation of arc welding processes. The Paton Welding J., 8, 13-21.

7. Lebedev, V.A. (2015) Mechanized and automatic synergic welding with pulsed electrode wire feed. Welding Int., 29(2), 140-144.

8. Starke, G., Hahn, D., Diana G. et al. (2016) Self-organizatiom and self-coordination in welding automation with collaborating teams of industrial robots. Machines, 4, 23.

9. Efimenko, L.A., Ramus, A.A., Merkulova, A.O. (2015) Peculiarities of austenite decomposition in heat-affected zone in welding of high-strength steels. Fizika Metallov i Metallovedenie, 116(5), 520-529 in Russian].

10. Krektuleva, R.A., Bezginov, R.O., Cherepanov, O.I., Cherepanov, R.O. (2015) Investigation of thermophysical processes in contacting pair of materials $\mathrm{St3}-\mathrm{Al}$ in consumable electrode argon-arc welding. Fizicheskaya Mezomekhanika, 18(3), 92100 [in Russian].

11. Zinoviev, V.E. (1989) Thermophysical properties of metals at high temperatures: Refer. Book. Moscow, Metallurgiya [in Russian].

12. Lyakishev, N.P. (1996) State diagrams of binary metallic systems: Refer. Book. In: 3 Vol. Vol. 1. Ed. by N.P. Lyakishev. Moscow, Mashinostroenie [in Russian].

13. Krektuleva, R.A., Cherepanov, O.I., Cherepanov, R.O. (2017) Numerical investigation of residual thermal stresses in welded joints of the heterogeneous steels with account of technological features of multipass welding. Applied Mathemathical Modelling, 42, 244-256.

14. Bezhin, O.N., Kosyakov, V.A., Krektuleva, R.A. (1998) Formation of thermal localized structures in the weld during consumable electrode pulsed-arc welding. PMTF, 39, 232(6), 172-177 [in Russian]. 


\title{
INVESTIGATION OF ELECTRICAL AND THERMAL CHARACTERISTICS OF PLASMATRON FOR MICROPLASMA SPRAYING OF COATINGS FROM POWDER MATERIALS
}

\author{
Yu.S. BORISOV, S.G. VOINAROVYCH, A.N. KYSLYTSIA, \\ E.K. KUZMYCH-IANCHUK and S.N. KALIUZHNYI \\ E.O. Paton Electric Welding Institute of the NAS of Ukraine
}

11 Kazymyr Malevych Str., 03150, Kyiv, Ukraine. E-mail: office@paton.kiev.ua

\begin{abstract}
The volt-ampere characteristics were studied and the thermal efficiency of the MP-04 plasmatron for the installation of microplasma spraying MPN-004 was determined under the conditions of formation of a laminar argon microplasma jet. The range of operating voltages of the plasmatron was determined and a family of volt-ampere characteristics was plotted, each of which was taken at the constant composition and flow rate of working gas, length of open region of the arc and constant design dimensions of the plasmatron. Analysis of the experimental results shows that volt-ampere characteristics of the MP-04 plasmatron are ascending and linear. It was established that at operating values of current and flow rate of plasma-forming gas, the voltage is in the range of 22-32 V. The thermal efficiency of the plasmatron, the bulk mean initial enthalpy and the temperature of plasma jet were determined depending on the arc current and flow rate of plasma-forming gas by the method of heat flow calorimetry. It was found that under the conditions of microplasma powder spraying process, thermal efficiency of the plasmatron is in the range of $30-55 \%$ and at gas flow rates, exceeding 40 l/h, it practically does not change with the change in current. 16 Ref., 1 Table, 7 Figures.
\end{abstract}

Ke yword s : microplasma spraying, argon plasma jet, volt-ampere characteristics of plasmatron, temperature and enthalpy of plasma jet, thermal efficiency, voltage and current of plasma arc, plasma-forming gas flow rate

At present, the processes of thermal coating are increasingly used in industry. One of the main methods of thermal coating is plasma spraying. Most often, for this purpose plasmatrons are used, which generate a turbulent plasma jet with an electric power of up to $200 \mathrm{~kW}$ and a spot diameter of the sprayed material of 15-30 mm. The use of such plasmatrons for spraying small-sized or thin-walled parts can lead to their overheating and buckling because of a high thermal power of plasma jet. In addition, in the case of spraying small-sized parts or local surface areas (5-10 mm or less), large losses of sprayed material occur, and it also becomes necessary to perform an additional operation to mask the areas which are not subjected to spraying. These circumstances resulted in the development of a new method of thermal coating at the E.O. Paton Electric Welding Institute, which is microplasma spraying (MPS) [1, 2].

For realization of the microplasma spraying method, at the E.O. Paton Electric Welding Institute the microplasmatron was designed and patented, equipped with a stand-off, directly cooled anode with an erosion-resistant insert [3]. The power of the designed MP-04 microplasmatron is up to $2.5 \mathrm{~kW}$.

A specific feature of the microplasma spraying process in the case of coating of powder materials is the mode of laminar plasma jet flow with the use of coaxial blowing of plasma jet with argon for its stabilization.

During the development of the technology of microplasma spraying of coatings using powder as a sprayed material, it was necessary to study both the characteristics of the MP-04 microplasmatron as well as the parameters of the microplasma jet generated by it. In the work, such energy characteristics as coefficient of thermal efficiency of the plasmatron $(\eta)$, dependence of arc discharge voltage on current during change in gas flow rates - volt-ampere characteristics (VACh) of the arc, enthalpy $(\Delta \mathrm{H})$ and plasma temperature were studied.

Investigations procedure. The procedure of heat flow calorimetry, used to determine the characteristics of the MP-04 microplasmatron as applied to the conditions of MPS from wire materials, is described in [4]. The main difference in the operation of the plasmatron for spraying powder materials is the mode of laminar plasma jet flow. It is known that plasma arc voltage depends on the design of the plasmatron, arc current, composition and flow rate of the working gas. In this connection, measuring of VACh was performed at a constant composition and flow rate of the working gas, length of the open region of the arc and constant 


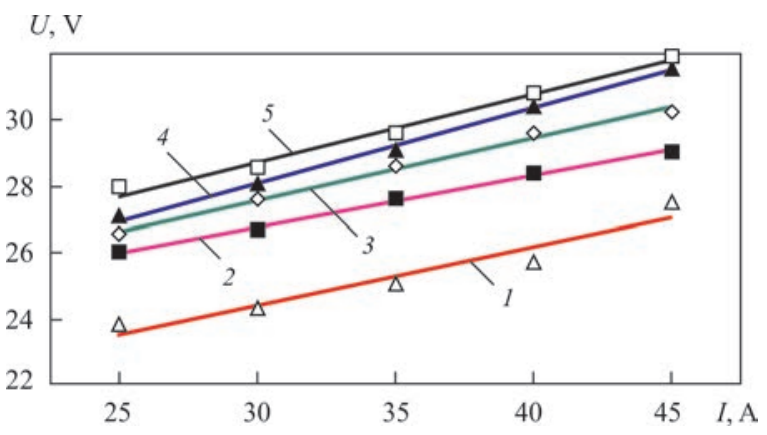

Figure 1. VACh of MP-04 plasmatron. Plasma-forming gas flow rate: $1-40 ; 2-60 ; 3-80 ; 4-100 ; 5-120 \mathrm{l} / \mathrm{h}$

design dimensions of the plasmatron: diameter of the plasma-forming nozzle channel was $1.0 \mathrm{~mm}$, electrode diameter was $1.5 \mathrm{~mm}$, distance from electrode end to nozzle end was $1.0 \mathrm{~mm}$, distance from nozzle end to anode was $1.5 \mathrm{~mm}$. As a plasma-forming and shielding gas, argon was used. The flow rate of plasma-forming gas was changed within 40-120 l/h, the flow rate of shielding gas in all experiments was maintained equal to $240 \mathrm{l} / \mathrm{h}$.

The main thermal characteristics of the plasmatron are its thermal efficiency $\left(\eta_{\mathrm{th}}\right)$, enthalpy $(\Delta H)$ and temperature of plasma jet.

Measurement of VACh of the MP-04 microplasmatron during spraying of powder materials. VACh allows establishing the range of stable operation of the power source at the change in operating modes of the plasmatron. To determine the range of operating voltages of the MP-04 plasmatron, the family of VAChs was plotted (Figure 1).

Processing of the experimental results shows that the VAChs of the MP-04 plasmatron are ascending and have a linear form. The similar VAChs were also obtained during the study of laminar plasmatron in [5]. It follows from [6] that ascending VAChs in most cases are more energetically favourable, since during the use of power sources they do not require the introduction of additional ballast resistance into the circuit, the drop of voltage at which can reach $50 \%$. Thus, the ascending VAChs of the MP-04 microplasmatron

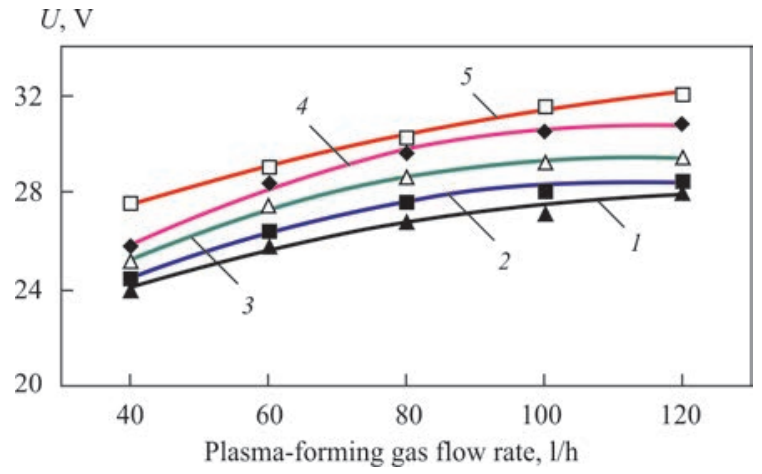

Figure 2. Change of arc column voltage of MP-04 plasmatron, depending on gas flow rate for different values of current: $1-25$; $2-30$; $3-35 ; 4-40 ; 5-45 \mathrm{~A}$ allow using the power sources with it having both a steeply falling external VACh as well as a rigid external VACh [7].

It was found, that at a constant cathode-anode distance and at a constant gas composition, the voltage increases with an increase in current and flow rate of plasma-forming gas (Figures 1, 2), simultaneously increasing the power of the plasmatron. The rise in voltage with the increased flow rate of working gas can be explained by an increase in the degree of the arc column constriction. During blowing of the arc discharge, at its boundary the deionization process occurs due to intense heat exchange between the gas and the arc column, which leads to a reduction in the discharge diameter and an increase in the electric field intensity in it. The more intense the arc is constricted, the lower the current value, when its VACh transfers into ascending one.

From VACh (Figure 1) it is seen that for operating values of current and flow rate of plasma-forming gas, the voltage is in the range of 22-32 V. Using the dependence given in the work [8], it can be assumed that the power source for arc excitation and stable operation of the MP-04 plasmatron should provide the ability to perform a smooth adjustment of current in the range of 20-60 A and open circuit voltage of at least $60 \mathrm{~V}$.

Determination of thermal efficiency of the plasmatron, power, enthalpy and temperature of Ar-plasma jet during microplasma spraying. A growth in voltage at the increase in the flow rate of plasma-forming gas leads to a linear increase both in the arc power (Figure 3) as well as in the thermal efficiency of the plasmatron (Figure 4), determined according to [4].

The obtained thermal efficiency of the MP-04 microplasmatron at the given operating parameters is in the range of $30-55 \%$. According to literature data and calculations performed using the CASPSP software package for computer simulation of the plasma spraying process, the thermal efficiency of plasmatrons

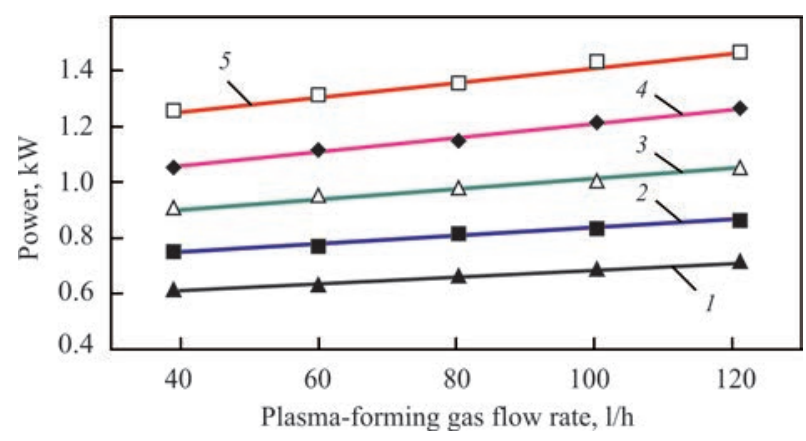

Figure 3. Change of power of MP-04 plasmatron depending on gas flow rate for different values of current: $1-25 ; 2-30 ; 3-$ $35 ; 4-40 ; 5-45 \mathrm{~A}$ 


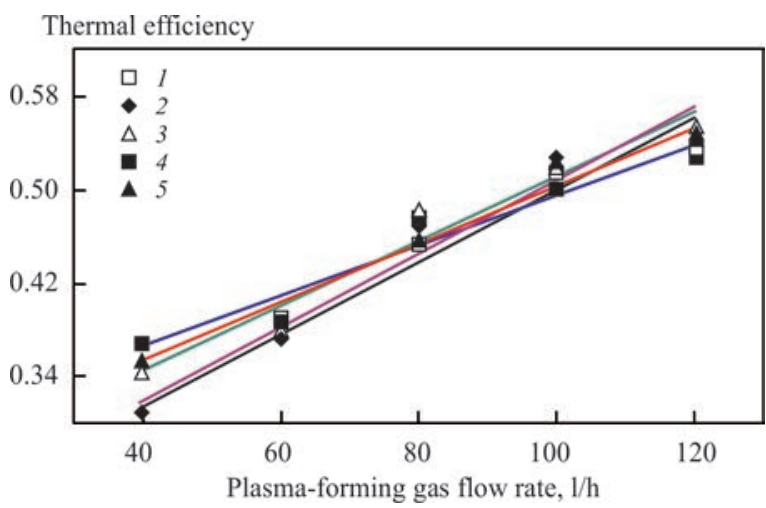

Figure 4. Change of thermal efficiency of MP-04 plasmatron depending on gas flow rate for different values of current: $1-45$ $2-40 ; 3-35 ; 4-30 ; 5-25 \mathrm{~A}$

without an interelectrode insert applied during traditional plasma spraying using argon, is 50-70 \% [9].

The increase in thermal efficiency of the MP-04 microplasmatron with a growth in the flow rate of plasma-forming gas is explained by a decrease in heat losses from the arc column to the nozzle walls due to the increase in the degree of the arc column constriction and, as a result, improvement of their thermal insulation from the arc column, as well as due to a more intensive cooling of the anode by a gas flow. Thus, the higher the gas flow rate, the lower the heat load on the nozzle and, therefore, the longer the life of the nozzle.

However, since voltage and, consequently, jet power grow less intensively than gas flow rate, the values of enthalpy and temperature decrease with the growth in gas flow rate (Figure 5). In this case, the maximum calculated enthalpy of $32000 \mathrm{~J} / \mathrm{l}$ is observed at a minimum gas flow rate $(40 \mathrm{l} / \mathrm{h})$ and a maximum current ( $45 \mathrm{~A}$ ), and the minimum calculated enthalpy of $11000 \mathrm{~J} / 1$ is observed at a maximum gas flow rate (120 l/h) and a minimum current (25 A).

Based on the data on the dependence of argon temperature on enthalpy [10], the temperature of microplasma jet is $10000-13500 \mathrm{~K}$. According to literature data and calculations performed using CASPSP for traditional plasma spraying, the initial temperature of

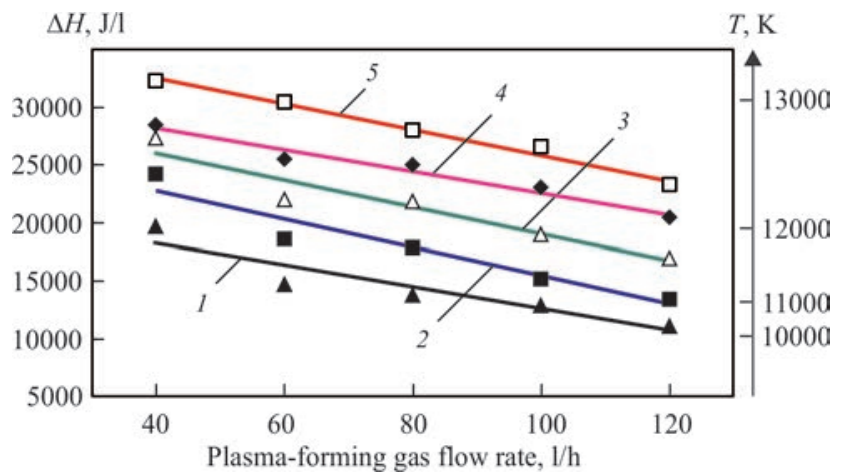

Figure 5. Change of enthalpy depending on gas flow rate for different values of current: $1-25 ; 2-30$; $3-35$; $4-40$; $5-$ $45 \mathrm{~A}$

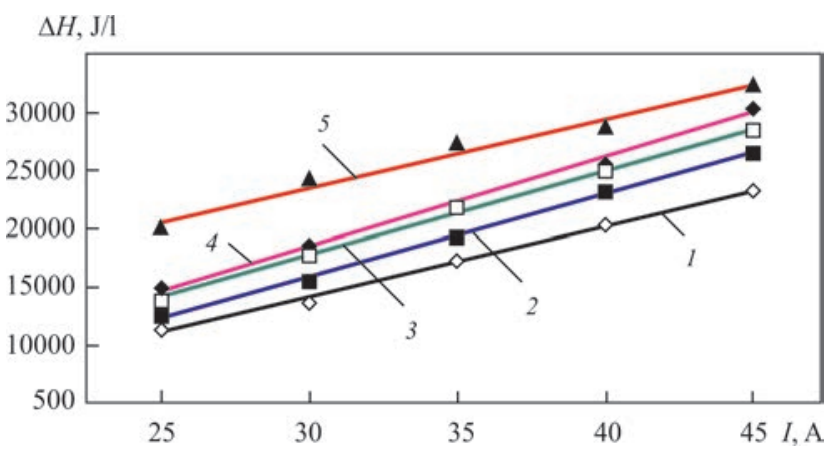

Figure 6. Change of enthalpy depending on current at different values of plasma-forming gas flow rate: $1-25$; $2-30$; $3-35$; $4-40 ; 5-45 \mathrm{~A}$

argon plasma leaving the nozzle is $7000-13000 \mathrm{~K}$ [7, 11-15].

At a fixed voltage, the arc power can be controlled by a more flexible parameter - arc current. The jet enthalpy with increasing current, and, consequently, the arc power, rises linearly at all gas flow rates (Figure 6).

Since the voltage is mainly determined by the design of the plasmatron and the composition of plasma-forming gas, during spraying a coating of powder material, the choice of the mode of operation of the plasmatron consists in establishing the optimal combination of current and flow rate of plasma-forming gas. The lower and upper levels of the flow rate of plasma-forming gas are associated with the operating conditions of the microplasmatron (thermal load on nozzle walls, anode resistance and process stability).

The carried out investigations showed that the thermal efficiency of the MP-04 plasmatron practically does not change with a change in the current at gas flow rates exceeding $40 \mathrm{l} / \mathrm{h}$ (Figure 7). A decrease in the thermal efficiency of the plasmatron with a rise in current in the case of a gas flow rate of $40 \mathrm{l} / \mathrm{h}$ is associated with an increase in losses in the nozzle walls due to insufficient arc constriction.

The evaluation of power losses on radiation with the open column region of a microplasma arc was performed using the formula (3) [4].

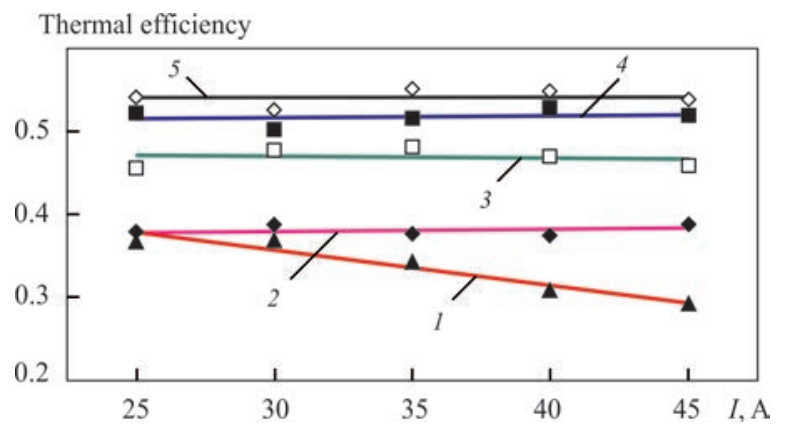

Figure 7. Change of thermal efficiency of MP-004 plasmatron depending on current at different values of plasma-forming gas flow rate: $1-40 ; 2-60 ; 3-80 ; 4-100 ; 5-120 \mathrm{l} / \mathrm{h}$ 
Values of volumetric losses of power of argon plasma of atmospheric pressure on radiation

\begin{tabular}{|c|c|c|c|c|c|c|c|}
\hline$(\bar{T}), \mathrm{kK}$ & 10 & 11 & 12 & 13 & 14 & 15 & 16 \\
\hline$\psi \cdot 10^{10}, \mathrm{~W} / \mathrm{m}^{3}$ & 0.0033 & 0.011 & 0.030 & 0.062 & 0.096 & 0.118 & 0.124 \\
\hline
\end{tabular}

The results of a calculated evaluation of the volumetric losses of power of argon plasma of atmospheric pressure on radiation are given in Table.

In the case when $l=3 \mathrm{~mm}, d=1 \mathrm{~mm},(\bar{T})=13 \mathrm{kK}$, the power losses on radiation will be $1.46 \mathrm{~W}$, which corresponds to approximately $0.1 \%$ of the arc power.

The results of experiments on measuring argon plasma radiation given in [16] show that at a temperature of about $13500 \mathrm{~K}$, the radiation correction is about $2 \%$.

\section{Conclusions}

1. As a result of measuring the electrical and thermal characteristics of the laminar microplasma argon jet used in microplasma spraying by powder materials, the volt-ampere characteristics of the MP-04 plasmatron were determined. It is shown that they have a linear form and are ascending, while the operating voltage of the arc in the current range of $25-45 \mathrm{~A}$ is 22-32 V.

2. It was found that the thermal efficiency of the MP-04 microplasmatron in the current range of 2545 A grows with an increase in the flow rate of plasma-forming gas. The maximum thermal efficiency reaches $55 \%$ at a gas flow rate of $120 \mathrm{l} / \mathrm{h}$. The efficiency of the plasmatron practically does not change with a change in the current at gas flow rates exceeding $40 \mathrm{l} / \mathrm{h}$. An increase in current at a gas flow rate of $40 \mathrm{l} / \mathrm{h}$ leads to a decrease in the efficiency of the plasmatron, which is associated with an increase in losses in the nozzle walls as a result of insufficient arc constriction.

3. It was found that under the given conditions, the calculated value of plasma jet enthalpy reaches $32 \mathrm{~kJ} / \mathrm{l}$ and the maximum calculated temperature of microplasma argon jet in the operating range of the MP-04 microplasmatron is $13500 \mathrm{~K}$. Thus, due to the increased ratio of the arc power to the flow rate of plasma-forming gas in the case of microplasma spraying (about $2 \mathrm{~kW}$ ), as compared to traditional plasma spraying (about $1 \mathrm{~kW}$ ), the temperature of microplasma jet with a power of $1.5 \mathrm{~kW}$ is in many cases higher than the temperature of plasma jet generated by conventional plasmatrons of 10-40 kW capacity.

1. Borisov, Yu., Borisova, A., Pereverzev, Yu., Ramaekers, P.P.J. (1997) Microplasma spraying. In: Proc. of $5^{\text {th }}$ Europ. Conf. on Advanced Material and Processes. Netherlands, 237-241.

2. Borisov, Yu.S., Pereverzev, Yu.N., Bobrik, V.G. , Vojnarovich, S.G. (1999) Deposition of narrow-strip coatings by microplasma spraying method. Avtomatich. Svarka, 6, 53-55 [in Russian].

3. Borisov, Yu.S., Vojnarovych, S.G. et al. (2002) Plasmatron for coating deposition. Pat. Ukraine 2002076032UA, Int. Cl. B23K10/00 [in Ukrainian].

4. Borisov, Yu.S., Kyslytsia, O.M., Voinarovych, S.G. et al. (2018) Investigation of plasmatron electric and energy characteristics in microplasma spraying with wire materials. The Paton Welding J., 9, 18-22.

5. Zheenbaev, Zh., Engelsht, V.S. (1975) Laminar plasmatron. Frunze, Ilim [in Russian].

6. Koroteev, A.S. (1980) Electric arc plasmatrons. Moscow, Mashinostroenie [in Russian].

7. Borisov, Yu.S., Kharlamov, Yu.A. et al. (1987) Thermal coatings of powder materials. Kiev, Naukova Dumka [in Russian].

8. Paton, B.E., Gvozdetsky, V.S., Dudko, D.A. et al. (1979) Microplasma welding. Kiev, Naukova Dumka [in Russian].

9. (2007) Software CASPSP-3.12 for computer modeling of plasma spraying process. Avtomatich. Svarka, 5, 5-6 [in Russian].

10. Engelsht, V.S., Gurovich, V.Ts., Desyatkov, G.A. et al. (1990) Theory of electric arc column. Low-temperature plasma. Vol. 1. Novosibirsk, Nauka [in Russian].

11. Grey, J., Jackobs, P. (1964) Rocket technique and cosmonautics, 3, 25.

12. Elyashevich, M.A. (1970) Problems of physics of low-temperature plasma. Ed. by M.A. Elyashevich. Ins-te of Physics of AS BSSR. Minsk, Nauka i Tekhnika [in Russian].

13. Abdrazakov, A., Zheenbaev, Zh., Karikh, F.G. (1968) Investigation of electric arc and plasmatron. Frunze, Ilim [in Russian].

14. Krasnov, A.N., Zilberberg, V.T., Sharivker, S.Yu. (1970) Low-temperature plasma in metallurgy. Metallurgiya [in Russian].

15. Morenov, A.I., Petrov, A.V. (1967) Determination of velocities and pulsations of jet in plasmatrons for coating deposition. Svarochn. Proizvodstvo, 2, 3-6 [in Russian].

16. Tankin, R.S., Berry, J.M. (1964) Experimental investigation of radiation from an argon. Phys. of Fluids, 7, 1620-1624. 


\title{
PROCESSES OF NONCONSUMABLE ELECTRODE WELDING WITH WELDING CURRENT MODULATION (Review). Part 1. Peculiarities of burning of nonstationary arcs with refractory cathode
}

\author{
U. BOI ${ }^{1}$ and I.V. KRIVTSUN ${ }^{2}$ \\ ${ }^{1}$ Guangdong Institute of Welding (China-Ukraine E.O. Paton Institute of Welding) \\ 363 Chiansin Str., Tianhe, 510650, Guangzhou. E-mail: wuby@gwi.gd.cn \\ ${ }^{2}$ E.O. Paton Electric Welding Institute of the NAS of Ukraine \\ 11 Kazymyr Malevych Str., 03150, Kyiv, Ukraine. E-mail: office@paton.kiev.ua
}

\begin{abstract}
Works devoted to the processes of inert-gas nonconsumable electrode welding with current modulation were reviewed. In the first part of the review attention is focused on studies, dealing with the features of running of thermal, gas-dynamic and electromagnetic processes in nonstationary arcs with refractory cathode at different modes of arc current modulation. 35 Ref., 2 Tables, 18 Figures.
\end{abstract}

Keywords: arc with refractory cathode, arc plasma, TIG welding, welding current modulation, pulse, frequency, fill factor, amplitude

Inert-gas nonconsumable electrode arc welding (TIG) now is one of the main technological processes for producing high-quality permanent joints of critical structures from steels, titanium and aluminium alloys [1]. At the same time, this welding process does not meet the ever increasing requirements of modern industrial production, because of low penetrability of the welding arc with the refractory cathode and low process efficiency (welding speed). Therefore, over the last decades the efforts of scientists and specialists have been aimed at improvement of the effectiveness of TIG welding at preservation of the high quality of welds.

Modulation of welding current in TIG welding is one of the most widely applied methods to control the thermal, gas-dynamic and electromagnetic characteristics of the arc, as well as the characteristics of its thermal and dynamic (force) impact on the metal being welded. Variation of current modulation parameters, such as frequency, relative pulse duration, amplitude and shape, allows controlling in a rather wide range the depth and shape of metal penetration, thermal cycle of welding, and, therefore, affecting the structure and properties of the metal of the weld and HAZ.

Many studies are devoted to investigation of the processes of TIG welding with arc current modulation [2-32]. Modes with low-frequency (modulation frequency $f \leq 50 \mathrm{~Hz})[3,5,6,8,9,11,15,25,30]$, medium-frequency $(f \sim 5 \mathrm{kHz})[2,4-9,15,17]$ and high-frequency $(f>10 \mathrm{kHz})[2,5,6,10,13-15,17$,
20-24, 27-29] with pulse current modulation were experimentally studied. Works $[7,11,12,16,18,19$, 24, 26-29, 31, 32] are devoted to theoretical study and mathematical modeling of TIG welding by modulated current. Let us consider the results of investigations, described in the above works in greater detail. Here, in the first part of this review we will focus on the works devoted to experimental studies of physical processes in nonstationary arcs with refractory cathode in different modes of arc current modulation.

In TIG welding with welding current modulation the processes of transfer of energy, pulse, mass and charge in arc column plasma are nonstationary, that is due to the change of energy, gas-dynamic and electromagnetic characteristics of arc plasma under the impact of periodically changing current. As a result, the distributed and integral characteristics of plasma of a nonstationary welding arc, as well as characteristics of its impact on the metal being welded, can differ considerably from the respective characteristics for direct current arcs (at other conditions being equal), the degree of this difference depending on pulse repetition rate and shape fill factor, modulation amplitude and other factors.

Based on experimental data of works [21-23] of Chinese scientists, the effective value of voltage of a $3 \mathrm{~mm}$ arc with a refractory cathode (W=2\% Ce) of $2.4 \mathrm{~mm}$ diameter increases practically in proportion to current modulation frequency in welding $6 \mathrm{~mm}$ stainless steel 0Cr18Ni9Ti in argon (welding speed of $120 \mathrm{~mm} / \mathrm{min}$ ), as shown in Figure 1. In these experiments, the following parameters of pulse modulation 


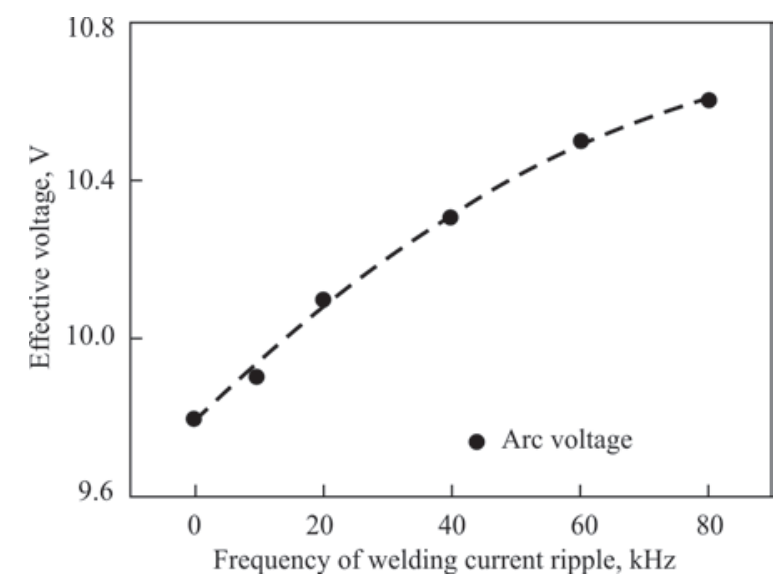

Figure 1. Dependence of effective value of arc voltage on welding current modulation frequency [22]

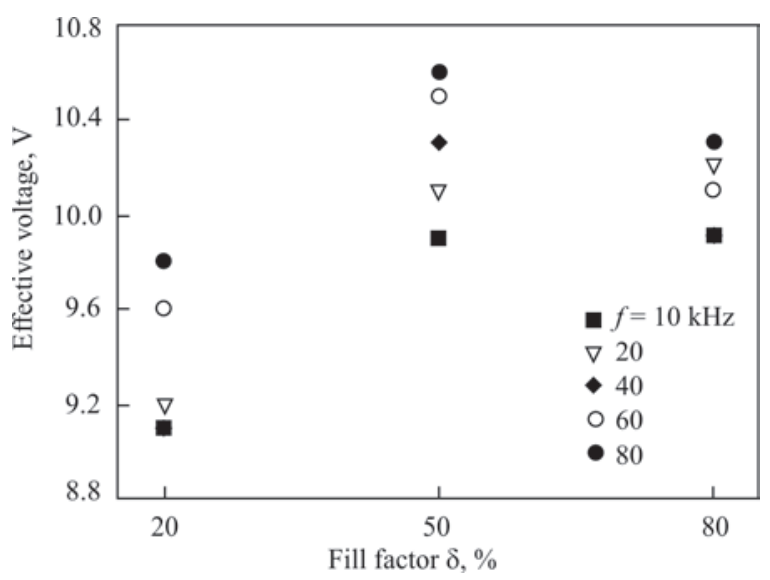

Figure 2. Effective values of arc voltage at different frequencies of current modulation, depending on fill factor [21, 22]

of current were used: square wave pulses, repetition rate $f$ was varied in the range of $10-80 \mathrm{kHz}$, base current $I_{\mathrm{b}}=50$ A, pulse current $I_{\mathrm{p}}=130$ A, effective current value

$$
I_{\text {eff }}=\sqrt{(1-\delta) I_{\mathrm{b}}^{2}+\delta I_{\mathrm{p}}^{2}}=98.5 \mathrm{~A},
$$

where $\delta$ is the fill factor, determined as the ratio of pulse duration to modulation period (in the considered case $\delta=0.5$ ). The respective experiment on direct current welding was conducted at $I=100$ A that practically coincides with effective value of modulated current.
Table 1. Parameters of the studied mode of HFP modulation of arc current [21, 22]

\begin{tabular}{|c|c|c|c|c|c|}
\hline $\begin{array}{c}\text { Mode } \\
\text { number }\end{array}$ & $\delta, \%$ & $f, \mathrm{kHz}$ & $I_{\text {eff, }} \mathrm{A}$ & $I_{\mathrm{b}}, \mathrm{A}$ & $I_{\mathrm{p}}, \mathrm{A}$ \\
\hline 1 & 20 & $10-80$ & 89.4 & 60 & 160 \\
\hline 2 & 50 & $10-80$ & 98.5 & 50 & 130 \\
\hline 3 & 80 & $10-80$ & 96.0 & 45 & 105 \\
\hline
\end{tabular}

The effect of fill factor $\delta$ on effective value of arc voltage at TIG welding of stainless steel with high-frequency pulse (HFP) modulation of current was investigated in [21, 22]. Three modes of pulse modulation were studied, the parameters of which are summarized in Table 1.

Results of measurement of the respective values of arc current are shown in Figure 2. As follows from experimental data, given in this Figure, with $\delta$ increase the effective value of arc voltage first rises, and then remains practically constant in the frequency range of $10-20 \mathrm{kHz}$ and somewhat decreases at $f>40 \mathrm{kHz}$. This weakens the impact of frequency on effective value of voltage and high values of the fill factor.

A marked reduction of transverse dimensions of the column of the arc with a refractory cathode at increase of modulation frequency, illustrated in Figure 3, was noted in works [21-23], by comparing the images of arc plasma at different values of current modulation frequency.

Obtained data allowed the authors performing quantitative evaluation of the force acting on the surface of metal being welded, the values of which are given in Table 2, and are indicative of increase of the above force with increase of modulation frequency $f$ and fill factor $\delta$.

Work [8] is an experimental study of a $3 \mathrm{~mm}$ nonstationary argon arc with a $2 \mathrm{~mm}$ refractory cathode $(\mathrm{W}+2 \% \mathrm{Th})$ burning in the frequency range of current modulation from $0.05 \mathrm{~Hz}$ (practically constant current) up to $5 \mathrm{kHz}$. The anode used was a copper water-cooled plate or sample from SUS 304 stainless steel $3 \mathrm{~mm}$ thick (in the latter case the arc moved relative to the sample at a constant speed equal to $1.6 \mathrm{~mm} / \mathrm{s}$ ). Pulse modulation of current was performed in the range from base current value $I_{\mathrm{b}}=10 \mathrm{~A}$
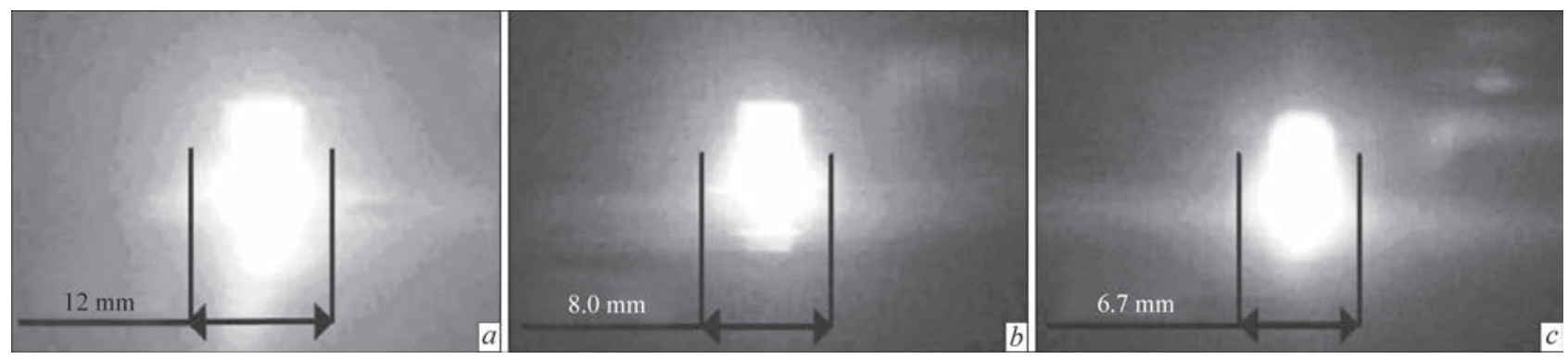

Figure 3. Photographs of the column of an arc at direct current (a) and at HFP modulation of current with the frequency of $20(b)$ and $80(c) \mathrm{kHz}(\delta=20 \%)[22,23]$ 
up to maximum value $I_{\mathrm{p}}=150 \mathrm{~A}$. Two pulse shapes were used: rectangular (square wave) and triangular (without pauses).

During the experiment it was found that the dynamic characteristics of the considered arc depend on the frequency and shape of current pulses, as well as anode material. In particular, at low frequencies $(f<1 \mathrm{~Hz})$, change of arc voltage occurs practically along the static volt-ampere characteristic (VAC) of the arc. For frequencies of $1-10 \mathrm{~Hz}$, even under the condition that the respective values of $\mathrm{DC}$ arc voltage for the base and maximum current values differ, the arcing voltage is practically constant with typical increase and decrease of instantaneous values at the moments of current rise and drop, respectively. The latter effect is observed, if the speed of current change at the pulse fronts exceeds the value of $1.5 \cdot 10^{5} \mathrm{~A} / \mathrm{s}$ and is attributed by the authors of [8] to delaying of the change in concentration of the charged particles, and, accordingly, of electrical conductivity of arc plasma at an abrupt rise and drop of current. In the range of modulation frequencies of $100 \mathrm{~Hz}-1 \mathrm{kHz}$ the average arc voltage decreases at base value of current and somewhat increases at peak value of current. Finally, at frequencies above $2.5 \mathrm{kHz}$ the arc behaves as an element of a circuit with constant ohmic resistance.

Dependencies of voltage $V$ of the arc with a copper (water-cooled) and steel (consumable) anode at base $V_{\mathrm{b}}=V\left(I_{\mathrm{b}}\right)$ and peak $V_{\mathrm{p}}=V\left(I_{\mathrm{p}}\right)$ current values on modulation frequency are shown in Figure 4. As follows from experimental data presented in this Figure, average value of arc voltage markedly decreases at base current value, whereas the respective value of voltage in the current pulse somewhat increases with increase of frequency. This allowed the authors of [8] to conclude that the average arc power has maximum value at small values of $f$ (actually for a DC arc) and decreases with increase of modulation frequency. So, for instance, the average arc power at $2.5 \mathrm{kHz}$ frequency, in the authors' estimates, is equal to just $70 \%$ of the respective value at $f=0.5 \mathrm{~Hz}$.

Work [5] is also devoted to investigations of the dynamic characteristics of free-burning and constricted (plasma) arc with a refractory cathode and copper water-cooled anode, burning in argon at direct current in the range of 20-250 A. In this work experimental frequency characteristics were used to check the applicability of the differential equation of arc dynamics, which was derived on the base of the channel model:

$$
\theta \frac{d U}{d t}+U=\theta R_{s} \frac{d i}{d t}+R_{d} i,
$$

where $R_{\mathrm{s}}=U_{0} / I_{0}$ and $R_{d}=d U / d I$ are the static and dynamic resistance of the arc, respectively; $\theta$ is the
Table 2. Force acting on the welded metal surface $(\mathrm{mN})$ at different parameters of pulse modulation of arc current [22]

\begin{tabular}{|c|c|c|c|}
\hline \multirow{2}{*}{$f, \mathrm{kHz}$} & \multicolumn{3}{|c|}{$\delta, \%$} \\
\cline { 2 - 4 } & 20 & 50 & 80 \\
\hline 0 (direct current) & 3.1 & 3.1 & 3.1 \\
\hline 10 & 5.9 & 9.6 & 4.9 \\
\hline 20 & 6.5 & 9.2 & 5.0 \\
\hline 40 & 9.1 & 11.8 & 4.4 \\
\hline 60 & 11.6 & 16.0 & 5.3 \\
\hline 80 & 17.6 & 17.1 & 4.4 \\
\hline
\end{tabular}

arc time constant, determining the change of arc column conductivity $G$ at a jumplike change of current $\frac{1}{\theta}=-\frac{d \ln G}{d t}$

Current modulation in the experiments was performed by superposition on direct current of a variable (sinusoidal) component with $4 \mathrm{~A}$ amplitude and frequency in the range from $20 \mathrm{~Hz}$ up to $160 \mathrm{kHz}$. It was found that for a constricted arc (tungsten electrode diameter, plasmaforming nozzle diameter and electrode insertion into the nozzle were equal to $4 \mathrm{~mm}$, electrode spacing was $11 \mathrm{~mm}$, plasma gas flow rate varied in the range from 0.055 up to $0.17 \mathrm{~g} / \mathrm{s}$ ) the arc time constant decreases from 50 to $15 \mu \mathrm{m}$ with increase of current and plasma gas flow rate that qualitatively and quantitatively coincides with the results of calculations for currents above $50 \mathrm{~A}$. As regards
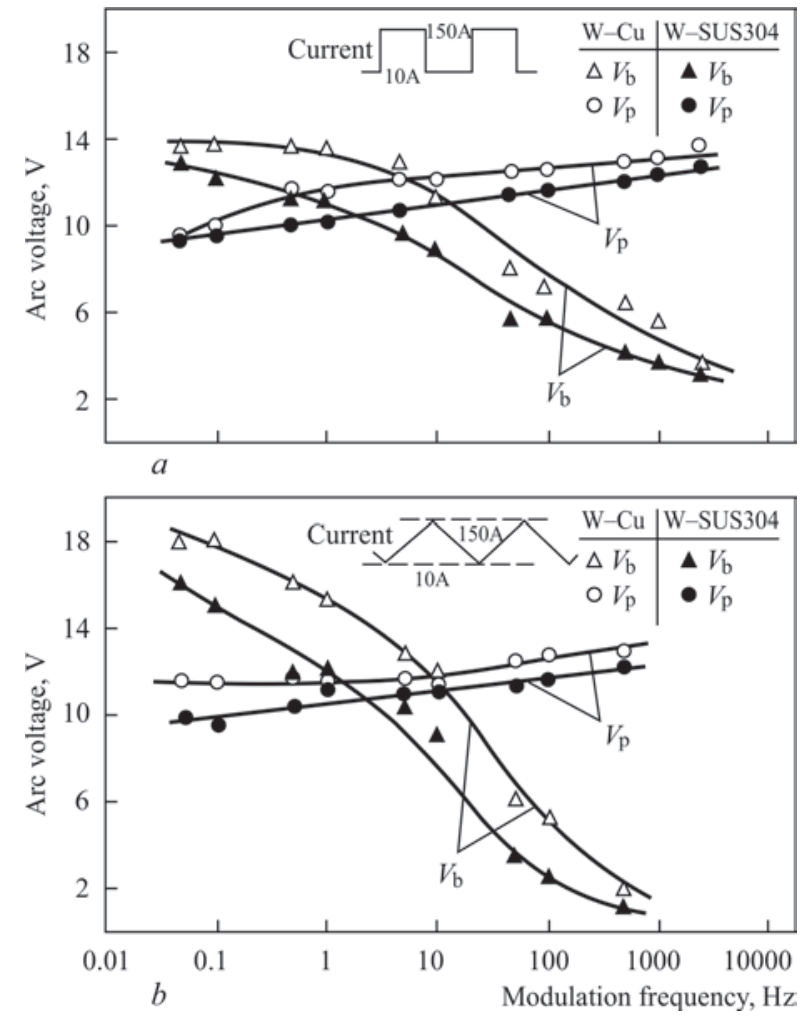

Figure 4. Arc voltage $V_{\mathrm{b}}$ (at base) and $V_{\mathrm{p}}$ (at peak values of current), depending on its pulse modulation frequency: $a$ - rectangular pulses (average values of $V_{\mathrm{b}}$ and $V_{\mathrm{p}}$ ); $b$ - triangular pulses (maximum values of $V_{\mathrm{b}}$, and $V_{\mathrm{p}}$ ) [8] 
free-burning argon arc (cathode diameter of $4 \mathrm{~mm}$, arc length of 2-6 mm), experimentally determined frequency characteristics of the arc differ from the calculated ones both in the area of low and high frequencies. In particular, calculation of the time constant for a $2 \mathrm{~mm}$ arc yields the values of $2-14 \mu$ s, and unlike the constricted arc, greater $\theta$ values correspond to greater current values. Analysis of the obtained data led the authors of [5] to the conclusion that the channel model of the arc, used to derive equation (1), is too simplified for description of a free-burning arc in argon and at analysis of its dynamics, it is necessary to take into account heat transfer due to convection, as well as energy losses for radiation.

In work [9] results of experimental studies of the optical and electrical characteristics of the arc with a refractory cathode, burning both at direct current and at its modulation, are described. Electric arc with a tungsten $(\mathrm{W}+2 \% \mathrm{Th})$ cathode of $2.38 \mathrm{~mm}$ diameter and $30^{\circ}$ sharpening angle of the working end was used in the experiments, and shielding gas (Ar) was fed through a nozzle of $9.5 \mathrm{~mm}$ diameter. The arc was powered from a source, which provided direct current in the range from 0 up to $300 \mathrm{~A}$, and to which a transistor regulator was connected for modulation of current with up to $3000 \mathrm{~Hz}$ frequency at different shape of the pulses. A copper water-cooled anode (solid and split with $0.075 \mathrm{~mm}$ width of the gap) or an anode from stainless steel 304 of $22.22 \mathrm{~mm}$ diameter and $7.62 \mathrm{~mm}$ thickness, soldered into a copper water-cooled holder, were used. A photodiode array, containing 256 elements and operating in a wide range of wave lengths (400-1200 nm) was applied to measure the intensity of arc radiation. A lens and a diaphragm were used to focus the arc radiation on the array surface, after passing through a light filter, preventing photodiode saturation by high intensity radiation. The optical system was tuned to measure the distribution of radiation intensity in a plane, located at the distance of $0.01 \mathrm{~mm}$ from the anode surface.

Experiments on measurement of radiation intensity of DC arc (in the range of 50-300 A), of length

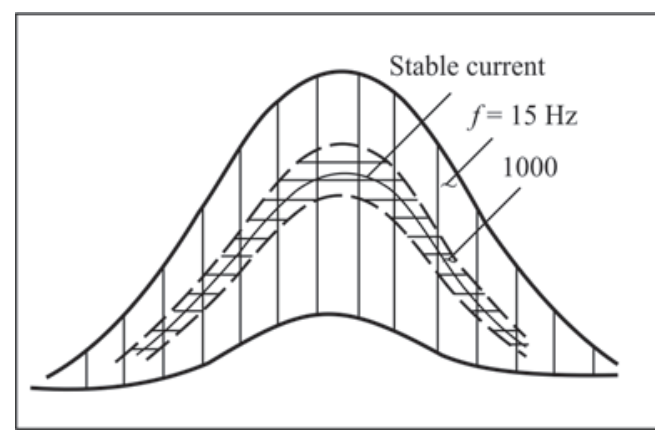

Figure 5. Typical shapes of a signal from photodiode array, characterizing arc radiation intensity distribution [9] from $2.0 \mathrm{~mm}$ up to $6.3 \mathrm{~mm}$, showed that in the immediate vicinity of the anode surface the distribution data can be approximated with sufficient accuracy by the respective Gaussian curve

$$
\varphi(x)=\varphi_{0} \exp \left(-\frac{x^{2}}{2 \sigma^{2}}\right),
$$

where $x$ is the distance from the plane passing through the axis of symmetry of the arc $(x=0)$, and distribution parameter $\sigma$ is defined as the distance, at which the value of the function is equal to $60 \%$ of the respectively value of $\varphi_{0}$ in the above plane. Processing of experimental data for an arc of $4 \mathrm{~mm}$ length yielded $\sigma$ values increasing with arc current rise from $1.0 \mathrm{~mm}$ at $I=50$ A up to $2.4 \mathrm{~mm}$ at $I=300 \mathrm{~A}$ and independent on the used anode type (copper water-cooled or steel) within the measurement error.

In the case of sinusoidal modulation of arc current in the range of 30-270 A (average current value $\langle I\rangle=$ $=150 \mathrm{~A}$ ) the measured distribution of arc radiation intensity essentially depends on modulation frequency, as shown in Figure 5. So, at small values of $f$, the corresponding distribution periodically changes with the frequency equal to the selected modulation frequency between the distribution of radiation intensity of a DC arc at $I=I_{\min }=30 \mathrm{~A}$ and its distribution for an arc at $I=I_{\max }=270 \mathrm{~A}$. Such behaviour is preserved right up to the frequency of the order of $500 \mathrm{~Hz}$. With increase of modulation frequency the amplitude of the above changes decreases and at $f>1000 \mathrm{~Hz}$ the distribution of radiation intensity of an arc of modulated current behaves similar to the distribution for a DC arc at $I=$ $\langle I\rangle-150$ A.

In work [9] an experimental determination of the density of electric current on the anode surface was also performed. A split anode procedure was used, described in detail in [33], and it was assumed that the anode current density has Gaussian distribution along the radius, similar to (2). It is established that the thus determined values of the parameter of $\sigma$ distribution for a direct current arc, increase with the increase of current and arc length. Comparison of the obtained values of the parameter of radial distribution of current density on the anode with the respective $\sigma$ values for a linear distribution of radiation intensity showed that the above values practically coincide for arcs of length from 2.0 up to $6.3 \mathrm{~mm}$ in the current range of 50-300 A. This allowed the authors to conclude that at the change of current (also due to modulation) and length of the arc, the transverse size of the current channel on the anode surface with a sufficiently high degree of accuracy follows the respective changes of the transverse size of distribution of its radiation in- 

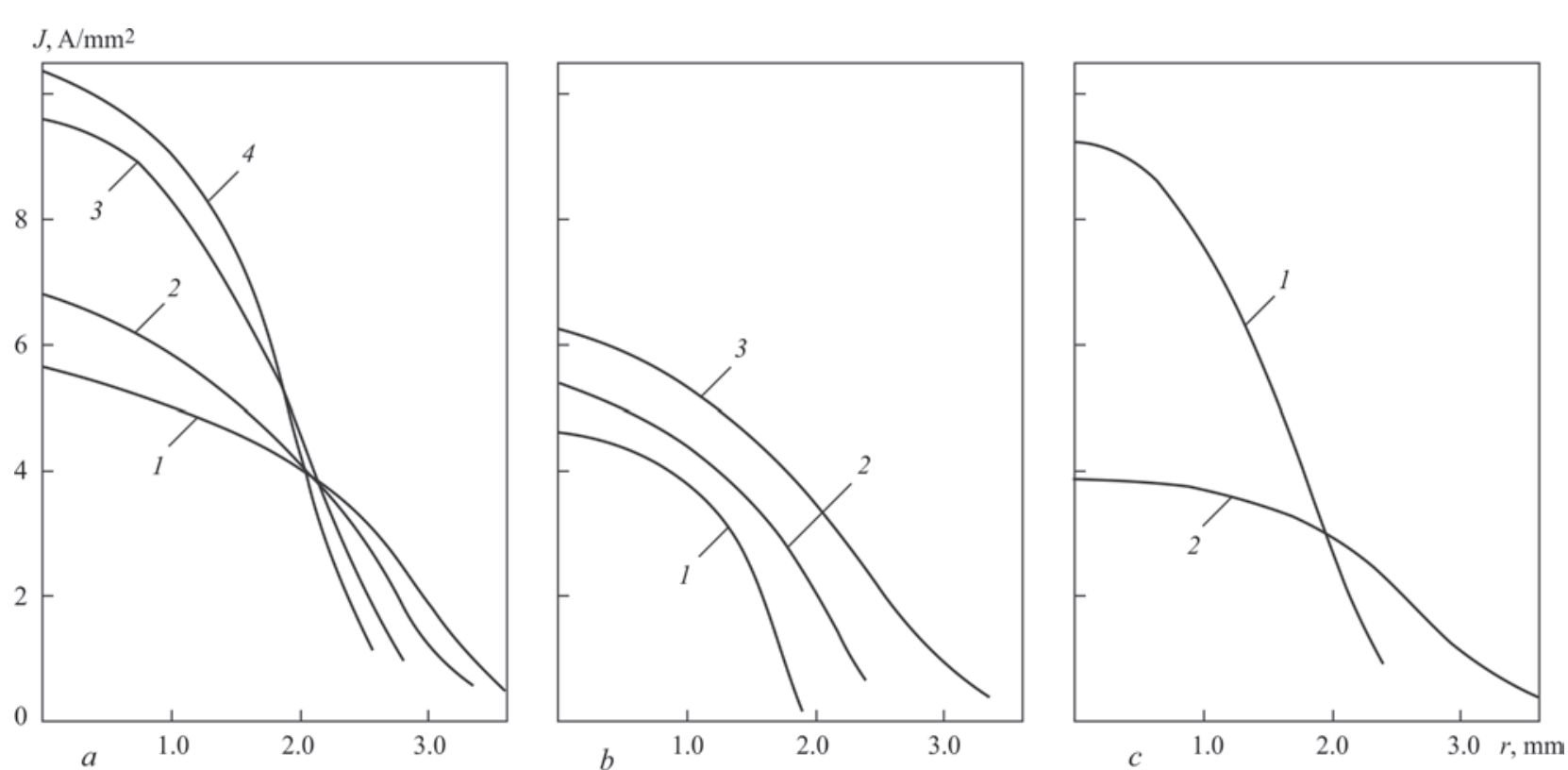

Figure 6. Radial distributions of average over the modulation period values of electric current density on the anode surface: $a-\langle I\rangle=$ $100 \mathrm{~A} ; L=4 \mathrm{~mm}(1-$ direct current; $2-f=5 ; 3-10 ; 4-20 \mathrm{kHz}) ; b-f=5 \mathrm{kHz}, L=2 \mathrm{~mm}(1-\langle I\rangle=30 ; 2-50 ; 3-100 \mathrm{~A})$; $c-\langle I\rangle=100 \mathrm{~A} ; f=10 \mathrm{kHz}(1-L=4 ; 2-8 \mathrm{~mm})[10]$

tensity. Thus, a simpler and faster method of measuring the arc radiation intensity can be used instead of the experimental determination (by split anode method) of the distribution of anode current density.

Here, it should be noted that the assumption of Gaussian distribution of density of anode current of the arc, used by the authors [9], is insufficiently substantiated. From the viewpoint of theory, the most theoretically sound is the approach based on solution of Abel integral equation. Here, the task of restoration of current density distribution in the arc anode region is mathematically incorrect and requires development of stable algorithms for processing the experimental data, obtained using a split anode. In [34], a new procedure was proposed for restoration of density of anode current, based on application of a stable method of numerical calculation of the second derivative from experimentally measured discrete function of arc current distribution through the split anode sections.

Work [10] is devoted to experimental study of distributions of average values of current density and pressure of the arc on the anode surface at high-frequency pulse modulation of current. All the experiments were conducted with application of an electric arc with tungsten (cerium-activated) cathode of $3 \mathrm{~mm}$ diameter with $60^{\circ}$ angle of working end sharpening. The shielding gas used was argon, fed through a nozzle of $10 \mathrm{~mm}$ diameter with the flow rate of $12 \mathrm{l} / \mathrm{min}$. The arc anode was copper water-cooled one with $1.0 \mathrm{~mm}$ orifice for measuring the arc pressure and current density (in the latter case an insulated tungsten probe of $0.9 \mathrm{~mm}$ diameter was inserted into the above orifice). Arc length $L$ was varied in the range of 2-8 mm, arc current modulation was performed by square-wave pulses (meander) without base with repetition rate $f$ of up to $20 \mathrm{kHz}$, average current $\langle I\rangle$ was assigned in the range of 30 to $130 \mathrm{~A}$.

Results of experimental measurement of radial distributions of time-averaged values of electric current density and arc pressure on the anode surface are given in Figures 6, 7. As follows from the curves given in these Figures, the average value of current density in the center of the region of anode binding of the arc rises with increase of modulation frequency (see Figure 6, $a$ ), as well as average current value (see Figure $6, b$ ) and, contrarily, decreases with increase of arc length (see Figure 6, $c$ ).

As regards the distributions of average value of arc pressure, its value in the center of area of anode binding of the arc, by the data of [10], changes nonmonotonically with increase of current modulation frequency. In the frequency range from 0 to $5 \mathrm{kHz}$, the above value grows, whereas at further increase of frequency up to $20 \mathrm{kHz}$, the maximum value of arc pressure on the anode surface decreases noticeably (see Figure 7, a). Experimentally measured pressure in the center of anode binding of the arc at modulation frequency $f=10 \mathrm{kHz}$ rises with increase of average current (see Figure $7, b$ ) and decreases at increase of arc length (see Figure 7, $c$ ).

On the whole, experimental data obtained in work [10], allowed the authors to make a conclusion about contraction (reduction of the transverse size) of the anode region of the arc with the refractory cathode at pulse modulation of current. Here, the degree of such a contraction rises with increases of frequency 

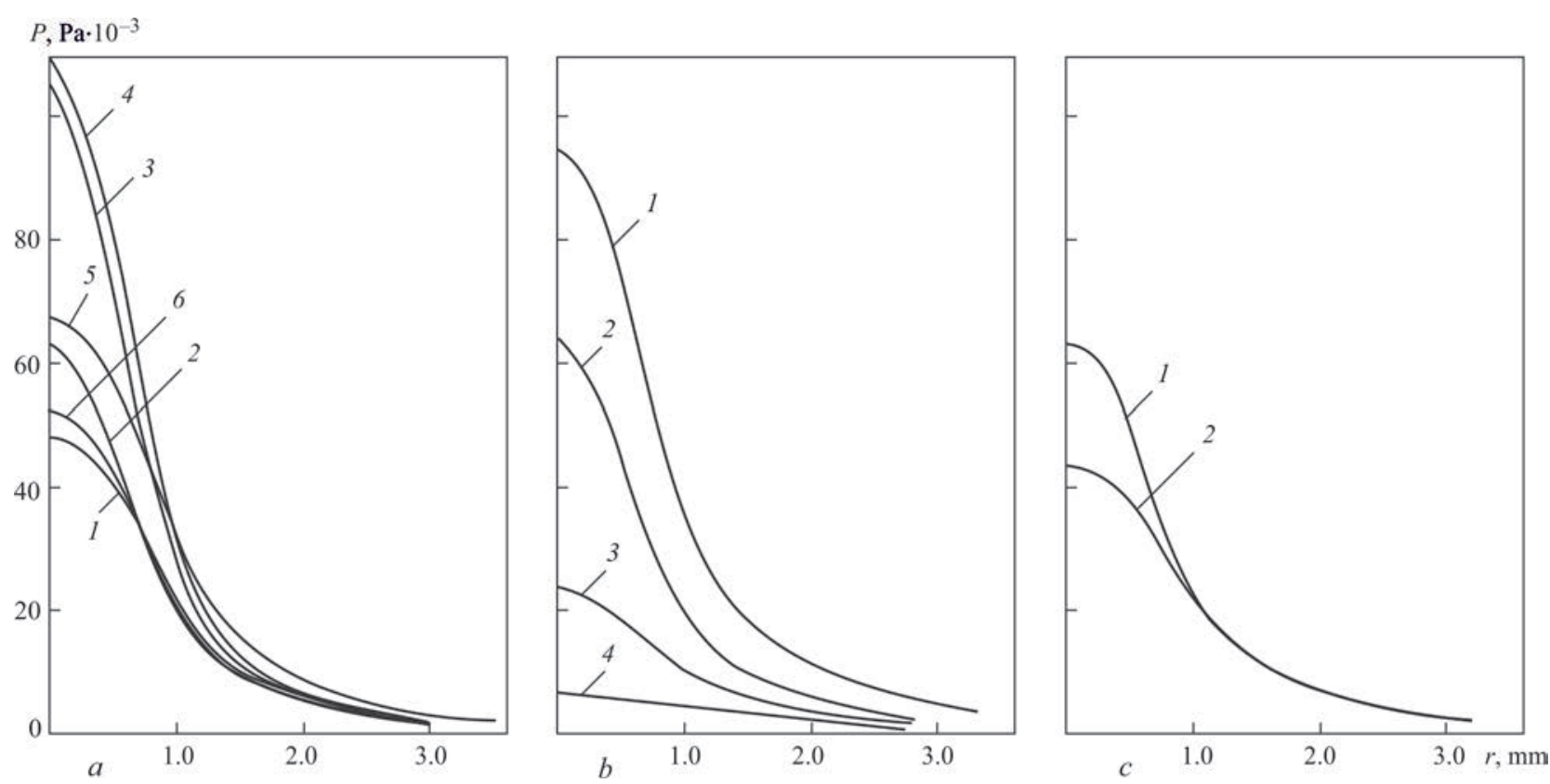

Figure 7. Radial distributions of arc pressures on the anode surface average over the modulation period: $a-\langle I\rangle=100 \mathrm{~A} ; L=4 \mathrm{~mm}$ ( 1 - direct current; $2-f=300 ; 3-3 ; 4-5 ; 5-10 ; 6-20 \mathrm{kHz}) ; b-f=10 \mathrm{kHz}, L=4 \mathrm{~mm}(1-\langle I\rangle=130 ; 2-100 ; 3-70$; $4-40 \mathrm{~A}) ; c-\langle I\rangle=100 \mathrm{~A} ; f=10 \mathrm{kHz}(1-L=2 ; 2-6 \mathrm{~mm})[10]$

from 0 up to $5 \mathrm{kHz}$ and decreases in the range from 5 to $20 \mathrm{kHz}$. The latter circumstance allows recommending the TIG process with HFP modulation of arc current for welding thin metals, using modulation frequency of the order of $20 \mathrm{kHz}$.

Completing consideration of work [10], it should be noted that the data given in report [13], disprove the regularity found by authors of [10], and consisting in increase of arc pressure on the anode surface with increase of current modulation frequency in the range of $0-5 \mathrm{kHz}$ and its decrease at further frequency rise. In particular, the dependence given in Figure 8 is indicative of a continuous increase of the above value with increase of modulation frequency - quite fast in the range from 0 up to $5 \mathrm{kHz}$ and slower at $f>5 \mathrm{kHz}$.

In work [14], the developed by the authors specialized power source ensuring HFP modulation of cur-

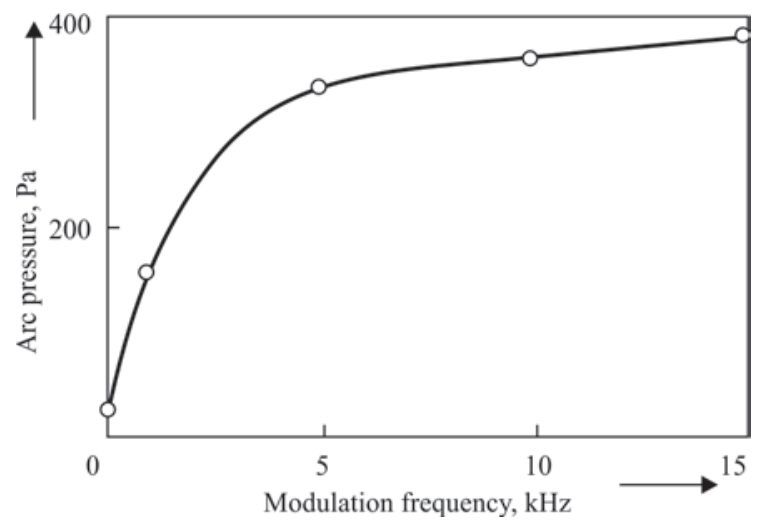

Figure 8. Arc pressure on the anode surface as a function of current modulation frequency: $2 \mathrm{~mm}$ arc with a refractory $(\mathrm{W}+$ $2 \% \mathrm{Th}$ ) cathode of $2.4 \mathrm{~mm}$ diameter; sharpening angle of $60^{\circ}$, average current of $50 \mathrm{~A}$; amplitude value of current of $150 \mathrm{~A}$; pause current of $5 \mathrm{~A}$ [13] rent with up to $20 \mathrm{kHz}$ frequency at high peak values of current (up to $500 \mathrm{~A}$ ), was used to experimentally study the influence of modulation parameters on the degree of contraction of an arc with the refractory cathode, arc pressure distribution over the anode surface, as well as its arcing stability. Experimental stands shown schematically in Figure 9, were used for determination of the above characteristics of the arc. The current shape realized in the experiments for two characteristic values of modulation frequency, is shown in Figure 10. Here, its value $I_{\mathrm{p}}$ in the pulse was equal to $500 \mathrm{~A}$, and average current $\langle I\rangle$ had a constant value, equal to $150 \mathrm{~A}$.

Results of the conducted experiments showed that arc pressure in the center of the region of anode binding of the arc rises continuously with increase of modulation frequency (at preservation of values $\langle I\rangle, I_{\mathrm{p}}$ ), as shown in Figure 11. In particular, for a $2 \mathrm{~mm}$ arc at $f=15 \mathrm{kHz}$ the above value is two times higher than
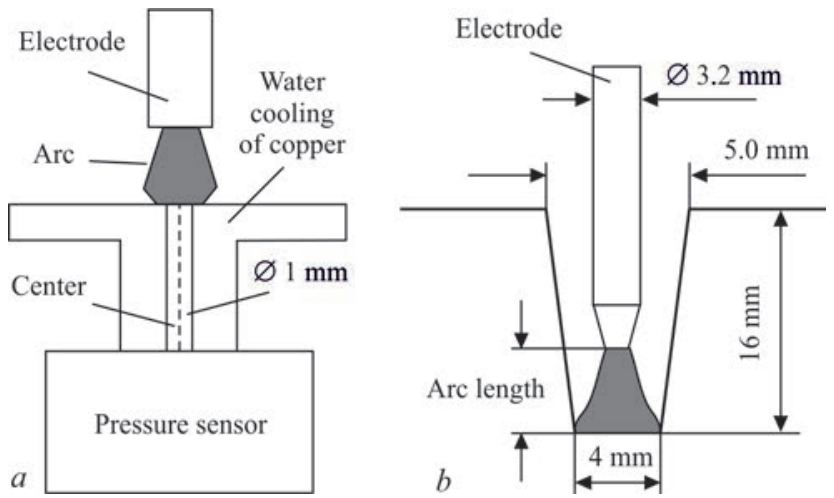

Figure 9. Diagrams of experimental stands for measurement of the pressure of an arc with a refractory cathode ( $a$ ) and determination of its arcing stability $(b)$ [14] 


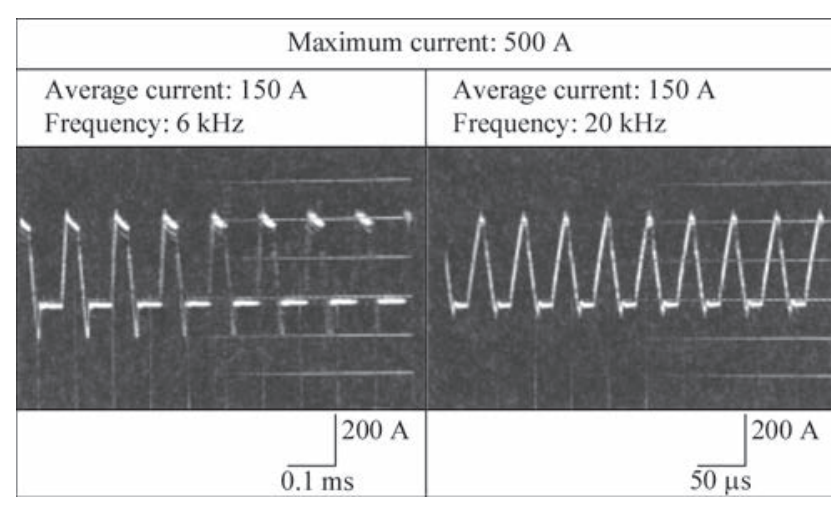

Figure 10. Characteristic shapes of arc current at different values of modulation frequency [14]

the respective value at $f=5 \mathrm{kHz}$, and three times higher than that for an arc of direct current equal to $\langle I\rangle$.

The photos of the arc at smaller average current $(\langle I\rangle=50 \mathrm{~A}$ ) given in Figure 12, allowed the authors of [14] to conclude that the degree of arc contraction and its arcing stability at HFP modulation of current ( $f=10 \mathrm{kHz}$ ) are higher than for the respective DC arc. In their opinion, this is related to the fact that the luminous area of the arc column at high-frequency modulation of current is essentially longer, compared to the respective area in DC arc, and it takes up the entire discharge gap. Experimental studies of the arc behaviour in a narrow groove, shown in Figure 9, $b$, confirmed the conclusion about a higher spatial stability of the arc with HFP modulation of current. So, the arc at modulation frequency $f=10 \mathrm{kHz}$ was stable at length $L$ of up to $5 \mathrm{~mm}$, whereas DC arc had deviations even at $L=2 \mathrm{~mm}$.

Work [15] is devoted to experimental investigation of physical characteristics of arc plasma at pulse modulation of current of an arc with the refractory cathode. Experiments were performed using an arc with a refractory cathode $(\mathrm{W}+2 \% \mathrm{Ce}$ ) of $3 \mathrm{~mm}$ diameter, angle of working end sharpening of $60^{\circ}$, arc length of $4 \mathrm{~mm}$, and shielding gas was argon. Selected as the arc power source was a batch-produced welding machine EWM Tetrix 500 with a special device connected to it, which ensured arc current modulation by rectangular pulses, in the frequency range up to $80 \mathrm{kHz}$. Pulse

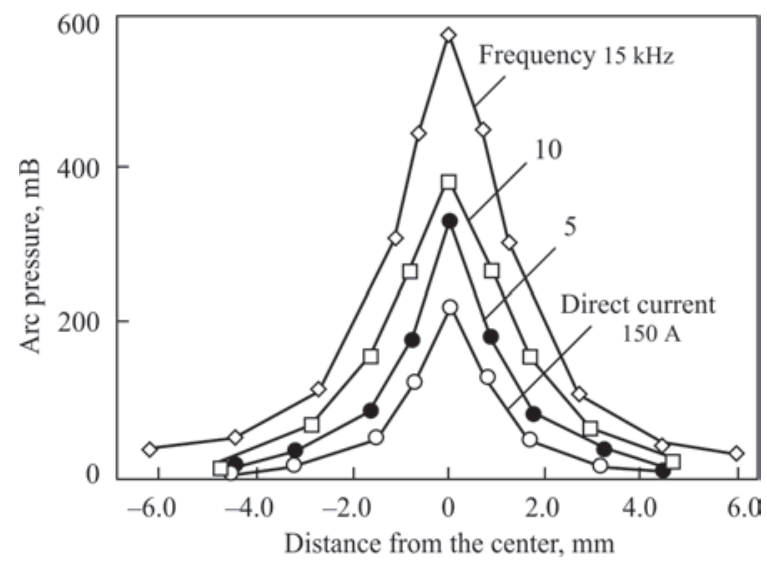

Figure 11. Distribution of arc pressure along the anode surface (relative units) at different values of current modulation frequency: maximum current $-500 \mathrm{~A}$; average current $-150 \mathrm{~A}$; arc length $-2 \mathrm{~mm}[14]$

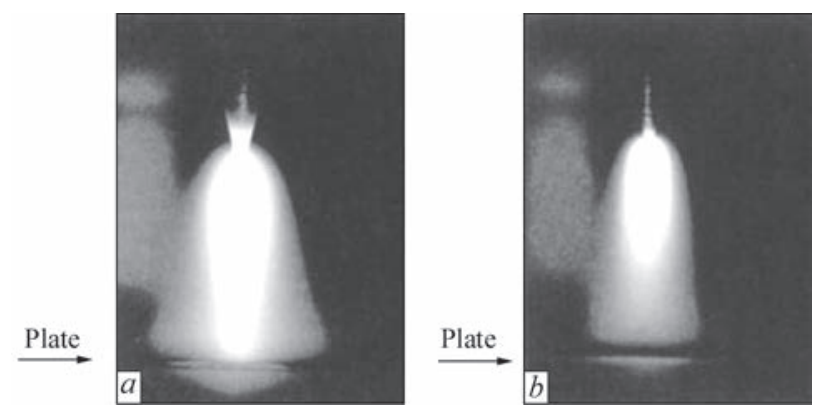

Figure 12. Appearance of an arc with HFP modulation of current (a) and DC arc (b), equal to $\langle I\rangle$ for $a$ : frequency $-10 \mathrm{kHz}$; maximum current $-500 \mathrm{~A}$; average current $-50 \mathrm{~A}$; for $b$ : direct current - 50 A [14]

current $I_{\mathrm{p}}$ was set to be equal to $100 \mathrm{~A}$, base current $I_{\mathrm{b}}$ was assigned on the level of $50 \mathrm{~A}$.

Figure 13 gives photos of the arc during a current pulse and at base current for different values of modulation frequency $f$. As follows from this Figure, with $f$ increase the arc column shape changes from pear shape with diffuse binding to the anode to a spherical shape with a dark space near the anode. Here, for frequencies above $50 \mathrm{~Hz}$, the appearance of the arc during the current pulse practically does differ from its shape during the pause.

Presented in Figure 14 dependencies of arc voltage at peak value of current $U_{\mathrm{p}}=U\left(I_{\mathrm{p}}\right)$ and at its base

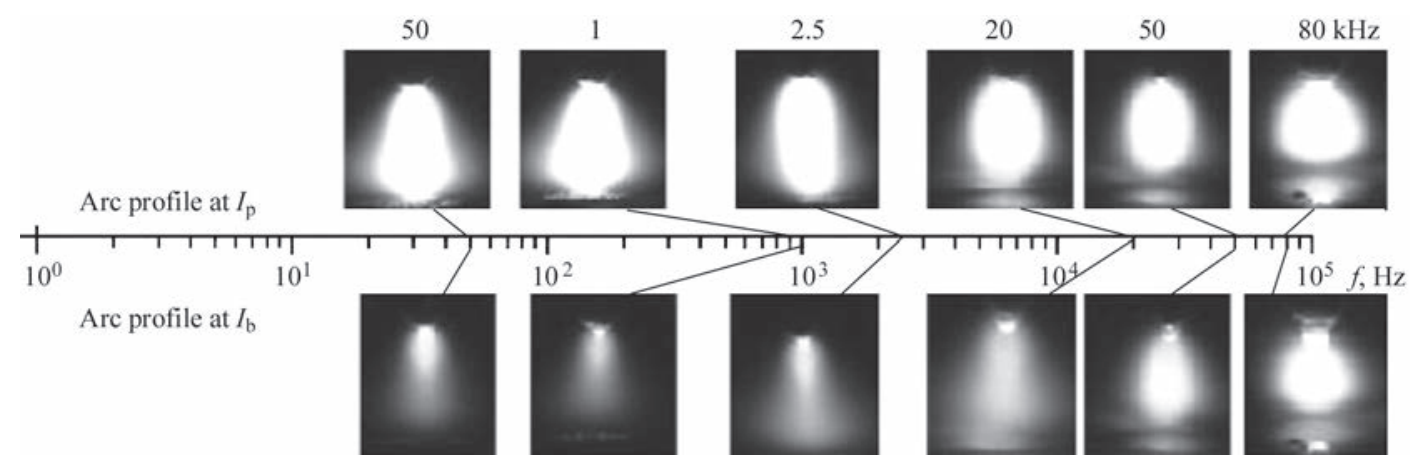

Figure 13. Appearance of the arc at $I=I_{\mathrm{p}}$ (top) and at $I=I_{\mathrm{b}}$ (below) for different values of current modulation frequency [15] 


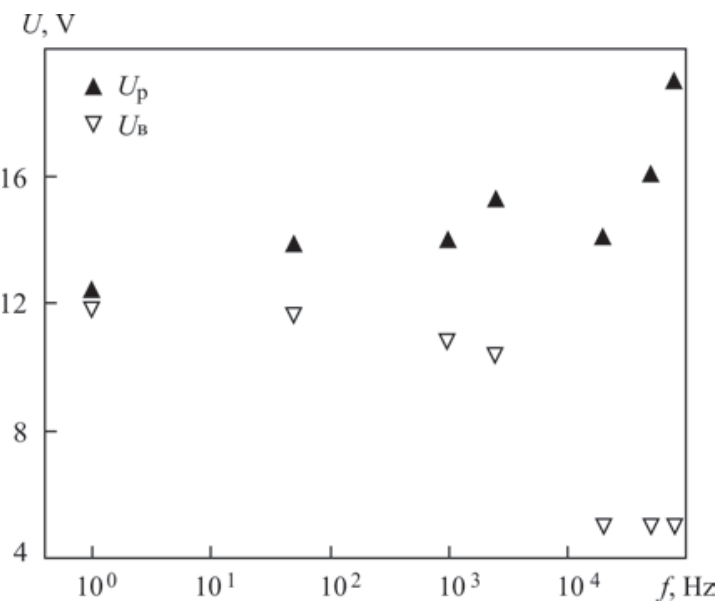

Figure 14. Dependencies of arc voltage in the pulse (1) and in the pause (2) on current modulation frequency [15]

value $U_{\mathrm{b}}=U\left(I_{\mathrm{b}}\right)$ on pulse modulation frequency are indicative of a significant increase of $U_{\mathrm{p}}$ and lowering of $U_{\mathrm{b}}$ with $f$ increase, that qualitatively corresponds to the experimental data, given in [8] (see Figure 4). This leads to the arc voltage oscillating with ever increasing amplitude at increase of pulse modulation frequency.

Figure 15 gives the dependence of electron concentration $N_{\mathrm{e}}$ in arc column plasma at peak values of current on its modulation frequency. In order to find $N_{\mathrm{e}}$ the authors [15] used experimental data on widening of the spectral lines of arc plasma radiation due to Stark effect [35]. According to the obtained data, electron concentration in the arc column first grows with increase of current modulation frequency (right up to frequencies of the order of $20 \mathrm{kHz}$ ), and then drops abruptly. A possible cause for such behaviour of $N_{\mathrm{e}}$ is the fact that measurements of electron concentration were conducted near the anode, where plasma glow is markedly weaker at frequencies above $20 \mathrm{kHz}$, due to the change of arc column shape (see Figure 13).

In (17) the effect of current modulation frequency on arc characteristics was studied experimentally at TIG welding of aluminium alloy 5A06 $3 \mathrm{~mm}$ thick

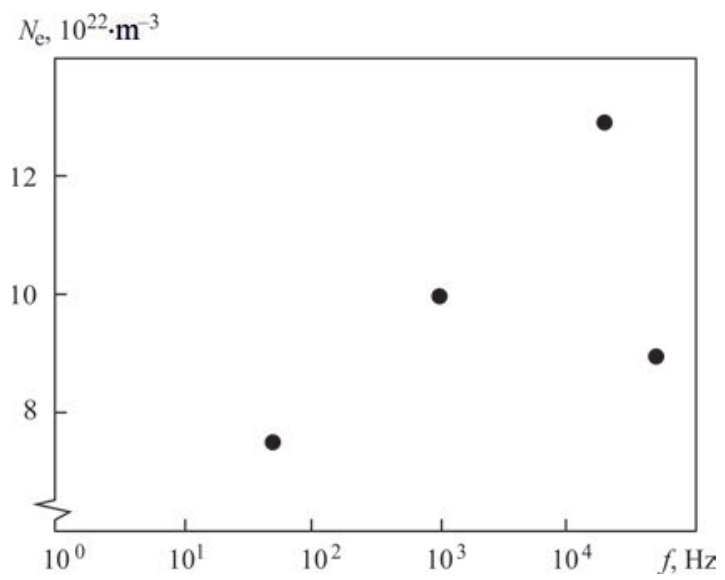

Figure 15. Dependence of electron concentration in the arc column at peak current values on its modulation frequency [15]

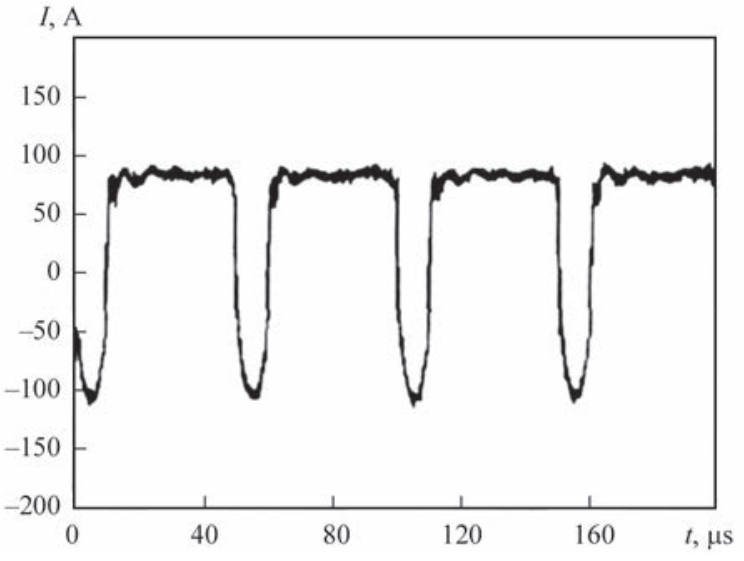

Figure 16. Dependence of arc current on time at TIG welding of an aluminium alloy in the mode of different polarity pulses [17] in the mode of current pulses of different polarity. An arc of $3 \mathrm{~mm}$ length with tungsten cathode of $2.4 \mathrm{~mm}$ diameter was used in the experiments. Arc current was modulated by rectangular pulses (rate of current change at pulse fronts was equal to $50-100 \mathrm{~A} / \mu \mathrm{s}$ ) with amplitude of straight polarity current $I_{\mathrm{p}}=80 \mathrm{~A}$ and of reverse polarity current $I_{N}=120 \mathrm{~A}$ at $8 / 2$ ratio of durations of pulses of straight $t_{\mathrm{p}}$ and reverse $t_{N}$ polarity. Modulation frequency $f$ was varied in the range of $0.1-20 \mathrm{kHz}$. Oscillogram of welding current versus time at $f=20 \mathrm{kHz}$ is given in Figure 16.

Respective oscillograms of arc current and voltage at $f=5 \mathrm{kHz}$ are shown in Figure 17.

Figure 18 gives the measured values of arc voltage (during straight and reverse polarity of current), depending on modulation frequency. These experiments were performed using the following mode of current modulation: $I_{\mathrm{p}}=100 \mathrm{~A} ; I_{N}=120 \mathrm{~A} ; t_{p} / t_{N}=8 / 2$. As follows from Figure 18, arc voltage rises rather quickly with increase of modulation frequency in the range of $f<1 \mathrm{kHz}$, and at further frequency increase the rate of its rise drops markedly. Here, the voltage of straight polarity arc is essentially lower by absolute value than

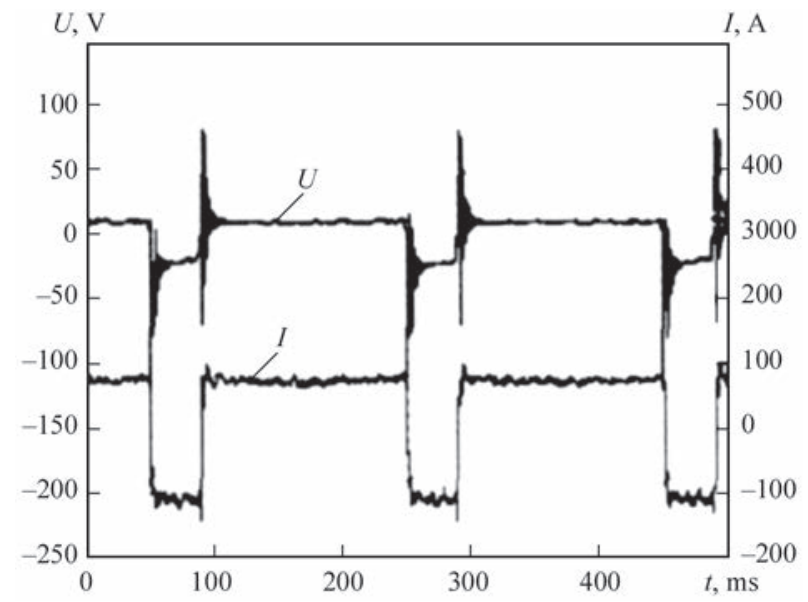

Figure 17. Oscillograms of voltage (upper curve) and current of the arc (lower curve) at TIG welding in the mode of different polarity pulses [17] 
the respective value for reverse polarity arc in the entire studied frequency range.

Analysis of the results of experimental work, devoted to study of the peculiarities of physical phenomena, proceeding in nonstationary electric arcs in TIG welding with pulse modulation of welding current, leads to the following conclusions:

1. Shape of the luminous area of nonstationary arc column at TIG welding with high-frequency ( $f>$ $>10 \mathrm{kHz}$ ) pulse modulation of current differs markedly from the respective shape for an arc of direct current, equal to average value of modulated current. This difference consists in a reduction of transverse dimensions (contraction) of the near-anode zone of the arc column, and, consequently, in increase of current density on the anode surface at increase of modulation frequency. As a result, the arc column shape changes from pear shape with diffuse binding to the anode at direct current to a spherical one with a dark space near the anode at HFP modulation of current. Here, for frequencies above $50 \mathrm{kHz}$ the arc column shape during the current pulse practically does not differ from its respective shape during the pause.

2. High-frequency pulse modulation of current of an arc with a refractory cathode leads to an essential increase of the pressure of arc plasma flow on the anode surface, compared to DC arc pressure. At TIG welding with HFP modulation of current this causes an additional bending of weld pool surface, which results in lowering of the heat source into the metal being welded and, accordingly, increase of the arc penetrability. As regards the influence of current modulation frequency on arc pressure, this value grows rapidly with increase of frequency in medium frequency range $(f<5 \mathrm{kHz})$, whereas at further increase of modulation frequency by the data of different authors the arc pressure behaves differently: it somewhat decreases [10], stabilizes [13] or continues growing [14].

3. As regards the dependence of arc voltage on current modulation frequency in TIG welding, the authors of the considered works also have no consensus. So, for instance, by the data of [21-23] the effective value of voltage rises practically in proportion to modulation frequency. Experimental data of work [8] are indicative of the fact that the average value of arc voltage during the current pause decreases noticeably, whereas the average value of voltage during the pulse increases only slightly with frequency increase. As a result, both the average and effective values of arc voltage decrease with increase of current modulation frequency. Finally, in [15] it is shown that the arc voltage during the current pause decreases at increase of

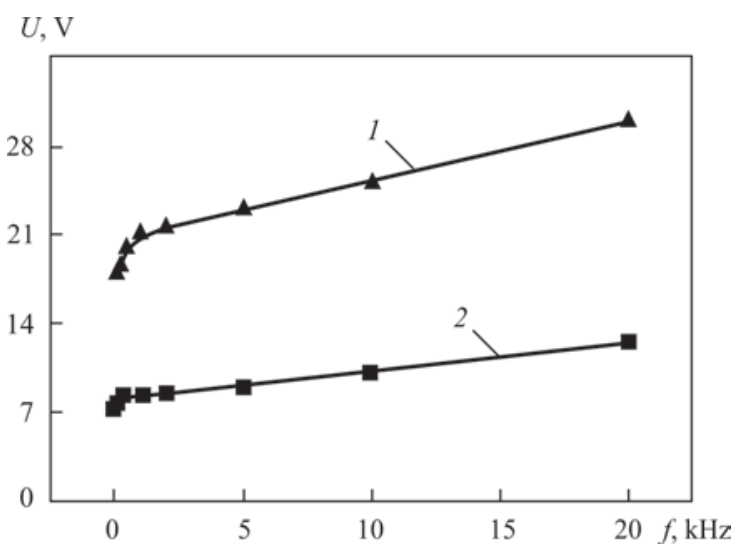

Figure 18. Dependence of absolute values of voltage of an arc of reverse (1) and straight (2) polarities at TIG welding in the mode of different polarity pulses on current modulation frequencies

modulation frequency practically at the same rate, as the voltage during the pulse increases.

1. Lienert, T.J., Babu, S.S., Siewert, T.A., Acoff, V.A. (2011) ASM Handbook. Vol. 6A. Welding fundamentals and processes. Ohio, USA, ASM International.

2. Roden, W.A. (1972) High-frequency, pulsed-current GTA welding. In: Proc. of National Aerospace Engineering and Manufacturing Meeting (2-5 Oct. 1972, San Diego, California, USA). Paper 720874, 1-8.

3. Leitner, R.E., McElhinney, G.H., Pruitt, E.L. (1973) An investigation of pulsed GTA welding variables. Welding J., Res. Suppl., 9, 405-410.

4. Yamaoto, T., Shimada, W., Gotoh, T. (1976) Characteristics of high frequency pulsed DC TIG welding process. Doc. IIW 212-628-76, 16-22.

5. Sokolov, O.I., Gladkov, E.A. (1977) Dynamic characteristics of free-burning and constricted welding arc of direct current with nonconsumable electrode. Svarochn. Proizvodstvo, 4, 3-5 [in Russian].

6. Omar, A.A., Lundin, C.D. (1979) Pulsed plasma — pulsed GTA arcs: A study of the process variables. Welding J., Res. Suppl., 4, 97-105.

7. Cook, G.E., Eassa, H.E.-D.E.H. (1985) The effect of high-frequency pulsing of a welding arc. IEEE Transact. on Industrial Application, 1A-21, 5, 1294-1299.

8. Kolasa, A., Matsunawa, A., Arata, Y. (1986) Dynamic characteristics of variable frequency pulsed TIG arc. Transact. of JWRI, 15(2), 173-177.

9. Saedi, H.R., Unkel, W. (1988) Arc and weld pool behavior for pulsed current GTAW. Welding J., Res. Suppl., 11, 247-255.

10. Zhao, J., Sun, D., Hu, S. (1992) Arc behavior of high frequency pulse TIG welding arc. Transact. China Weld Inst., 13(1), 59-66.

11. Kim, W.H., Na, S.J. (1998) Heat and fluid flow in pulsed current GTA weld pool. Int. J. of Heat and Mass Transfer, 41(21), 3213-3227.

12. Wu, C.S., Zheng, W., Wu, L. (1999) Modelling the transient behaviour of pulsed current tungsten-inert-gas weld pools. Modelling and Simul. Mater. Sci. Eng., 7(1), 15-23.

13. Dzelnitzki, D. (2000) Muendersbach TIG — direct-current welding with high-frequency pulses, an interesting process variant. EWM Hightec Welding GmbH. 200. WM008801. DOC; 08.00 .

14. Onuki, J., Anazawa, Y., Nihei, M. et al. (2002) Development of a new high-frequency, high-peak current power source 
for high constricted arc formation. Japan. J. Appl. Phys., 41 5821-5826.

15. Song, Y., Yan, S., Xiao, T. et al. (2010) A Study on the macro-micro physical properties in pulsed arc plasma. Transact. of JWRI, 39(2), 17-18.

16. Wu, C.S. (2008) Welding heat process and pool geometry. Beijing, China Machine Press, 102-104.

17. Cong, B., Qi, B., Zhou, X. (2009) TIG arc behavior of ultrafast-convert high-frequency variable polarity square wave. Transact. China Welding Institution, 30(6), 87-90.

18. Traidia, A., Roger, F., Guyot, E. (2010) Optimal parameters for pulsed gas tungsten arc welding in partially and fully penetrated weld pools. Int. J. of Thermal Sci., 49, 1197-1208.

19. Traidia, A., Roger, F. (2011) Numerical and experimental study of arc and weld pool behaviour for pulsed current GTA welding. Int. J. of Heat and Mass Transfer., 54, 2163-2179.

20. Karunakaran, N., Balasubramanian,V. (2011) Effect of pulsed current on temperature distribution weld bead profiles and characteristics of gas tungsten arc welded aluminum alloy joints. Transact. Nonferrous Met. Soc. China, 21, 278-286.

21. Yang, M., Qi, B., Cong, B. et al. (2012) The influence of pulse current parameters on arc behavior by austenite stainless steel. Transact. China Welding Institution, 33(10), 67-71.

22. Qi, B., Yang, M., Cong, B. et al. (2012) Study on fast-convert ultrasonic frequency pulse TIG welding arc characteristic. Mater. Sci. Forum., 704-705, 745-751.

23. Qi, B., Yang, M., Cong, B. et al. (2013) The effect of arc behavior on weld geometry by high-frequency pulse GTAW process with 0Cr18Ni9Ti stainless steel. Int. J. Adv. Manuf. Technol., 66, 1545-1553.

24. Yang, M., Qi, B., Cong, B. et al. (2013) Study on electromagnetic force in arc plasma with UHFP-GTAW of Ti-6Al-4V. IEEE Transact. on Plasma Sci., 41(9), 2561-2568.

25. Yang, Z., Qi, B., Cong, B. et al. (2013) Effect of pulse frequency on weld appearance behavior by TC4 titanium alloys. Transact. China Welding Institute, 34(12), 37-40.
26. Krivtsun, I.V., Krikent, E.V., Demchenko, V.F. (2013) Modelling of dynamic characteristics of a pulsed arc with refractory cathode. The Paton Welding J., 7, 13-23.

27. Yang, M., Yang, Z., Cong, B. et al. (2014) A study on the surface depression of the molten pool with pulsed welding. Welding J., Res. Suppl., 93(8), 312-319.

28. Yang, M., Yang, Z., Qi, B. (2015) The effect of pulsed frequency on the plasma jet force with ultra high frequency pulsed arc welding. IIW, 8, 875-882.

29. Sydorets, V.N., Krivtsun, I.V., Demchenko, V.F. et al. (2016) Calculation and experimental research of static and dynamic volt-ampere characteristics of argon arc with refractory cathode. The Paton Welding J., 2, 2-8.

30. Cunha ,T.V.d., Louise-Voigt ,A., Bohorquez, C.E.N. (2016) Analysis of mean and RMS current welding in the pulsed TIG welding process. J. Materials Proc. Technology, 231, 449-455.

31. Silva, D.C.C., Scotti, A. (2016) Using either Mean or RMS values to represent current in modeling of arc welding bead geometries. Ibid., 240, 382-387.

32. Demchenko, V.F., Boi, U., Krivtsun, I.V., Shuba, I.V. (2017) Effective values of electrodynamic characteristics of the process of nonconsumable electrode welding with pulse modulation of arc current. The Paton Welding J., 8, 2-11.

33. Nestor, O.H. (1962) Heat intensity and current density distributions at the anode of high current, inert gas arcs. J. Appl. Phys., 33(5), 1638-1648.

34. Demchenko, V.F., Boi, U., Krivtsun, I.V. et al. (2016) Procedure of density distribution restoration of electric current in arc anode spot with refractory cathode according to experimental data obtained by the method of split anode. In: Proc. of $8^{\text {th }}$ Int. Conf. on Mathematical Modeling and Information Technologies in Welding and Related Processes (19-23 September 2016, Odessa Ukraine), 21-28.

35. Grim, G. (1978) Spectral line broadening in plasma. Moscow, Mir [in Russian].

\section{NEW BOOK}

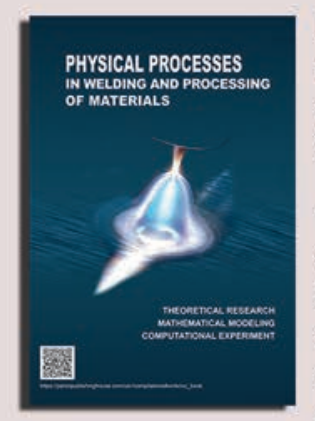

Physical processes in welding and material treatment. Theoretical investigation, mathematical modelling, numerical simulation collection of articles and reports: Collection of articles and reports edited by Prof. I.V. Krivtsun. Kyiv: International Association «Welding», 2018. - 642 p. ISBN 978-617-7015-74-0 (in Russian, English, Ukrainian).

The collection includes 86 papers and reports of research workers of the Department of physics of gas discharge and plasma technique at the E.O. Paton Electric Welding Institute of the NAS of Ukraine, being published in the period of 1978-2018. It generalizes the forty-year experience of research activity of the Department in the field of theoretical research and computer modelling of physical phenomena taking place in arc, plasma, laser and hybrid processes of welding, surfacing and coating deposition. It can be interesting and useful to the scientists, engineers and technologists dealing with the problems of arc, plasma, laser and hybrid welding and material treatment as well as post graduates and students studying theoretical basics of welding and related processes.

\section{Orders for the collection, please send to the Editorial Board.}

Collection in the open acces:

https://patonpublishinghouse.com/compilations/Krivtsun_Sbornik_2018_small.pdf 


\title{
MODELING THE TECHNOLOGY OF DEPOSITION OF A LAYER OF VARIABLE CHEMICAL COMPOSITION
}

\author{
V.P. IVANOV, L.K. LESHCHYNSKYI and S.V. SHCHERBAKOV \\ SHEI «Pryazovskyi State Technical University» of MES of Ukraine \\ 7 Universytetska Str., 87500, Mariupol, Ukraine. E-mail: ivanov_v_p@pstu.edu
}

\begin{abstract}
It is shown that the nature of the change of chemical composition of the weld (deposited metal) is determined by the law of control of volume feed rate of the alloying electrode, which was derived by mathematical modeling of the effect of surfacing technology on the process of weld pool alloying. It is found that the high gradient of charge of chemical composition along the weld length is ensured by a discrete change of the volume feed rate of the alloying electrode. At a rectangular waveform of the electrode feed pulse, the alloying element distribution in the weld metal is asymmetrical at the stage of increase and decrease of the concentration that is manifested to a greater extent with increase of weld pool volume. Experimentally confirmed calculation results are presented, which show that the trapezoidal shape of the pulse allows reducing the asymmetrical nature of change of the composition. It is found that the nature and gradient of alloying element distribution in the weld can be changed at pulsed feed of the alloying electrode by a sinusoidal law. Conditions of forming a deposited layer of variable composition and hardness along the length of the barrel of a roll of continuous billet mill were determined. 12 Ref., 1 Table, 7 Figures.
\end{abstract}

Keywords : mathematical modeling, weld pool, deposited metal, variable chemical composition, alloying electrode, feed pulse shape, forming roll, variable hardness along the barrel length

Application of a technology which allows changing the metal composition during welding (surfacing) [1, 2] is largely determined by the ability to provide the specified changes of alloying element content in the transition areas, as well as stabilization of the composition between these areas [3]. At the same time, it is necessary to take into account the fact that deviation of weld metal composition from the required one can be caused by changes of mode parameters. This is related to deviations in product geometry, errors in equipment setting up, as well as possible voltage fluctuations. Moreover, change of the mode parameters can be related to a change of the processed surface curvature, which affects the conditions of weld pool formation [4]. Here, it should be noted that solution of the problem of geometrical adaptation of welding speed vector (deposition of working layers) of a complex configuration, is provided by process control system, automated and robotic equipment. Application of programming by off-line and on-line methods, and well as contact and contactless sensors, and arc tracking devices, allows controlling complex movements of the welding torch in space. In contrast, the process of technological adaptation is difficult to automate. Moreover, deviations of mode parameters, even in case of their successful adaptation, will inevitably lead to changes in metal composition under changed environmental conditions.

At the same time, such changes can be performed purposefully, so as to ensure the correspondence of the distribution of metal properties to the nature and intensity of loading. In work [5] a calculated dependence was derived by processing the experimental data, in order to perform an approximate assessment of the nature of the change of alloying element concentration in the metal at linear increase of its content in the electrode from $X$ up to $Y$. Proceeding from processing results, the law of concentration change in the weld, close to the exponential one, is characterized by linear dependence of the angle of inclination of the tangent to the exponent $(Y-X) / D=\operatorname{tg} \alpha$, where $D$ is the characteristic length of the area of transition from $X$ to $Y, \alpha$ is the angle which determines the gradient of the rate of alloying electrode feeding into the pool. Much more complicated is the problem of development of an adequate mathematical model that allows prediction of the effect of the change of alloying conditions during surfacing on the weld chemical composition, in particular at a high speed of these changes. In [6] volume rate of alloying element feeding into the pool and weld pool dimensions (volume) are considered as input parameters for modeling the alloying process at deposition of metal of variable chemical composition. However, application of these models for development of variants of the technology of deposition of a working layer of a variable composition and properties requires studying the effect of volume rate of alloying element feeding into the weld pool on their content in the weld. The objective of the work was to study in a mathematical model the possibilities of controlling the process of alloying welds of a variable chemical composition and properties. 


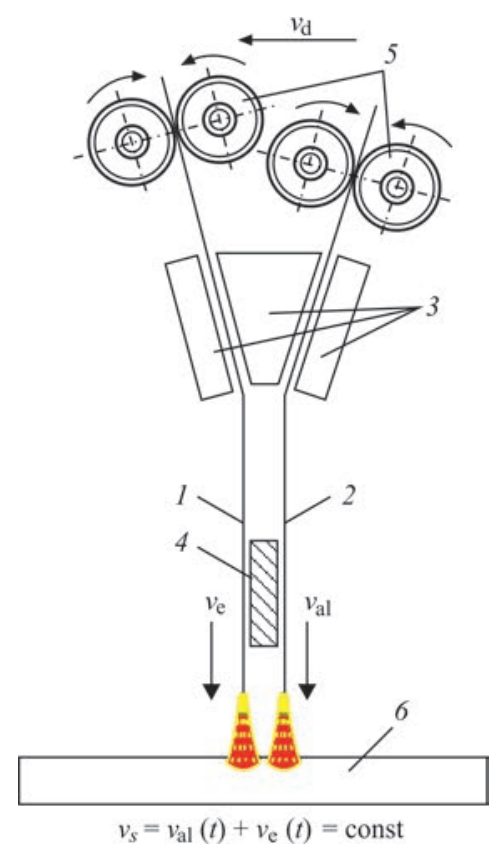

Figure 1. Scheme of deposition by two strip electrodes: 1 - low-alloyed electrode, 2 - alloyed electrode; 3 - guides; 4 - current conduit; 5 - feed rollers; 6 - base metal; $v_{\mathrm{d}}$ - deposition rate

Modeling conditions envisage feeding into the pool a constant volume of two electrodes differing by their chemical composition, while the total mass feed rate remains constant at the change of feed rate of each of them (Figure 1). Change of concentration $C(t)$ in the transition area depends on volume rate of alloying element feed, and degree of its absorption from the electrode and flux. In addition, weld dilution by base metal (previous layer) is taken into account, as well as buffering effect of pool volume $(V)$ that limits the possibility of high alloying gradients. For a quasistationary state of the pool, when its volume can be taken constant, the following dependence for calculation of the change of composition $C(t)$ in the transition area was obtained from the equation of alloying element material balance in [6]:

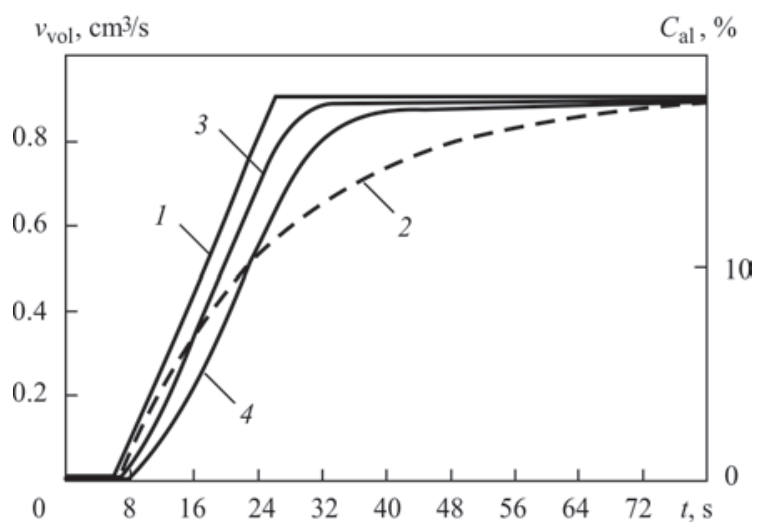

Figure 2. Dependence of the nature of weld composition change $C(t)$ on the law of the change of volume rate of alloying electrode feed $v_{\mathrm{al}}(t): 1-$ law of the change of $v_{\mathrm{al}}(t) ; 2-C(t)$ calculation by the data of [5]; 3 - calculation by dependence (1) for $V=2 \mathrm{~cm}^{3}$; 4 - same, for $V=5 \mathrm{~cm}^{3}$

$$
\begin{gathered}
C(t)=e^{-\frac{v_{\mathrm{d}}}{V} t} \times \\
\times\left\{\begin{array}{l}
\int_{0}^{t}\left[v_{\mathrm{al}}(t) C_{\mathrm{al}} \eta_{\mathrm{e}}+v_{s} k_{\mathrm{f}} C_{\mathrm{f}} \eta_{\mathrm{f}}+C_{\mathrm{bm}}(t) v_{\mathrm{bm}} \eta_{\mathrm{bm}}\right] \times\{ \\
0 \frac{1}{V} e^{\frac{v_{\mathrm{d}}}{V} t} d t+C_{0}
\end{array}\right\},
\end{gathered}
$$

where $C_{\mathrm{al}}, C_{\mathrm{f}}, C_{\mathrm{bm}}(t)$ is the volume concentration of the alloying element in the electrode, flux and its distribution in the base metal (previous layer); $\eta_{\mathrm{e}}, \eta_{\mathrm{f}}, \eta_{\mathrm{bm}}$ are the coefficients of element transition from the electrode, flux, base metal; $k_{\mathrm{fl}}$ is the relative mass of the flux; $v_{\mathrm{d}}(t)=v_{\mathrm{s}}+V_{\mathrm{bm}}(t)$ is the volume deposition rate; $v_{\mathrm{bm}}(t)$ is the volume rate of base metal penetration; $\gamma(t)$ is the fraction of base metal participation in the weld; $v_{\mathrm{s}}=v_{\mathrm{al}}(t)+v_{\mathrm{e}}(t)=$ const is the total volume rate of electrode feed; $v_{\mathrm{al}}(t), v_{\mathrm{e}}(t)$ is the volume feed rate of electrode that contains the alloying element, and does not contain it, respectively; $C_{0}$ is the integration constant.

By the given law $C(t)$, taking into account the known parameters of the deposition process, the rate of alloying electrode feed, $v_{\mathrm{al}}(t)$ is determined using the dependence derived in [6]:

$$
\begin{gathered}
v_{\mathrm{al}}(t)=\frac{1}{C_{\mathrm{al}} \eta_{\mathrm{e}}} \times \\
\times\left\{V \frac{d C(t)}{d t}-\left[v_{s} k_{\mathrm{f}} C_{\mathrm{f}} \eta_{\mathrm{f}}+C_{\mathrm{bm}}(t) v_{\mathrm{bm}} \eta_{\mathrm{bm}}-v_{\mathrm{d}} C(t)\right]\right\} .
\end{gathered}
$$

Dependencies (1), (2) allow more adequate prediction of the nature of concentration change both at the increase and at the decrease stage, depending on the change of alloying electrode feed rate. With increase of its feed rate by a linear law (Figure 2, curve 1) the nature of variation of the composition, derived by calculation by dependence (1) depends on weld pool volume (curves 3,4 ). Here, for weld pool volume (up to 8-10 $\mathrm{cm}^{3}$ ), changes of $C(t)$, depending on (1), differ considerably from those given in [5]. However, for the pool specified in this work of up to $40-50 \mathrm{~cm}^{3}$ volume that forms during the process of electroslag remelting, the results of both the calculations coincide.

Results of investigations using the model considered in this paper at different variants of the laws of the volume feed rate change of alloying electrode and their comparison with the results of the experiment, lead to the conclusion of the model adequacy and its applicability for prediction of weld chemical composition. This enables real-time control of the alloying process, as the signal on the winding of electrode feed motor is used as the input parameter. Modeling also showed that the overalloying effect can be used in order to increase the alloying level or shorten the time of transition $[6,7]$. For this purpose, the law of the feed rate change during the transition envisages an area in which the maximum 

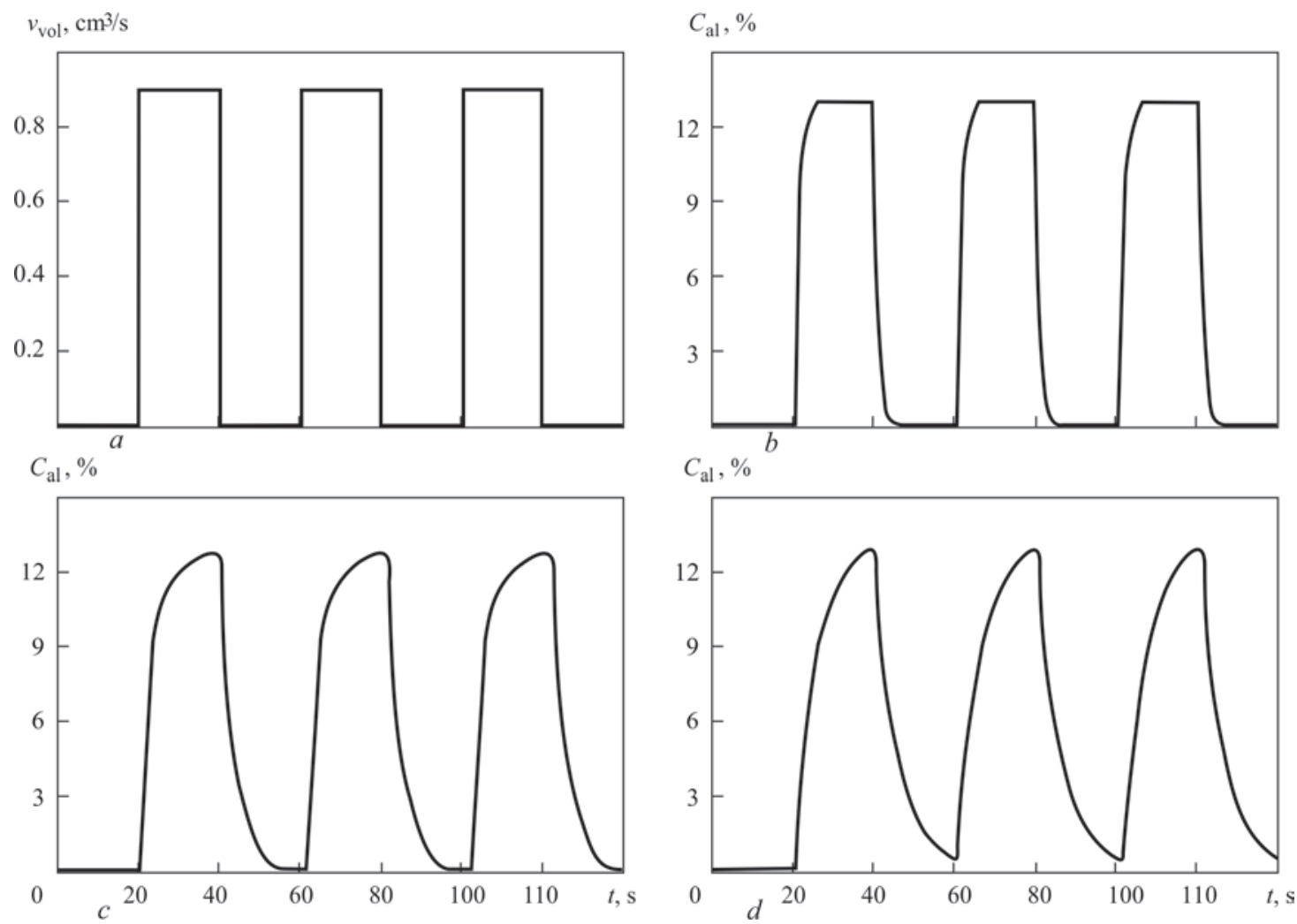

Figure 3. Nature of the change of weld composition $C(t)$ at rectangular shape of alloying electrode feed pulses: $a-$ law of the change of $v_{\text {al }}(t) ; b-C(t)$ calculation for $V=1 ; c-$ for $V=3$; $d$ - same, for $V=5 \mathrm{~cm}^{3}$

rate is kept constant, or electrodes are used which have a higher content of the alloying element than is required for obtaining the necessary concentration in the weld. However, the need to apply (impossibility to replace) the
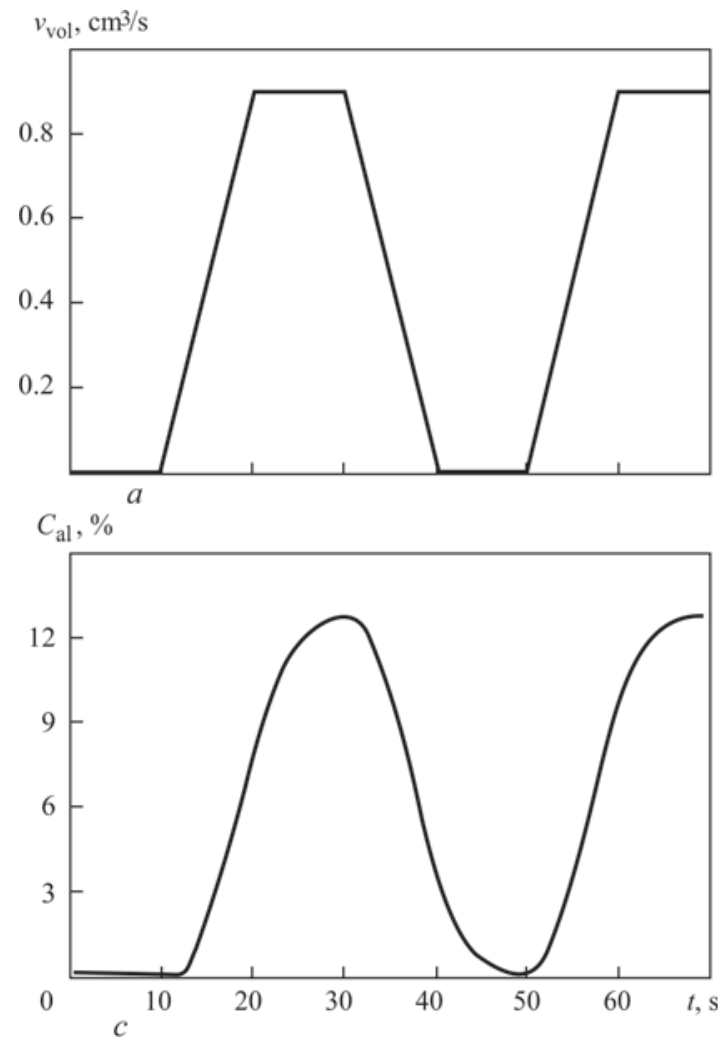

high-alloyed electrode beyond the overalloying area is accompanied by a significant increase of the expenses, and application of this variant of the technology is economically not feasible under production conditions.
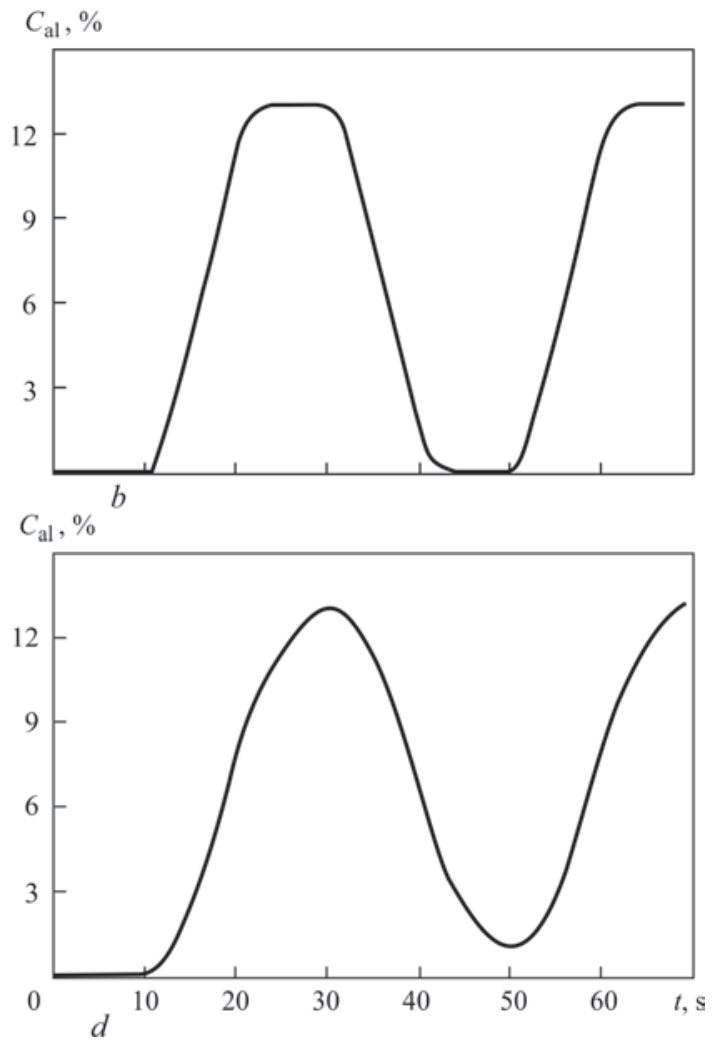

Figure 4. Change of weld composition $C(t)$ at trapezoidal shape of alloying electrode feed pulses: $a-$ law of $v_{\mathrm{al}}(t)$ change; $b-C(t)$ calculation for $V=1 ; c-$ for $V=3$; $d$ - same for $V=5 \mathrm{~cm}^{3}$ 


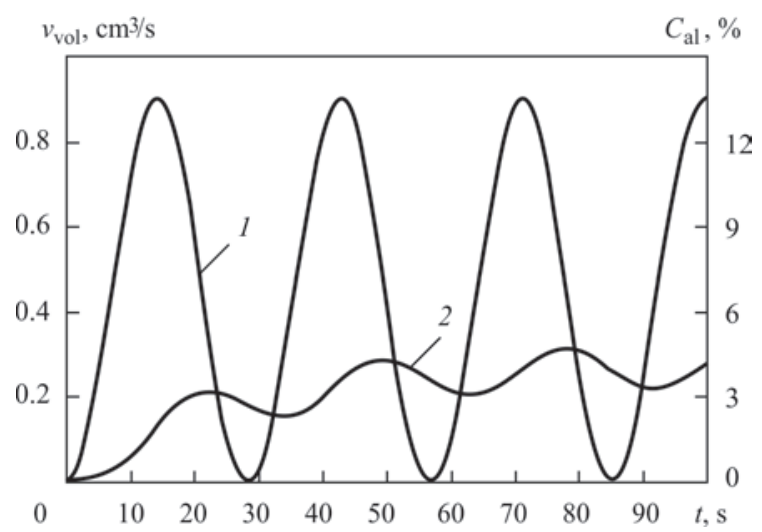

Figure 5. Effect of sinusoidal shape of alloying electrode feed pulses on $C(t)$ change: $1-$ law of $v_{2 l}(t)$ change; $2-C(t)$ calculation $\left(V=3 \mathrm{~cm}^{3}\right)$

Proceeding from the calculated data, a discrete change of alloying electrode feed rate $v_{\mathrm{al}}(t)$ provides a close to jumplike change of the composition $C(t)$ (Figure 3). In practice such a discrete change of the alloying element content in most of the cases is realized using a folded (along the length) electrode. As one can see from Figure 3, in case of a rectangular shape of the feed rate pulse, the high alloying gradient at the initial stage of the rising branch decreases at its final stage right up to smooth change of $C(t)$. The nature of such changes in the descending branch is similar. Modeling revealed that irrespective of weld pool volume and time parameters, at a symmetrical shape of the pulse, the alloying element distribution at the rising stage and concentration lowering are asymmetrical.

Such an asymmetry is manifested to a smaller extent for the trapezoidal shape of the feed pulse, particularly with the reduction of the weld pool volume (Figure 4). At the same time, according to experimental data [6, 7], these areas on the curve of alloying element distribution in the deposited metal differ to a smaller degree. Moreover, changing the slope of the function of alloying electrode feed rate to this or that side, it is possible to ensure the symmetry of the ascending and descending branches of alloying element concentration in the weld [8]. Considering the effect of gradient sign on the shape of the curve of concentration change, characteristic for central and not axial symmetry, the symmetry of the ascending and descending branches of concentration is provided by breaking up the curve of concentration change into sections with different law of alloying electrode feed rate.

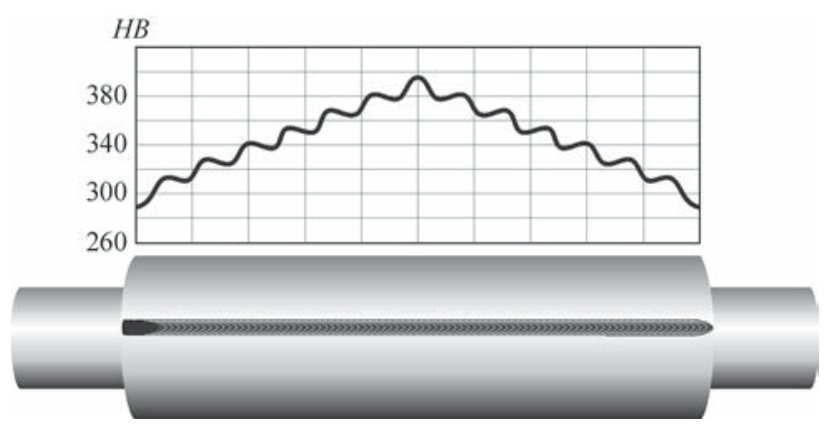

Figure 7. Hardness distribution along the forming roll barrel at formation of the deposited layer from longitudinal welds

As shown by modeling results, in the presence of two sections at the stage of electrode feed rate increase and decrease, the symmetry of the change of weld alloying is ensured, in order to solve a whole range of tasks of investigation and development of technology for deposition of metal having a variable chemical composition.

Change of parameters of the sinusoidal law of volume feed rate of the electrode allows deriving a similar law of alloying element distribution along the weld length (Figure 5). Here, the change of the level of weld metal alloying in the direction of the vector of deposition rate enables obtaining a layer of variable composition and hardness.

Known are the methods and devices that allow realization of the sinusoidal law of the change of electrode wire and strip feed rate $[9,10]$. Irrespective of the method of generation of oscillations, the range of parameters used in such devices, allows controlling the characteristics of electrode metal transfer, but does not allow controlling the change of weld chemical composition, because of the inertia of the process of weld pool formation. Deposition of weld areas, differing by their chemical composition, depends on the ability to ensure a periodic change of the rate of feeding electrodes with different degrees of alloying. Here, the duration and relative pulse duration of feed pulses should greatly exceed the time of weld pool existence. In addition, it is necessary to provide the possibility of variation of these parameters in a broad range.

For realization of the task of program control of electrode feed rate, a circuit of controlling the DC commutator motors of SL type was developed on the base of a programmable microcontroller ATmega328P (Figure 6). Controller programming and system operation

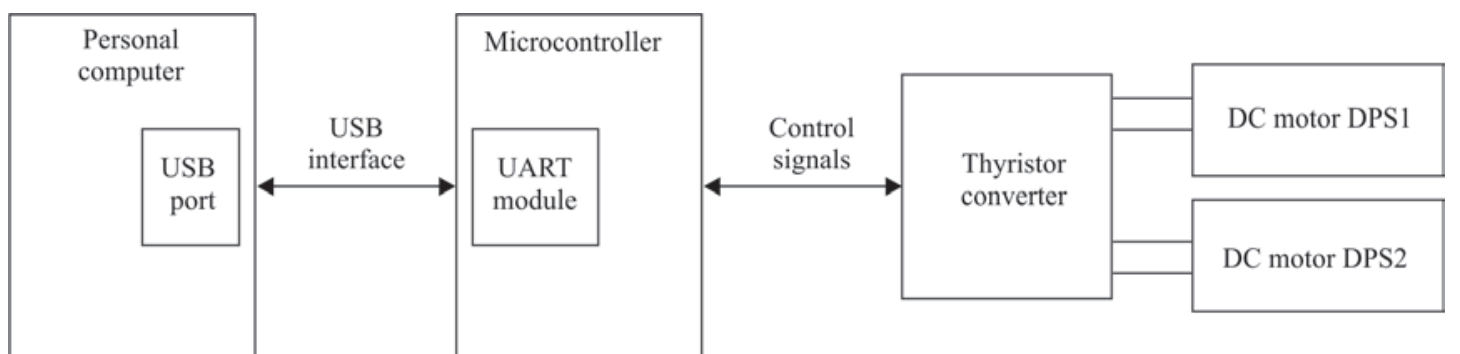

Figure 6. Structural scheme of the control system of electrode feed motors 
Composition and hardness of the deposited layer along the roll length

\begin{tabular}{|c|c|c|c|}
\hline \multirow[b]{2}{*}{$\begin{array}{c}\text { Chromium content and } \\
\text { hardness }\end{array}$} & \multicolumn{3}{|c|}{ Area location on roll barrel } \\
\hline & $\begin{array}{l}\text { on barrel } \\
\text { edge }\end{array}$ & $\begin{array}{l}\text { at the dis- } \\
\text { tance of } 1 / 4 \\
\text { of the length } \\
\text { from the edge }\end{array}$ & $\begin{array}{l}\text { in the middle } \\
\text { of the barrel }\end{array}$ \\
\hline Chromium content, wt.\% & 1.12 & 6.2 & 12.6 \\
\hline $\begin{array}{c}\text { Hardness, } H B^{*} \text { at } \\
T=430^{\circ} \mathrm{C}\end{array}$ & $\frac{340}{290}$ & $\frac{410}{340}$ & $\frac{450}{390}$ \\
\hline
\end{tabular}

control are performed with application of a personal computer connected via a built-in interface converter USB-UART (Universal Asynchronous Receiver-Transmitter). A standard thyristor converter was used to form pulses of current for control of drives for feeding electrodes with different content of alloying elements. AC supply voltage of the circuit is rectified and modulated by PWM signals, coming to the thyristor control pin from the controller discrete output. This allows ensuring control of electrode feed rate, in keeping with the dependencies given in the graphs (Figures 3-5). Here, the duration of individual sections is comparable with the time of weld pool existence.

Proceeding from results of modeling the processes of deposition of a layer of variable chemical composition, a technology was developed for reconditioning of working rolls of crimp stand of a continuous billet rolling mill (roll material is $50 \mathrm{KhN}$ steel, barrel diameter is $600 \mathrm{~mm}$, barrel length is $1000 \mathrm{~mm}$ ). It is known that cracking under the impact of thermal fatigue and impact loading, associated with formation of circumferential cracks that go deeply into the roll body, becomes much more pronounced when making the surface layer from circumferential welds [11]. Therefore, the deposited layer was formed from welds, oriented along the forming barrel [12] that allowed increasing the resistance to formation of circumferential cracks in the surface layer of hot roll under the impact of thermal cycles. At application of electrode strip of $40 \times 0.65 \mathrm{~mm}$ cross-section (alloyed electrode of Sv-2Kh13, and low-alloyed electrode of 30KhGSA composition) a weld of variable composition, deposited along the roll forming barrel, is characterized by a change of chromium content from 1.12 to $12.6 \%$. Here, the deposited layer hardness after tempering rises from HB 290 to HB 390, respectively (Table).

The sinusoidal shape of alloying electrode feed pulses allows achieving the shown in Figure 7 nature of hardness variation - from the minimum value on the edges up to maximum value in the barrel middle part, that greatly reduces the nonuniformity of wear of working rolls of the crimp stand in continuous billet rolling mill.

\section{Conclusions}

1. Mathematical modeling of the technology for deposition of welds of variable chemical composition allows prediction of the change of alloying element content in the area of transition, depending on alloying electrode feed rate and weld pool volume. The model adequacy is confirmed by experimental results.

2. Modeling revealed that weld composition change close to the discrete one, can be achieved in the case of application of the law of alloying electrode feeding in the form of pulses of a trapezoidal shape. The asymmetry of the thus obtained areas of increase and decrease of alloying element concentration in the weld is manifested to a smaller degree with reduction of weld pool volume.

3. Modeling was the base for development of the technology of strengthening the forming rolls with formation of the deposited layer from the welds located along the barrel, and having the composition and hardness variable along their length, by changing the volume rate of alloying electrode feeding in the form of pulses of a sinusoidal shape.

1. Peremitko, V.V., Panfilov, A.I., (2017) Arc surfacing of layers of metal of varying composition and hardness. The Paton Welding J., 7, 38-42.

2. Shebanits, E.N., Omelyanenko, N.I., Kurakin, Yu.N. et al. (2013) Improving the fracture toughness and wear resistance of hard-faced hot-rolling-mill rolls. Metallurgist, 56(7-8), 613-617.

3. Leshchinsky, L.K., Matvienko, V.M., Mazur, V.O. Method of manufacture of roll of billet continuous casting machine. Ukraine Pat. 119373 [in Ukrainian].

4. Ryabtsev, I.A., Senchenkov, I.K. (2013) Theory and practice of surfacing works. Kiev, Ekotekhnologiya [in Russian].

5. Bennett, A.P. (1972) Prediction and control of composition profiles in graded transition joints. Metals and Materials, 3/4, 146-149.

6. Leshchinsky, L.K., Litvin, N.N., Ivanov, S.G. et al. (1983) Procedure for calculation of alloying process of varying composition welds. Avtomatich. Svarka, 11, 27-29 [in Russian].

7. Gulakov, S.V., Nosovsky, B.I. (2005) Surfacing of working layer with regulated distribution of properties. Mariupol, Novyj Mir [in Russian].

8. Leshchynsky, L.K., Ivanov, V.P. Method of surfacing of varying composition layer. Ukraine Pat. 124035 [in Ukrainian].

9. Lebedev, V.A. (2007) Dependence between the rates of pulsed wire feed and wire melting in welding with short-circuiting. The Paton Welding J., 4, 17-20.

10. Ivanov, V., Lavrova, E. (2014) Improving the efficiency of strip cladding by the control of electrode metal transfer. Applied Mechanics and Materials. Transact. Tech. Publications, 682. Switzerland, 266-269.

11. Shchetinin, S.V., Shchetinina, V.I., Stepnov, K.K. et al. (2010) Improvement of crack resistance of shrouded backup rolls. Breakage protection of metallurgical machines. Zb. Nauk. Prats PDTU, Mariupol, 12, 226-230 [in Ukrainian].

12. Leshchinsky, L.K., Stepnov, K.K., Matvienko, V.M. Method of manufacture of forming rolls. Ukraine Pat. 92559 [in Ukrainian]. 


\title{
PECULARITIES OF ELECTRON BEAM WELDING OF HOT-ROLLED ALUMINUM-LITHIUM ALLOYS*
}

\author{
D. DRIMAL, M. KASENCAK, F. KOLENIC, A. KRAMARCIK and L. KOVAC \\ PRVA ZVARACSKA a. s., Kopcianska 14, 85101, \\ Bratislava Slovak Republic. E-mail: drimal.daniel@pzvar.sk
}

\begin{abstract}
This paper presents results of experiments on electron beam welding of Al-Li alloys. The wrought AW 2099 alloy was used as experimental material. AW 2099 alloy in T83 condition of thickness $25 \mathrm{~mm}$ was used. The microstructure of experimental alloy was degraded by annealing and deformation before welding. The original thickness $25 \mathrm{~mm}$ was reduced to $3 \mathrm{~mm}$ by hot rolling without any subsequent additional heat treatment. The full penetration butt-welds and T-joint configurations were made by electron beam. These welded joints underwent investigation of basic mechanical testing (tensile strength, bending, hardness) and metallographic inspection for internal defects and microstructure identification. Welded joints didn't have significant internal defects, but tensile strength and plastic properties were deteriorated significantly by welding process and previous deformation. The heat treatment was performed for improvement of mechanical and plastic properties. The heat treatment mode consists of solution treatment (annealing) followed by quenching and subsequent aging cycles. 5 Ref., 5 Tables, 8 Figures.
\end{abstract}

Ke yw ords : aluminum-lithium alloys, electron beam welding, macrostructure of weld, tensile strength test

Aluminium alloys alloyed by lithium can be included in the category of high strength light alloys. These alloys are mostly used in aviation and space industry. Lithium as alloying element results into reduction of specific weight and increase of modulus of elasticity, while lithium effect is much stronger compared to others alloying elements. Addition of Li promotes formation of strong strengthening phases and increase of fatigue crack resistance. Recent investigations of Al-Li alloys resulted in formation of new generation of alloys. These alloys are characterized by not only weight reduction, but also improvement of properties such as corrosion resistance, good strength and ductility, and workability such as machining, forging, bending, and welding [1-4].

To get best results of $\mathrm{Al}-\mathrm{Li}$ alloys in terms of mechanical properties it is necessary to perform T8 treatment. The treatment consists of solution treatment, quenching, cold deformation and artificial treatment, which is a key factor to achieve desired structure and uniform precipitation. Cold deformation is necessary for generation of dislocation network that works as nuclei for strengthening phases formation with finer microstructure and development of conditions for precipitation in grain boundary regions. Phases on grain boundaries are unfavourable in terms of material toughness.
The Al-Li alloys are grouped by weldability [5]. Degradation of structural and mechanical properties of weld metal and HAZ should be taken into account due to welding heat cycle. The welding methods with limited heat input are favourable for joining $\mathrm{Al}-\mathrm{Li}$ alloys. The most common defects in fusion welds and HAZ are porosity, hot cracks and microstructure degradation. Porosity is caused mainly by lithium reactivity. Lithium is present in structure not only in form of phases, but also in form of different compounds (such as carbonate, hydroxide or hydride). These compounds decay due to effect of heat and form various gases that can be entrapped in the weld metal mostly in the weld root area. Porosity can be reduced by mechanical or chemical treatment of surface or weld metal stirring. Hot cracking susceptibility is caused by formation of low melting eutectics. Formation of hot cracks can be suppressed by using pulse current, reduction of heat input, reduction of stresses in welded joint area or by combination of these methods. Mechanical properties of Al-Li alloys welded joints can be reduced to $50 \%$ of mechanical properties of base metal. Mechanical properties degradation in weld metal and HAZ is caused by increase of phases that cannot used for strengthening. Using welding methods allowing limitation of heat input is preferable for $\mathrm{Al}-\mathrm{Li}$ alloy joining. The compressor impellers working in less aggressive environments can be the next

"Based on materials presented at IX International Conference «Beam Technologies in Welding and Materials Processing», September 9-13, 2019, Odessa, Ukraine. 
Table 1. Nominal chemical composition of AW 2099 alloy

\begin{tabular}{|c|c|c|c|}
\hline Element & Content, wt.\% & Element & Content, wt.\% \\
\hline $\mathrm{Cu}$ & $2.4-3.0$ & $\mathrm{Ti}$ & 0.10 max \\
\hline $\mathrm{Li}$ & $1.6-2.0$ & $\mathrm{Fe}$ & 0.07 max \\
\hline $\mathrm{Zn}$ & $0.4-1.0$ & $\mathrm{Si}$ & $0.05 \max$ \\
\hline $\mathrm{Mg}$ & $0.10-0.50$ & $\mathrm{Be}$ & 0.0001 max \\
\hline $\mathrm{Mn}$ & $0.10-0.50$ & Others, Each & $0.05 \max$ \\
\hline $\mathrm{Zr}$ & $0.05-0.12$ & Others, Total & $0.15 \max$ \\
\hline
\end{tabular}

application field of Al-Li alloys. Low specific weight and favourable mechanical properties allow reducing moment of inertia and therefore energy consumption of these machines. Impeller wheels of compressors are parts with complex shape and their production without joining technologies is in some cases extremely expensive and sometimes impossible. The impeller consists of two hub discs among which are slots. There are number of different designs and manufacturing approaches with some advantages and disadvantages. And the production issues are caused primary by difficult-to-reach welded joint. Two basic types of impeller design are welded by electron beam in PRVÁ ZVÁRAČSKÁ a. s. Company. The first design is based on two hub discs fabricated by milling and each disc includes half of the blade. Discs are joined by butt weld in the middle of the blade. Another design is chosen for impellers with narrow channel (less than $4 \mathrm{~mm}$ ). In the case of narrow channel impeller, one hub disc is milled with full blade and impeller is covered by second disc. The second hub disc is joined to the blades by T-weld.

Methods and materials. The aim of the work was to investigate possibilities of production of propeller wheels made of $\mathrm{Al}-\mathrm{Li}$ alloys by electron beam welding and evaluate the achieved results of mechanical properties.

The technology development and experiments were carried out on an experimental classification - PZ EZ4. The universal electron beam complex for welding and surface treatment of materials

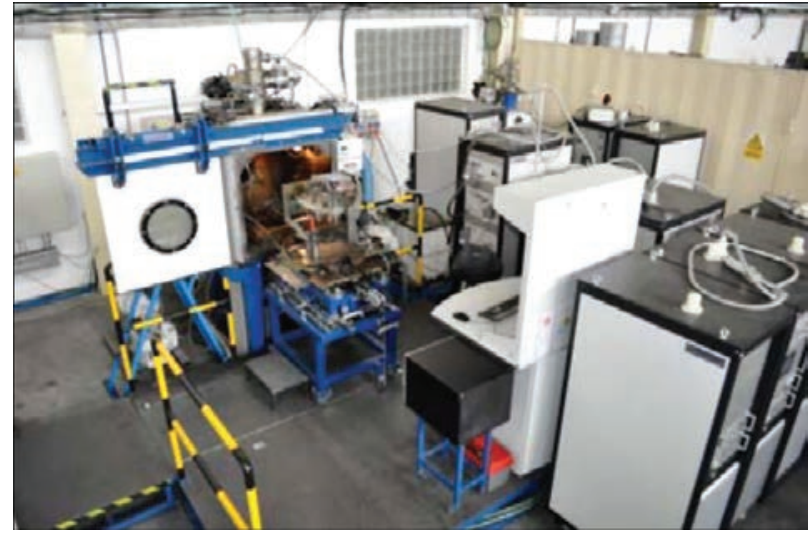

Figure 1. Workplace of electron-beam complex PZ EZ 4

is equipped with 3-axis positioning system continuously controlled and synchronized with technology. For powering the electron gun, the PZ EB 2.5 - 15 is used to generate an electron beam with accelerating voltage up to $60 \mathrm{kV}$ and output up to $15 \mathrm{~kW}$. The arbitrary waveform generator ETC M631 is integrated into the control system, which is used to control the electron beam deflection system.

AW 2099 alloy. Wrought AW 2099 alloy was used as experimental material (Table 1). AW2099 alloy was used in T83 condition with thickness $25 \mathrm{~mm}$. The microstructure of experimental alloy was degraded by annealing and deformation before welding. The original thickness $25 \mathrm{~mm}$ was reduced to $3 \mathrm{~mm}$ by hot rolling without any subsequent additional heat treatment. The full penetration butt-welds and T-joint configurations were made by electron beam.

These welded joints underwent visual inspection, basic mechanical tests (tensile strength, bending, hardness) and metallographic examination for internal defects and microstructure identification.

Heat treatment. The part of welded samples was subjected to heat treatment. Heat treatment consists of solution treatment at $T=540{ }^{\circ} \mathrm{C}$ for 90 minutes followed by quenching into water. Next step was artificial ageing at temperature $T=160{ }^{\circ} \mathrm{C}$ for 18 hours.
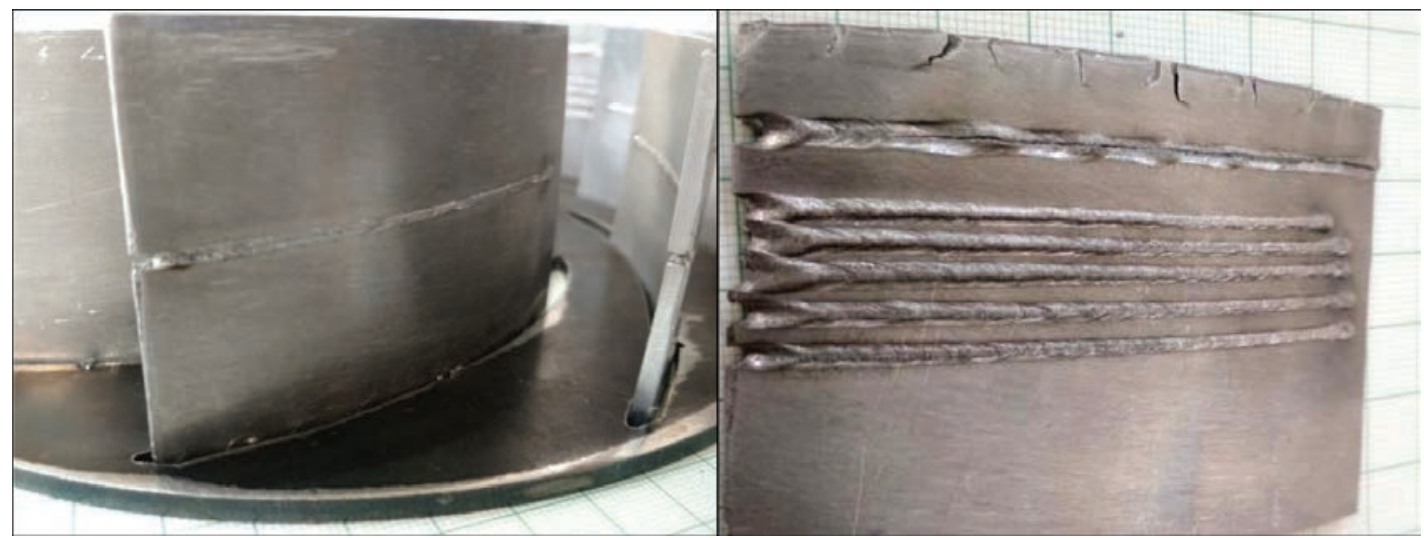

Figure 2. Model impeller with test blade 
Table 2. Final welding parameters for joining impeller by EBW through blade

\begin{tabular}{|c|c|}
\hline Accelerating voltage $U, \mathrm{kV}$ & 55 \\
\hline Initial welding current $I_{\mathrm{w}}, \mathrm{mA}$ & 40 \\
\hline Welding speed $v_{\mathrm{w}}, \mathrm{mm} \cdot \mathrm{s}^{-1}$ & 25 \\
\hline Initial focal current $I_{\mathrm{f}}, \mathrm{mA}$ & 800 \\
\hline Final defocus $I_{\mathrm{f}}, \mathrm{mA}$ & +10 \\
\hline Dynamic deflection & $\begin{array}{c}\sin 1500 \mathrm{~V} / \cos 1500 \mathrm{~V} ; \\
(0.5 \mathrm{~mm}) f=1000 \mathrm{~Hz}\end{array}$ \\
\hline
\end{tabular}

The temperatures and times for heat treatment have been chosen on the basis of available information from literature.

The research of joining technology was carried for both previously mentioned designs (butt weld BW - blade joining and T-weld disc and blade joining. The welding procedures were proposed based on experiences with welding of titanium and steel impellers for both approaches. Because of preliminary tests and cost reduction the welding experiments were performed only with model impellers. Only blades were fabricated from AW 2099 alloy. The model discs were fabricated from mild steel and contained the slot in which the blades were inserted. The straight blades' design was used for samples with regard to further investigation of mechanical properties.

Butt weld - blade welding. Welding process parameters were adjusted based on trials with model impellers (Figure 2). The welding process was developed for constant accelerating voltage $U=55 \mathrm{kV}$. The welding current speed and focal position were set to
Table 3. Final welding parameters for joining impeller by T-weld through disc

\begin{tabular}{|c|c|}
\hline Accelerating voltage $U, \mathrm{kV}$ & 55 \\
\hline Initial welding current $I_{\mathrm{w}}, \mathrm{mA}$ & 45 \\
\hline Focal current $I_{\mathrm{w}}, \mathrm{mA}$ & 807 \\
\hline Welding speed $v_{\mathrm{w}}, \mathrm{mm} \cdot \mathrm{s}^{-1}$ & 30 \\
\hline
\end{tabular}

achieve full penetration of the blade. Final parameters are listed in Table 2.

Production of T-weld to the blades through hub disc. Joining by T-weld through hub disc is used in case of narrow channel where BW - blade joining cannot be used because of electron beam dimensions. In this case the blade is part of hub disc and joint is formed by melting of blade disc interface. The welding process and test samples were made using simple T-joint configuration from AW 2099 sheets of $3.0 \mathrm{~mm}$ for simplification. The weld penetration is not the main factor of weld strength in the case of T-weld. The weld strength is determined by weld width in the disc-blade interface. However, this weld width is limited by blade thickness and its thermal capacity. This unwelded area not only reduces effective weld width, but also acts as notch in the weld. The notch effect can be reduced by inserting brazing filler material to the joint and by application of hybrid welding process to some extent.

Advantage of this method is constant welding process over the entire length of the blade without necessity of change of welding current or focal position. Another benefit is absence of spatter in the impeller channel, in case of proper process setup.

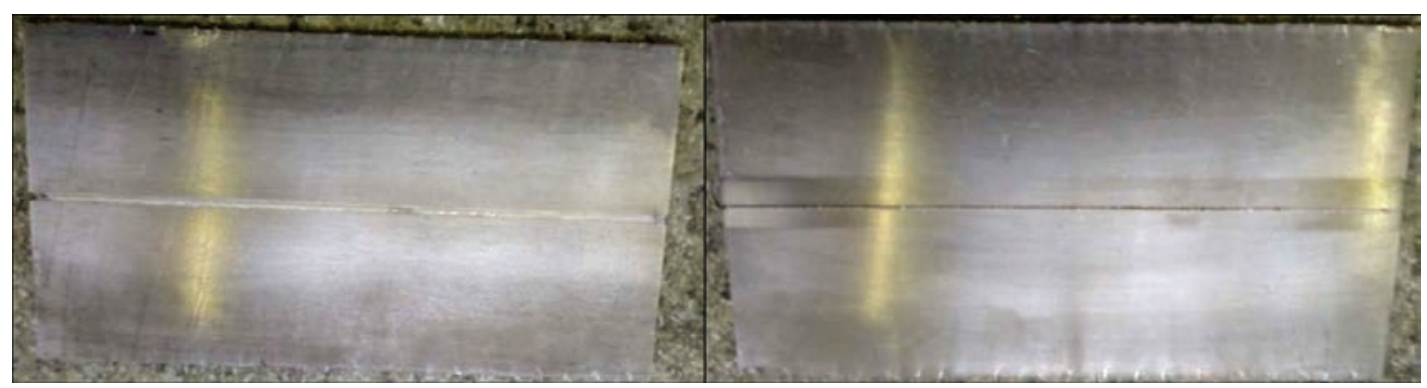

Figure 3. Surface and root of butt weld sample
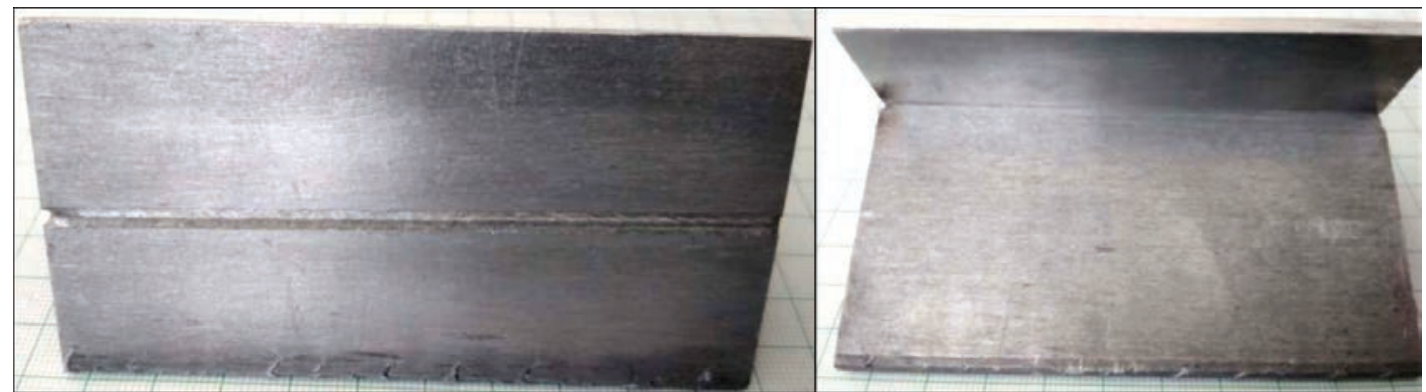

Figure 4. Surface of T-weld 


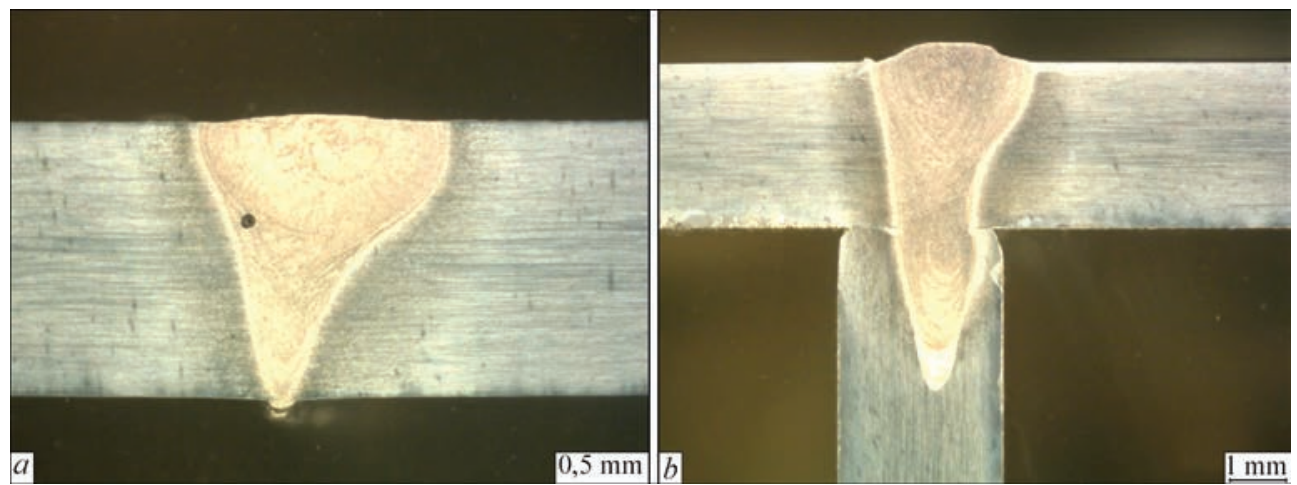

Figure 5. Macrostructure of weld without heat treatment: $a-\mathrm{BW} ; b-\mathrm{T}$-weld
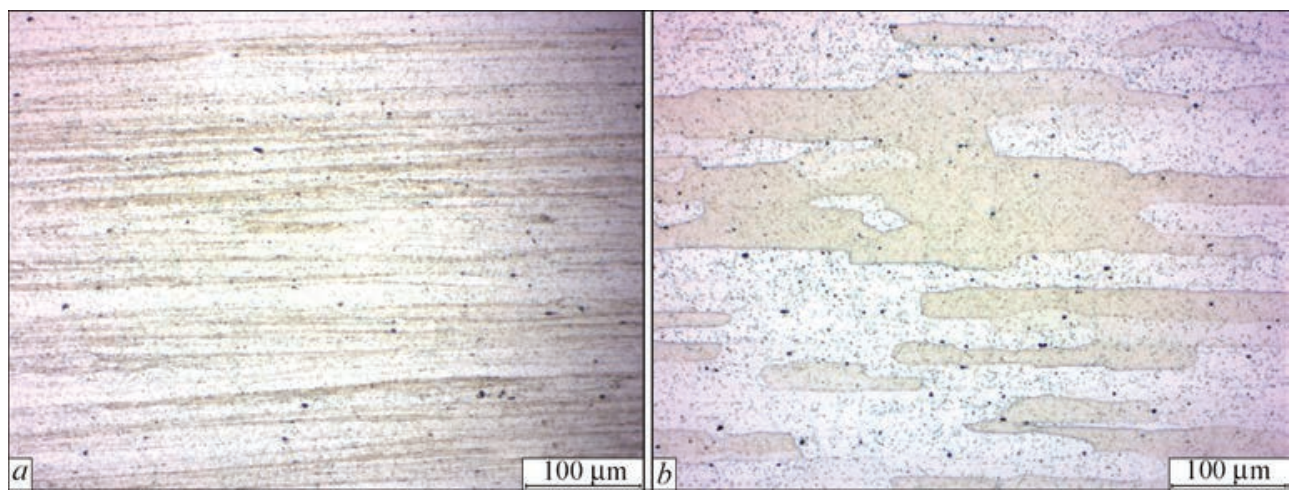

Figure 6. Microstructure of base metal: $a$ - without heat treatment; $b$ - with heat treatment

At the same time the determination of actual weld penetration, as well as nonwelded area dimensions are complicated when ultrasonic testing method is applied.

Welding parameters were set by trials based on full penetration welding of sheet of $3.0 \mathrm{~mm}$ thickness. The set welding current was increased by $5 \mathrm{~mA}$ to secure sufficient penetration to the blade. The circular patter dynamic deflection of electron beam was used to increase weld width in the disc-blade interface. Used welding parameters are listed in Table 3.

Results. Surface of samples of butt weld was uniform without significant imperfections such as undercut, excessive weld metal, surface porosity, cracks or spatters. Visual inspection of BW indicated excessive penetration. The root height was less than $0.5 \mathrm{~mm}$ over the whole weld length (Figure 3). Penetration inspection does not reveal any indications.

The surface of T-weld was uniform over the entire weld length without presence of spatters, porosity or cracks. No root penetration was observed out of blade material (Figure 4).

Macrostructure. Macrostructure of butt (Figure 5, a) weld reveals weld with full penetration without presence of any cracks. The weld metal includes one pore with diameter approx. $0.1 \mathrm{~mm}$. HAZ is not significant and its width is up to $1.5 \mathrm{~mm}$. Width of weld metal reaches $2.7 \mathrm{~mm}$ on the surface. Measured root width is $0.5 \mathrm{~mm}$. The shape of weld shows some asymmetry probably because of fixture residual magnetisms.

T-weld (Figure $5, b$ ) is not placed perfectly in the axis of blade and weld axis is shifted by $0.3 \mathrm{~mm}$. Weld
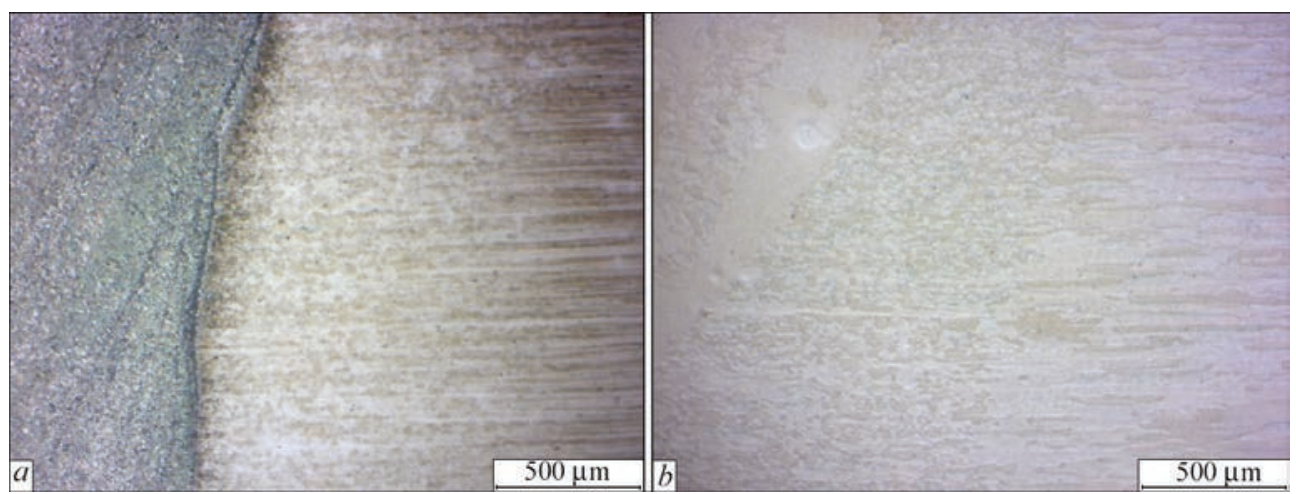

Figure 7. Microstructure of HAZ: $a$ - without heat treatment; $b$ - with heat treatment 


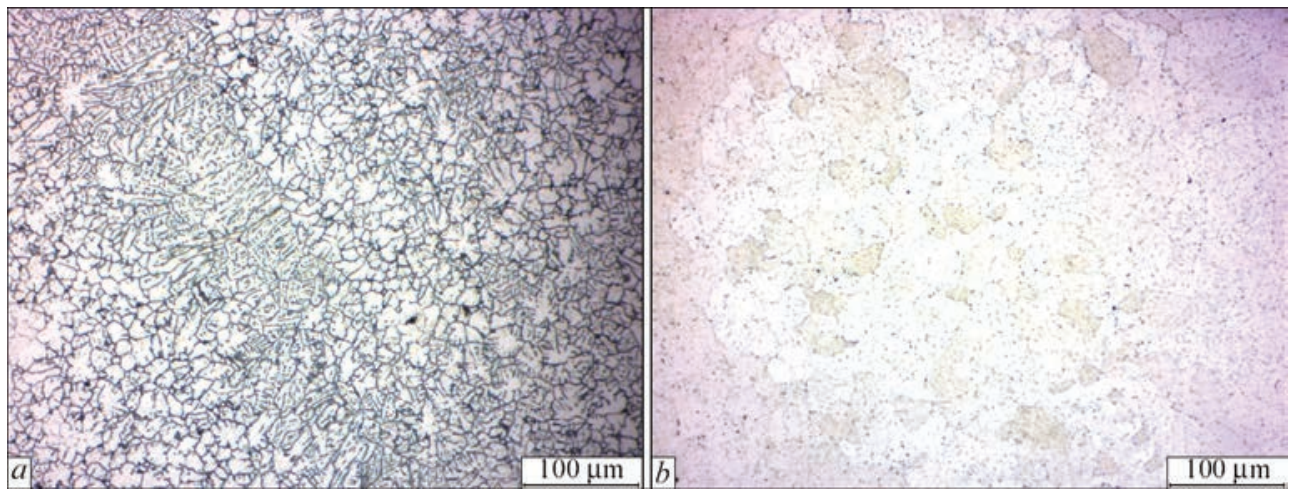

Figure 8. Microstructure of weld metal: $a$ - without heat treatment; $b$ - with heat treatment

Table 4. Result of tensile strength test of weld joints with and without heat treatment cycle

\begin{tabular}{|c|c|c|c|c|c|c|c|}
\hline Sample & \multicolumn{2}{|c|}{ Yield strength, $R_{\mathrm{p} 0.2}, \mathrm{MPa}$} & \multicolumn{2}{c|}{ Tensile strength, $R_{\mathrm{m}}, \mathrm{MPa}$} & Note \\
\hline Base metal without heat treatment & 410.5 & 405.2 & 407.4 & 434.3 & 428.3 & 428.0 & $A=2 \%$ \\
\hline BW without heat treatment & - & - & - & 281.1 & 284.0 & 282.8 & Failure in fusion zone \\
\hline BW with heat treatment & 283.7 & 284.5 & 278.3 & 409.0 & 405.7 & 407.0 & Failure in base metal \\
\hline T-weld without heat treatment & - & - & - & 58.5 & 58.6 & 58.2 & Failure in weld metal \\
\hline T-weld with heat treatment & 109.3 & 114.0 & 114.9 & 128.0 & 133.3 & 132.5 & Failure in weld metal \\
\hline
\end{tabular}

Table 5. Results of bend test of butt welded joints with and without heat treatment cycle

\begin{tabular}{|c|c|c|c|c|}
\hline Sample & \multicolumn{3}{|c|}{ Bend angle, $^{\circ}$} & Failure localization $^{\circ}$ \\
\hline BW without heat treatment & 16 & 11 & 9 & Failure in weld metal \\
\hline BW with heat treatment & 180 & 180 & 180 & No failure \\
\hline
\end{tabular}

is $1.4 \mathrm{~mm}$ wide on the disc-blade interface and this width is proportional to T-weld strength. HAZ is not very significant similarly to BW.

Microstructure. Microstructure of base metal consists of grains elongated in the rolling direction with precipitated strengthening particles (Figure 6, $a$ ). The nature of microstructure does not change noticeably after heat treatment (solution annealing with water, quenching and artificial ageing) only grain growth can be observed and phases are finer (Figure 6, $b$ ).

We can observe surface appearance changes in the HAZ because of recrystallization during welding cycle (Figure 7, a). The fusion zone is formed by fine globular grains. The structure shows some grain growth after heat treatment cycle.

Weld metal has columnar shaped grains near the fusion zone. The axis of the grains is oriented in the steepest heat gradient. The columnar grains are transformed into polyedric grains. The phases are mainly in the grain boundary region in case of samples without heat treatment cycle (Figure 8, a). The grain growth also takes place in weld metal during heat treatment cycle (Figure $8, b$ ). And the phases distribution is more uniform and phases are fine after heat treatment cycle (Figure $8, b$ ).
The static tensile strength (Table 4) and bend test (Table 5) were performed so far. The base metal after solution treatment and thickness reduction from $25.0 \mathrm{~mm}$ to $3.0 \mathrm{~mm}$ reaches tensile strength over $R_{\mathrm{m}}=428 \mathrm{MPa}$ and yield strength $R_{\mathrm{p} 0.2}=405 \mathrm{MPa}$, but elongation was only $A=2 \%$. The degradation of mechanical properties due to heat cycle takes place as expected. The tensile strength decreased by a third to over $281 \mathrm{MPa}$ for the butt weld. Measured tensile strength was only $58 \mathrm{MPa}$ in case of T-weld. This significant drop is also verified by calculation. The width of the blade was taken for calculation, not only weld width. The heat treatment cycle allows restoring to $94 \%$ (over $405 \mathrm{MPa}$ ) of the original tensile strength in case of butt weld. Tensile strength was doubled by heat treatment to the value of over $128 \mathrm{MPa}$ for T-weld. The failure of the samples without heat treatment occurs in fusion zone during tensile tests. The strength of weld metal was higher in comparison with base metal after heat treatment and therefore the failure takes place in base metal.

The bend test was performed with mandrel of $D=35 \mathrm{~mm}$ diameter with regard to the low plastic properties of original base metal $(A=2 \%)$. This size of mandrel was used also for bend test of welded joints 
after heat treatment for better comparison. Samples of butt weld without heat treatment cycles rupture at bend angle from $9^{\circ}$ to $16^{\circ}$. The failure was located in weld metal in all cases. No failure was observed after bend test of samples with heat treatment at bend angle of $180^{\circ} \mathrm{C}$ (Table 5).

\section{Conclusions}

The achieved result showed suitability of chosen approach for application of $\mathrm{Al}-\mathrm{Li}$ alloys in production of low stressed impeller with reduced power consumption. Proper setup of electron beam process results in production of sound welds with high quality. Over $94 \%$ of original value of tensile strength was reached for butt weld using heat treatment cycle for improvement of the plastic properties. Bend angle of $180^{\circ}$ was achieved for these samples.

The negative effect of welding heat impact on mechanical properties was identified as expected. This negative impact can be effectively suppressed by heat treatment cycle after welding. Optimum combination of solution treatment temperature and time together with artificial ageing can restore the properties almost to the original values.

It is necessary to focus on the way how to increase the width of T-weld to the maximum achievable size to secure the highest strength of the welded joint.

Further work has to be done in the field investigation of dynamical properties and parameters for opti- mization of heat treatment cycle in order to increase mechanical and plastic properties.

Acknowledgments. This work was supported by the Slovak Research and Development Agency under the contract No. APVV-15-0337, APVV-16-0300, APVV-17-0432 and by Ministry of Education, Science, Research and Sport of the Slovak Republic within the project Req-00048-0005.

\section{References}

1. Hrivnák, I. Zváranie a zvaritel'nost' materiálov. (2009) $V$ Bratislave: Slovenská technická univerzita. Edícia vysokoškolských učebníc. ISBN 978-80-227-3167-6.

2. Metalwebnews: Lithium aluminium alloys - the new generation aerospace alloys. Metal Web News, (C2007 https://web. archive.org/web/20070928094349/http:/www.metalwebnews.com/howto/alloys/alloys.pdf

3. Lin Y., Z.Q. Zheng and S.C. Li. (2013) Effect of solution treatment on microstructures and mechanical properties of 2099 Al-Li alloy. [cit. 2019-01-24]. DOI: https://doi.org/10.1016/j. acme.2013.07.005

4. Rioja, Roberto J. and John Liu. (2012) The evolution of Al-Li base products for aerospace and space applications. Metallurgical and Materials Transact. A. Springer US, 43(9), 33253337. DOI: https://doi.org/10.1007/s11661-012-1155-z

5. Wang, S., Y. Huang and L. Zhao. (2017) Effects of different aging treatments on microstructures and mechanical properties of $\mathrm{Al}-\mathrm{Cu}-\mathrm{Li}$ alloy joints welded by electron beam welding. [cit. 2019-01-24]. DOI: https://doi.org/10.1016/j. cja.2017.07.002

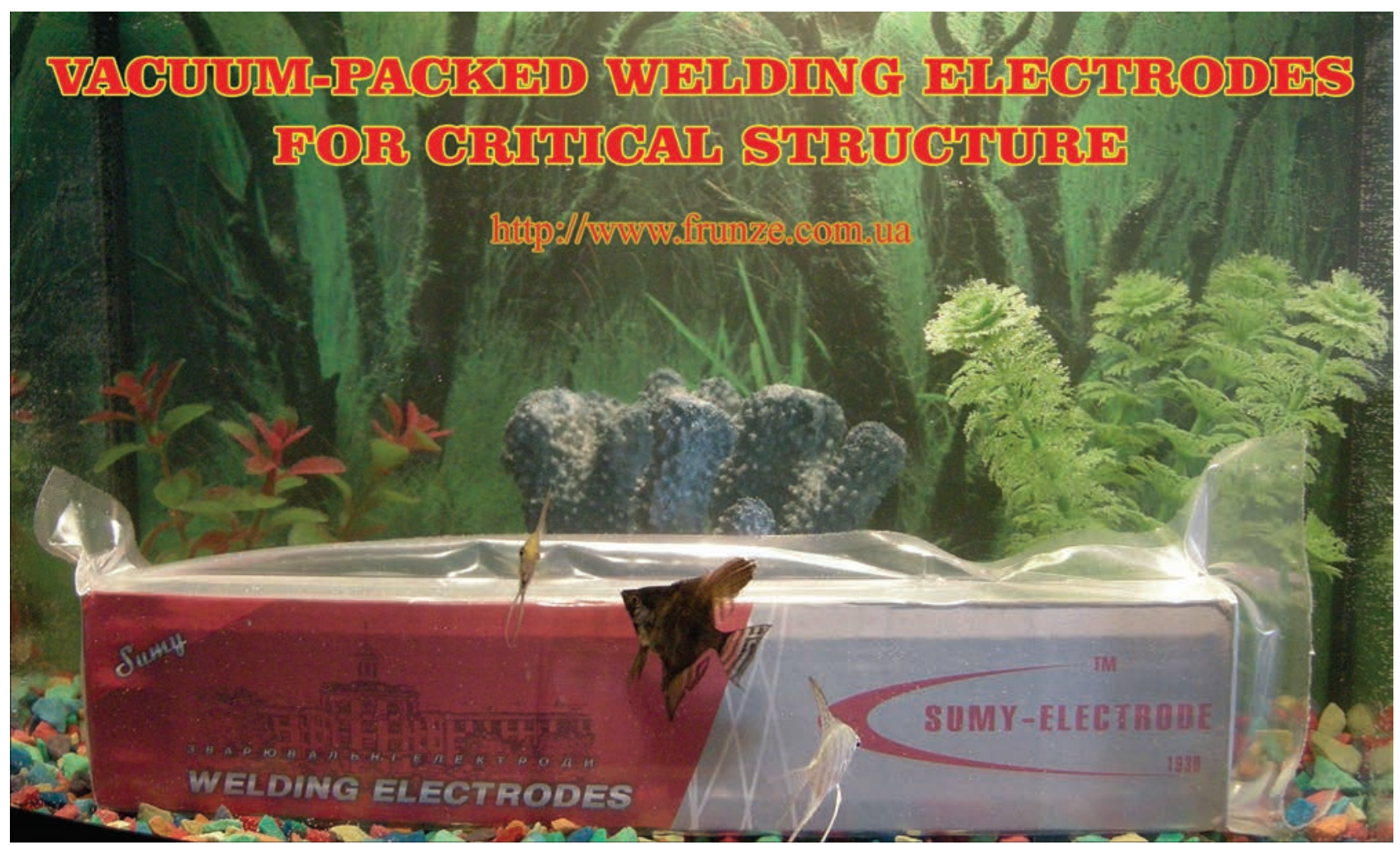




\title{
PROCEDURE OF ACCELERATED CORROSION TESTING FOR MODELING THE LONG-TERM EFFECT OF MODERATE CLIMATE ATMOSPHERE ON WELDED JOINTS
}

\author{
V.V. KNYSH, S.O. OSADCHUK, S.O. SOLOVEI, L.I. NYRKOVA and A.O. RYBAKOV \\ E.O. Paton Electric Welding Institute of the NAS of Ukraine \\ 11 Kazymyr Malevych Str., 03150, Kyiv, Ukraine. E-mail: office@paton.kiev.ua
}

\begin{abstract}
We propose a procedure of accelerated corrosion testing of welded joints for modeling the long-term effect of the most significant climatic factors of moderate climate atmosphere (temperature and relative humidity) on them. Duration of accelerated testing of welded joints in the humidity chamber to obtain corrosion damage, which is characteristic for welded joints of metal structures after approximately 12 years of operation, is substantiated. Fatigue testing of butt and tee welded joints of 15KhSND steel after preliminary exposure to 2 mln cycles at maximum stresses of $150 \mathrm{MPa}$, corrosion testing under the conditions of higher temperature and relative humidity without strengthening and with further strengthening by the technology of high-frequency mechanical peening, were performed. It is found that strengthening by the technology of high-frequency mechanical peening improves 10 times the cyclic fatigue life of butt and tee welded joints with accumulated fatigue and corrosion damage. 23 Ref., 5 Figures.
\end{abstract}

Keyw ord s : welded joint, corrosive environment, fatigue, accelerated corrosion testing, high-frequency mechanical peening, improvement of cyclic fatigue life

A considerable part of welded metal structures and constructions in the territory of Ukraine exposed to variable loading in service (bridges, overpasses, cranes, etc.), were put into operation in 1960-1980s. These structures are protected from the impact of climatic environmental factors (corrosion) by paint-lacquer coatings. During long-term operation, however, mechanical damage, cracking and delamination of the lacquer-paint coatings can take place. This leads to welded elements of the structures being exposed not only to variable loading, but also to corrosion impact [1, 2]. Formation of corrosion damage lowers the design thickness of structural elements and fatigue resistance characteristics of welded joints, leading to premature failure [3]. In case of an objective need of further operation of these structures, during performance of repair-restoration operations it is necessary to not only remove the corrosion products and renew the lacquer-paint coatings, but also increase the cyclic fatigue life of welded joints damaged by corrosion by additional strengthening treatment. For a guaranteed improvement of fatigue resistance characteristics of welded joints in metal structures, it is recommended to apply high-frequency mechanical peening (HFMP) [4-8]. To establish the effectiveness of application of HFMP technology for improvement of the fatigue life of welded structures with corrosion damage, it was necessary to model the long-term impact of moderate climate conditions by accelerated testing in the laboratory. Analysis of normative documents showed that until recently the comparative studies of corrosion resistance of structural steels under atmospheric conditions were conducted in Ukraine in keeping with the procedures specified in the normative documents [9-11]. After cancellation of GOSTs European norms began to be introduced $[12,13]$. However, both in the GOSTs and in the current standards [9-14], just the test conditions or a set of test conditions modeling the impact of corrosive factors are proposed, but information on the duration of sample exposure is absent.

Therefore, the objective of this work is development of a procedure of accelerated corrosion testing for modeling the long-term impact of moderate climate atmosphere on the welded joints and establishing the effectiveness of application of HFMP technology to improve its cyclic fatigue life.

Development of the procedure of accelerated corrosion testing. The procedure of accelerated corrosion testing of the samples was developed for moderate climate of Ukraine. The corrosion processes were essentially affected by the duration of the cycle of surface wetting, during which a film of moisture is present on the structural elements [15, 16]. In [17] the moderate climate is characterized by temperature range from -33 to $+35^{\circ} \mathrm{C}$, and the calculated time of moderate humidity above $80 \%$ at temperatures above $0{ }^{\circ} \mathrm{C}$ is equal from 2500 to $4200 \mathrm{~h} / \mathrm{y}$. The corrosion processes are the most active in the presence of phase 
films of moisture that form at the metal surface wetting by liquid precipitation or condensate. In keeping with the data of work [16], for moderate climate characteristic for the central regions of Ukraine, wetting by phase film amounts to $2520 \mathrm{~h} / \mathrm{y}$. Here, the annual average temperature in this region is equal to $11^{\circ} \mathrm{C}$ [18]. In the normative documents [9-14], in order to model the influence of climatic factors on metal corrosion, it is recommended to perform sample exposure under the conditions of higher temperature and humidity, salt spray or cyclic impact of these factors. As the presence of chlorides in the environment and their impact on metals is more characteristic for marine climate (coastal zone of Ukraine), then at development of the procedure of conducting accelerated corrosion testing only such factors were taken into account, as higher temperature and humidity. The impact of these factors was modeled under laboratory conditions in G4 hydrostat (humidity chamber).

According to the data of $[10,12]$ for carbon and low-alloyed structural steels, the temperature in the hydrostat should be maintained on the level of $40{ }^{\circ} \mathrm{C}$, so as not to change the mechanism of the corrosion processes. Here, air humidity (in the absence of forced circulation of air) is close to $100 \%$ that ensures formation of phase films of moisture, which initiate the corrosion processes during the entire time of exposure.

It is known that at the change of temperature from the initial to higher one, the reaction rate, including the corrosion rate, rises by Van't Hoff law [19]:

$$
V_{t_{2}}=V_{t_{1}} \gamma^{\frac{t_{2}-t_{1}}{10}},
$$

where $V_{t 2}$ is the reaction rate at higher temperature during performance of laboratory testing $t_{2}$ (in our case $t_{2}=40^{\circ} \mathrm{C}$, according to $\left.[10,12]\right) ; V_{t_{1}}$ is the reaction rate at temperature $t_{1}$. Temperature $t_{1}$ was taken to be the average annual temperature in the central regions of Ukraine, i.e. $11^{\circ} \mathrm{C}$ [18]; $\gamma$ — is the reaction temperature coefficient.

Taking into account the recommended value of temperature coefficient $\gamma=3$, the acceleration of the corrosion process at increased temperature and humidity, according to (1) will be equal to:

$$
\gamma^{\frac{t^{-}-t_{2}}{10}}=3^{\frac{40-11}{10}}=3^{2.9} \approx 24.2,
$$

Thus, the corrosion processes on the metal surface can be accelerated 24.2 times in G4 hydrostat at increased temperature of $40{ }^{\circ} \mathrm{C}$ and relative humidity of about $100 \%$. Considering that during one year the phase film of moisture on the metal surface is observed during $2520 \mathrm{~h}$ [16], one year of structure op- eration will be equivalent to sample exposure in the hydrostat for 2520/24.2 $=104 \mathrm{~h}$.

In welded metal structures in service the corrosion damage of elements is revealed, as a rule during scheduled examinations. At modeling of corrosion damage in the welded joints by an accelerated procedure, it is rational to take into account the maximum interval between examinations of such structures. For instance, for span structures of bridges, the period between the examinations is from 5 [20] up to 10 years [21]. Considering that 1 to 2 more years will pass after examination of such structures and detection of corrosion damage before the beginning of repair-restoration operations, it is rational to model on welded joint samples the corrosion damage which may develop on the surface of welded structural elements after operation for almost 12 years.

Thus, the characteristic corrosion damage of welded structures after 12 years of operation under the conditions of the impact of the most significant climatic factors (temperature and humidity) of moderate climate of the central regions of Ukraine, can be obtained by conducting accelerated corrosion testing in G4 hydrostat at higher temperature of $40{ }^{\circ} \mathrm{C}$ and air humidity close to $100 \%$ for $1200 \mathrm{~h}$.

Investigation material and procedure of fatigue testing. Experimental studies were conducted on samples of butt and tee welded joints of low-alloyed steel $15 \mathrm{KhSND}\left(\sigma_{\mathrm{y}}=400 \mathrm{MPa}, \sigma_{\mathrm{t}}=565 \mathrm{MPa}\right)$ which is widely applied for manufacture of elements of longterm metal structures (for instance, in span structures of railway and road bridges), has higher strength, is readily weldable, resistant to atmospheric conditions and serviceable in the temperature range from $-70^{\circ} \mathrm{C}$ up to $+45^{\circ} \mathrm{C}$.

Blanks for welded joint samples were cut out from hot-rolled plates $12 \mathrm{~mm}$ thick of category 12 in the rolling direction. The dimensions of blanks for butt joints were $600 \times 180 \mathrm{~mm}$, and of those for tee joints $-350 \times 70 \mathrm{~mm}$. Butt welded joints were produced by single-arc automatic welding of plates without edge preparation from both sides $(0-1.0 \mathrm{~mm}$ gap in the butt) using OP 192 flux (Oerlikon Company) with $4 \mathrm{~mm}$ Sv-08G1NMA wire. Welding was conducted at reverse polarity with power supply from electric rectifier VSZh-1600. Welding modes were as follows: first weld $U=55 \mathrm{~V} ; I=650-700 \mathrm{~A}$, $v=26.7 \mathrm{~m} / \mathrm{h}$; second one (from the reverse side): $U=57 \mathrm{~V} ; I=660-780 \mathrm{~A}, v=26.7 \mathrm{~m} / \mathrm{h}$. The second weld was made after complete cooling of the first one. 8 samples of $360 \times 70 \mathrm{~mm}$ size were prepared from each welded plate of $600 \times 360 \mathrm{~mm}$ size. Tee joints were produced by joining transverse stiffeners (also from steel 15KhSND) from two sides of the 

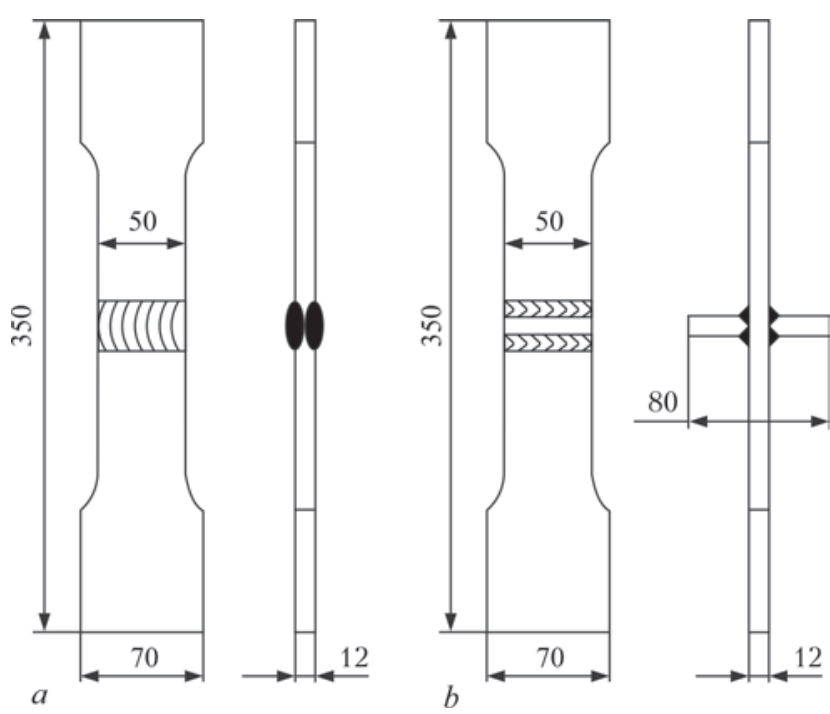

Figure 1. Samples of butt $(a)$ and tee $(b)$ welded joints

plate by fillet welds, using manual arc welding with UONI 13/55 grade electrodes. The root (first weld) was made by $3 \mathrm{~mm}$ electrodes, the second weld was formed by $4 \mathrm{~mm}$ electrode. The shape and geometrical dimensions of samples of butt and tee welded joints are given in Figure 1. The sample thickness is due to wide application of $12 \mathrm{~mm}$ thick rolled stock in engineering welded structures, and the working part width of $50 \mathrm{~mm}$ was selected proceeding from the testing equipment capacity.

The above procedure of conducting accelerated corrosion testing allows modeling the impact of moderate climate for 12 years on the condition of welded structure surface. Thus, it was also necessary to allow for the accumulated fatigue damage under the impact of variable cyclic loading after 12 years of operation. The following was taken into account. The design service life of the majority of welded structures for engineering applications is equal to $50-100$ years. Proceeding from the hypothesis of linear accumulation of fatigue damage over 12 years of operation, the welded joints should use $12-25 \%$ of their fatigue life to fracture, which can be determined from fatigue curves of these joints. Fatigue curves of the studied welded joints of 15KhSND steel were derived earlier on the base of testing by 2 mln cycles [22]. Here, the limited endurance limits after $2 \cdot 10^{6}$ stress alternation cycles for butt and tee welded joints were equal to 187 and $180 \mathrm{MPa}$, respectively. However, it is rational to perform fatigue damage accumulation in welded joints at lower levels of applied maximum stresses, which are closer to the working ones. In keeping with the recommendations of the International Institute of Welding [23] the fatigue curves of welded elements of structures have a constant angle of inclination in the range of $10^{5}-10^{7}$ cycles, that allows continuing the fatigue curve derived in work [22] from $2 \cdot 10^{6}$ to $10^{7}$ cycles. The required level of fatigue damage accumulation of
12-25\% was achieved by testing the welded joints in the initial condition by 2 mln cycles at maximum values of applied cycle stresses of $150 \mathrm{MPa}$ (30-37 MPa lower than the experimentally established limited endurance limits of the studied joints).

Thus, for modeling the accumulated fatigue and corrosion damage, characteristic for welded joints after 12 years of metal structure operation, all the samples were first exposed to $2 \cdot 10^{6}$ cycles of stress alternation in TsDM 10-pu testing machine at zeroto-stress loading cycle with maximum applied loads of $150 \mathrm{MPa}$, and then in keeping with the developed procedure, they were exposed in G4 hydrostat at the temperature of $40{ }^{\circ} \mathrm{C}$ and relative air humidity of $100 \%$ for $1200 \mathrm{~h}$. After corrosion testing one part of the samples remained unstrengthened, and the other part was strengthened by HFMP technology.

The welded joints were strengthened by HFMP technology using USTREAT-1.0 equipment, in which the manual compact impact tool with a piezoceramic converter is connected to an ultrasonic generator with output power of $500 \mathrm{~W}$. At treatment of welded joints by HFMP technology a narrow zone of weld metal transition to the HAZ (along the fusion line) was subjected to surface plastic deformation. A single-row four-striker attachment with $3 \mathrm{~mm}$ diameter of the strikers was used as the strengthening device. Strengthening was conducted without preliminary cleaning of the surface from the corrosion products.

Four series of samples were prepared for fatigue testing:

- samples of butt and tee joints after testing by 2 mln cycles and subsequent corrosion testing, samples of the first and second series, respectively;

- samples of butt and tee welded joints after testing by 2 mln cycles, subsequent corrosion testing and strengthening by HFMP technology, samples of the third and fourth series, respectively.

Experimental studies of fatigue resistance of all the four sample series were conducted in URS-20 testing machine at alternating tension with cycle asymmetry $R_{\sigma}=0$ and $5 \mathrm{~Hz}$ frequency at regular loading. Complete fracture of the samples or exceeding the test base of $2 \cdot 10^{6}$ cycles of stress alternation was taken as the test completion criterion.

Investigation results. After testing in the hydrostat, the welded joint samples were covered by a nonuniform layer of corrosion products of brown colour with embedded corrosion products of black colour. Sample cleaning to remove the corrosion products was not conducted after corrosion testing. As a result of strengthening by HFMP technology a characteristic groove without corrosion products formed along the line of weld metal transition to base metal (Figure 2). Results of fa- 


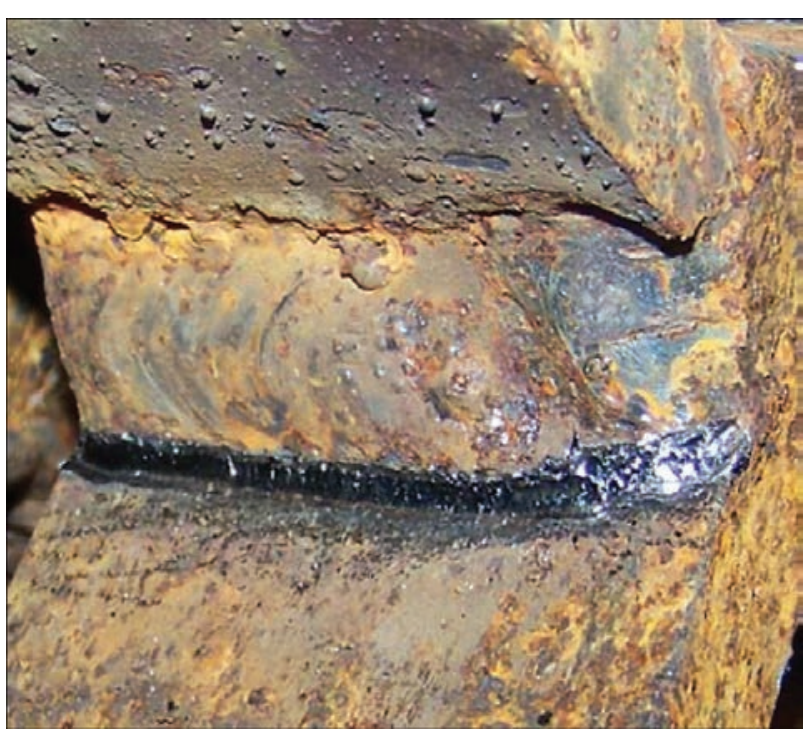

Figure 2. Appearance of weld zone of a tee welded joint of $15 \mathrm{KhSND}$ steel after testing by $2 \cdot 10^{6}$ cycles, corrosion testing for $1200 \mathrm{~h}$ in the hydrostat and strengthening by HFMP technology

tigue testing of samples of butt and tee welded joints of 15KhSND steel are given in Figures 3 and 4, respectively. Results of testing welded joints in the initial condition (without the impact of the corrosive environment), derived earlier in work [22], are also given there.

It is experimentally established that fatigue resistance characteristics of butt welded joints after cyclic loading $\left(2 \cdot 10^{6}\right.$ cycles of stress alternation) and further exposure to higher temperature and humidity of air for $1200 \mathrm{~h}$ (first series) are on the level of welded joints in the initial condition, tested in air (Figure 3, curves 1,2). Fracture of all the samples of the first series occurred along the line of transition of the weld to base metal. Strengthening by HFMP technology (third series) increases the limited endurance limits of such joints on the base of $2 \cdot 10^{6}$ cycles by $33 \%$ (from 187 up to $248 \mathrm{MPa}$ ), compared both to joints in the initial condition, and those with the specified level of accumulated fatigue and corrosion damage without strengthening (Figure 3). Here, cyclic fatigue life of the strengthened welded joints increases 10 times. Fracture of all the samples of the third series occurred mainly through the base metal at a distance from the fusion zone (Figure 5, a).

Characteristics of fatigue resistance of tee welded joints after cyclic loading and corrosion testing for $1200 \mathrm{~h}$ (second series) dropped by $25 \%$ (from 180 to $135 \mathrm{MPa}$ ), compared to joints in the initial condition, tested in air (Figure 3, curves 1, 2). Fracture of all the samples of the second series occurred along the line of weld to base metal transition. Strengthening by HFMP technology (fourth series) significantly increases fatigue resistance characteristics: limited endurance limit of such joints on the base of $2 \cdot 10^{6}$ cycles increases by $31 \%$ (from 180 up to $236 \mathrm{MPa}$ ), compared to samples

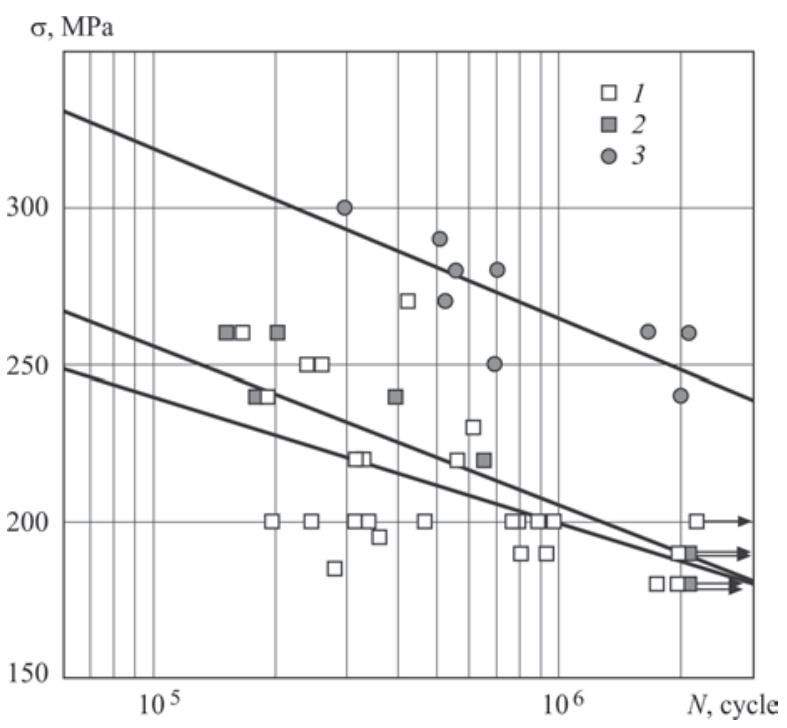

Figure 3. Fatigue curves of butt welded joints of 15KhSND steel: 1 - in the initial condition [22]; 2 - after testing by $2 \cdot 10^{6}$ cycles at maximum stresses of $150 \mathrm{MPa}$ and corrosion testing for $1200 \mathrm{~h}$ (first series); 3 - after testing for $2 \cdot 10^{6}$ cycles at maximum stresses of $150 \mathrm{MPa}$, corrosion testing for $1200 \mathrm{~h}$ and further strengthening by HFMP technology (third series)

in the initial condition, and cyclic fatigue life increases 8 times. Compared to second series samples (with the set level of fatigue and corrosion damage accumulation, without strengthening), the limited endurance limit on the base of $2 \cdot 10^{6}$ cycles of samples of the fourth series increases by $75 \%$ (from 135 up to $236 \mathrm{MPa}$ ), whereas cyclic fatigue life increases 10 times (Figure 4). Fracture of samples of the fourth series occurred both along the fusion line, and in the base metal away from the weld (Figure 5, b). One sample failed from incomplete penetration of the weld root along the stiffener, but its

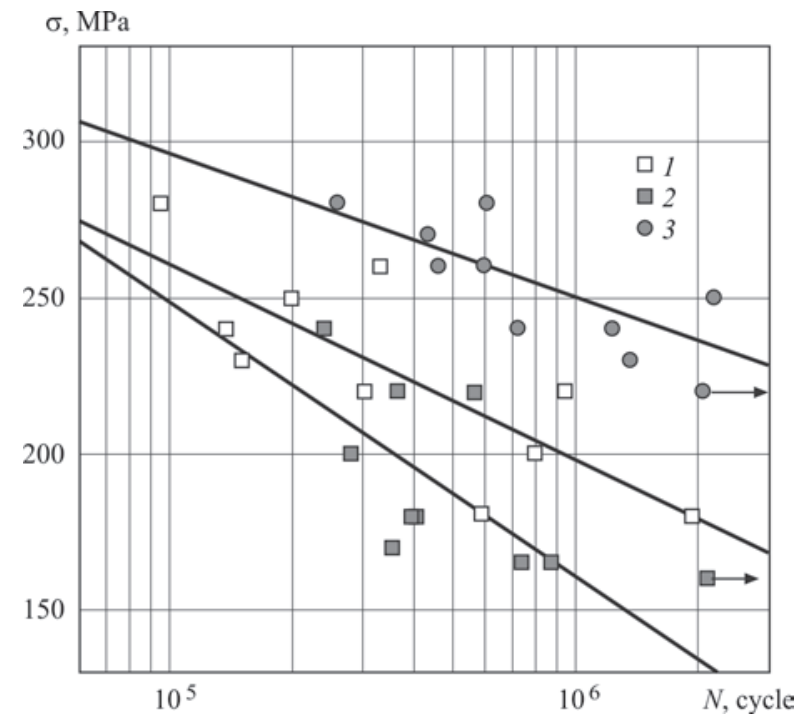

Figure 4. Fatigue curves of tee welded joints of 15KhSND steel: 1 - in the initial condition [22]; 2 - after cyclic testing at maximum stresses of $150 \mathrm{MPa}$ and corrosion testing for $1200 \mathrm{~h}$ (second series); 3 - after testing by $2 \cdot 10^{6}$ cycles at maximum loads of $150 \mathrm{MPa}$, corrosion testing for $1200 \mathrm{~h}$ and further strengthening by HFMP technology (fourth series) 


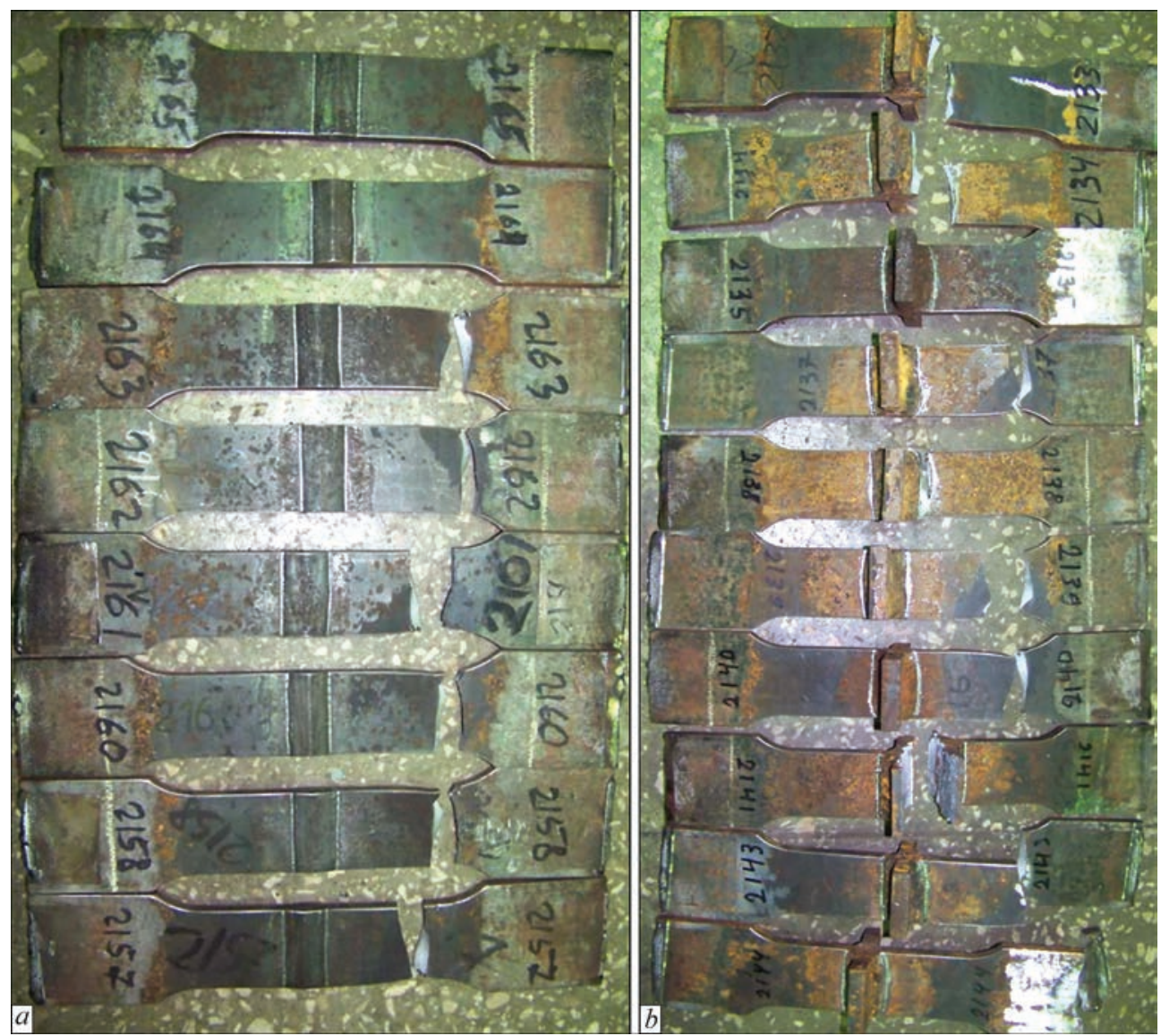

Figure 5. Appearance of samples of the third $(a)$ and fourth $(b)$ series after fatigue testing

cyclic fatigue life remained within the range of data scatter for sound welded joints.

Thus, obtained experimental results are indicative of the high effectiveness of HFMP technology application to improve the fatigue resistance characteristics of butt and tee welded joints of metal structures after their long-term operation under the conditions of variable loading and moderate climate atmosphere.

\section{Conclusions}

1. A procedure was developed for accelerated corrosion testing of welded joints in order to model the long-term impact on them of the most significant climatic factors (temperature and relative humidity) of moderate climate of the central regions of Ukraine. Rationality of modeling the corrosion damage forming on the surface of welded structure elements after 12 years of operation was substantiated. It is proposed to produce such corrosion damage of welded joint by conducting accelerated corrosion testing in G4 hydrostat at higher temperature of $40{ }^{\circ} \mathrm{C}$ and relative air humidity of $100 \%$ for $1200 \mathrm{~h}$.

2. It is established that strengthening by HFMP technology of butt welded joints of 15KhSND steel after preliminary testing by 2 mln cycles at maximum stress levels of $150 \mathrm{MPa}$ and exposure under the conditions of higher temperature and humidity of air for
$1200 \mathrm{~h}$ leads to 10 times increase of cyclic fatigue life and increase of the limited endurance limit on the base of $2 \cdot 10^{6}$ cycles by $33 \%$ (from 187 to $248 \mathrm{MPa}$ ).

3. Shown is the high effectiveness of strengthening by HFMP technology of tee welded joints of 15KhSND steel with the set level of accumulated fatigue and corrosion damage: limited endurance limit on the base of $2 \cdot 10^{6}$ cycles increases by $75 \%$ (from 135 up to $236 \mathrm{MPa}$ ), and cyclic fatigue life increases 10 times.

1. Kovtunenko, V.A., Sineok, A.G., Gerasimenko, A.M., Zadorozhny, V.A. (2005) Typical damages of welded metal structures of bridges. The Paton Welding J., 10, 27-32.

2. Ushakov, I.I., Mishchenko, V.Ya., Ushakov, S.I. (2013) Corrosion damage of steel structures and fundamentals of diagnostics: Manual. Moscow, ASB [in Russian].

3. Toyoda, M. (1995) How steel structures fared in Japan's great earthquake. Welding J., 74, 31-42.

4. Takanori Deluchi, Masashi Mouri, Junya Hara et al. (2012) Fatigue strength improvement for ship structures by ultrasonic peening. J. of Marine Sci. and Technol., 17(3), 360-369.

5. Fisher, J.W., Statnikov, E., Tehini, L. (2002) Fatigue strength improvement of bridge girders by ultrasonic impact treatment (UIT). Welding in the World, 46(9-10), 34-40.

6. Fikri Bashar Yalchiner, Zuheir Barsoum (2017) Life extension of welded structures using HFMI techniques — potential application to offshore structures. Procedia Structural Integrity, 5, 377-384.

7. Kirkhope, K.J., Bell, R., Caron, L. et al. (1999) Weld detail fatigue life improvement techniques. Pt 2: Application to ship structures. Marine Structures, 12(7-8), 477-496. 
8. Kudryavtsev, Y., Kleiman, J., Lugovskoy, A. et al. (2007) Rehabilitation and repair of welded elements and structures by ultrasonic peening. Welding in the World, 51(7-8), 47-53.

9. (1989) GOST 9.911-89: Unified system of corrosion and ageing protection. Weather-resistant steel. Accelerated corrosion test method [in Russian].

10. (1985) GOST 9.308-85: Unified system of corrosion and ageing protection. Metal and non-metal inorganic coatings. Methods of accelerated corrosion tests [in Russian].

11. (2006) ISO 9227-2006: Corrosion tests in artificial atmospheres. Salt spray tests.

12. (2015) DSTU ISO 6270-2:2015: Paints and varnishes. Determination of resistance to humidity. Pt 2: Procedure for exposing test specimens in condensation-water atmospheres [in Ukrainian].

13. (2015) DSTU ISO 12944-6:2015: Paints and varnishes. Corrosion protection of steel structures by protective paint systems. Pt 6: Laboratory performance test methods [in Ukrainian].

14. (2002) GOST R 51910-2002: Research and testing strategy by accelerated methods of environmental conditions influence for industrial products longevity and storage ability. Development and design [in Russian].

15. (2015) DSTU ISO 12944-1:2015: Paints and varnishes. Corrosion protection of steel structures by protective paint systems. Pt 1: General introduction.
16. (1974) GOST 9.039-74: Unified system of corrosion and ageing protection. Metals and alloys. Corrosion aggressiveness of atmosphere [in Russian].

17. (2015) ISO 12944-2:2015: Paints and varnishes. Corrosion protection of steel structures by protective paint systems. Pt 2: Classification of environments.

18. (1974) GOST 9.040-74: Unified system of corrosion and ageing protection. Metals and alloys. Calculated and experimental method for accelerated test of corrosion losses in atmospheric conditions [in Russian].

19. Semiokhin, I.A. (2001) Physical chemistry: Manual. Moscow, MGU [in Russian].

20. (2002) DBN V.2.3-6-2002: Transport structures. Bridges and pipes. Survey and test [in Russian].

21. (2008) ODM 218.4.001-2008: Guidelines on organization of survey and test of bridge structures on car roads [in Russian].

22. Knysh, V.V., Solovei, S.A.,Kirian, V.I., Bulash, V.N. (2018) Improvement of fatigue corrosion resistance of welded joints by high-frequency mechanical peening. Problemy Prochnosti, 3, 91-97 [in Russian].

23. Hobbacher, A. (2008) Recommendations for fatigue design of welded joints and components. Doc. IIW-1823-07, ex XIII2151r4-07/XV-1254r4-07.

\section{The Tenth International Conferensce}

Technologies in Welding and Related Mathematical Modeling and Information

\section{Processes}

Dedicated to the 150th anniversary of the acad. E.O. Paton - founder of the world's first welding institute

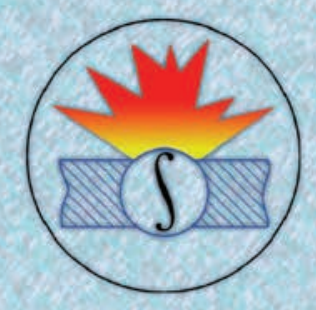

Ukraine, Odessa, Hotel «Arkadia»

September $14-18,2020$

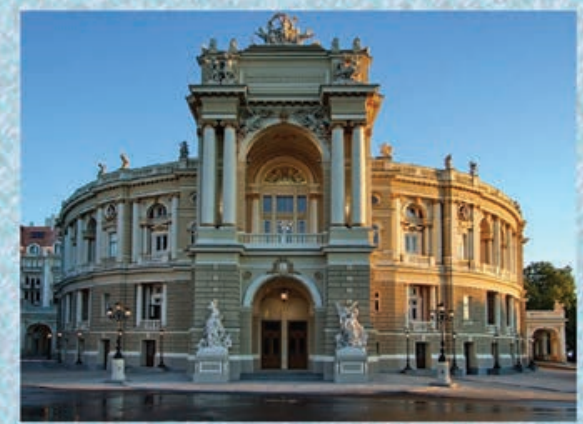

The National Academy of Sciences of Ukraine

The E.O. Paton Electric Welding Institute

International Association "Welding»

To participate in the Conference, it is necessary to fill the Registration Form and send it to the Organizing Committee before June 19,2020

Collections of proceedings of eight previous conferences «Mathematical Modelling and Information Technologies in Welding and Related Processes» on the site http://patonpublishinghouse.com/eng/proceedings

\section{Deadlines}

Registration form and Abstracts Before 19 June, 2020 Second call for papers and confirmation of participation Payment of Registration Fee
Before 17 July, 2020

Before 15 September, 2020

\section{Organizing Committee}

E. O. Paton Electric Welding Institute of NASU 11, Kazimir Malevich Str., Kyiv, 03150, Ukraine Tel./Fax: (38044) 200-82-77; 205-22-26 E-mail: journal@paton.kiev.ua http://pwi-scientists.com/eng/mmi2020 


\section{MULTIPURPOSE ELECTRON BEAM WELDING MACHINE}

V. NESTERENKOV, K. KHRYPKO and V. LUKYANOV

E.O. Paton Electric Welding Institute of the NAS of Ukraine

11 Kazymyr Malevych Str., 03150, Kyiv, Ukraine. E-mail: office@paton.kiev.ua

The E. O. Paton Electric Welding Institute (PWI) has been specializing for many decades in electron-beam welding (EBW) techniques for many modern structural alloys, including the development of EBW equipment and related production methods. The past two decades, the PWI designed and manufactured a lot of units, used for EBW of various products. All these units can be roughly divided into several types according to the of volume welding chamber: «small», «medium», «large» and «extra large». 6 Ref., 3 Figures.

Keywords : electron beam welding machine, control system, graphical user interface

The Electric Welding Institute designed and manufactured the KL-115 (Figure 1) multipurpose electron beam welding machine. The machine has an internal welding electron beam gun located on the cantilever mechanism with 5 degrees of freedom, namely gun motion along the three Cartesian coordinate axes $X$, $Y, Z$ and its tilting in two cross planes [1]. To rotate all kinds of welded rotation figures, the machine is equipped with 3 different welding positioners: with a horizontal axis of workpiece rotation (equipped with a corresponding tailstock to support long parts), with a vertical axis of rotation and with an inclinable $\left(0-90^{\circ}\right)$ axis of rotation. Thus, the machine has 7 movable mechanical axes controlled by the CNC (with the ability to control up to 4 axes at the same time), which, together with a sufficiently large volume of the welding chamber, provides very wide technological capabilities of the welding machine [2, 3]. At the same time, although it can be used for welding both linear and curved seams of workpieces of any suitable shape and size for many industries, but, given the configuration, the emphasis here is primarily on the possibility of welding rotation figures, namely various rather big elements of aircraft engines and similar products.

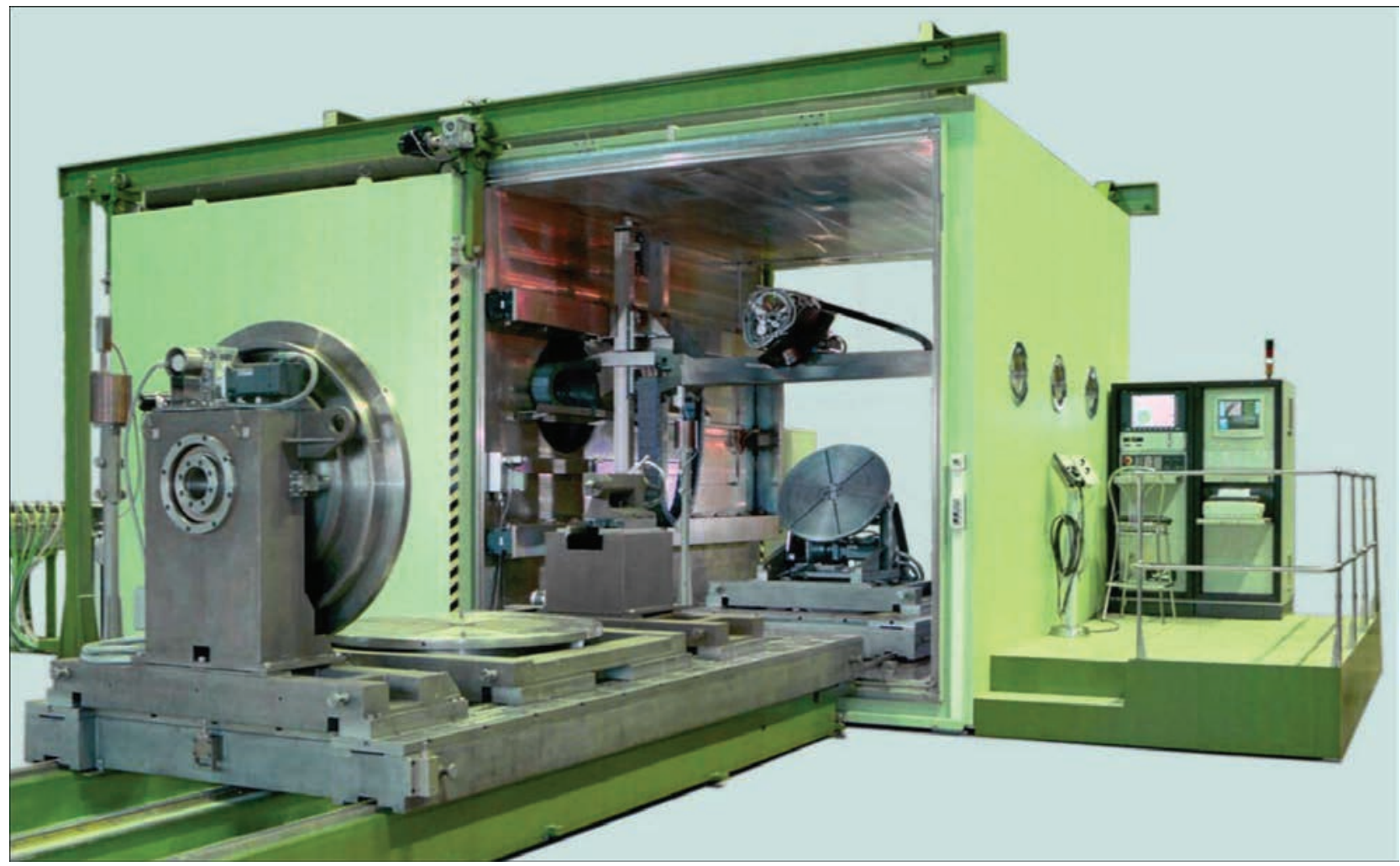

Figure 1. KL-115 electron beam welding machine 


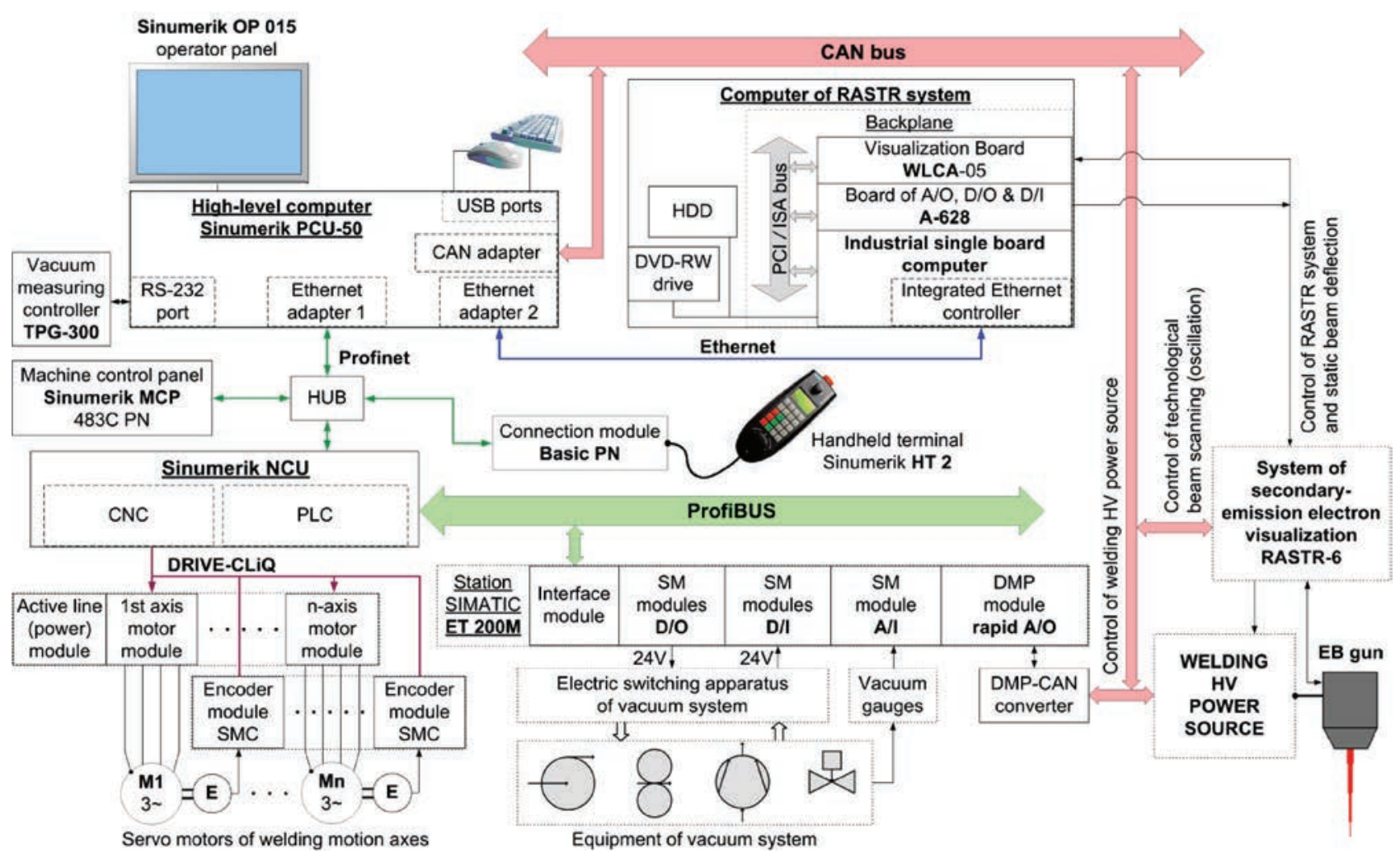

Figure 2. KL-115 machine control system diagram

The machine has an up-to-date control system (Figure 2) on the base of a complete industrial system Sinumerik 840Dsl of the company Siemens [4]. Part of equipment, which is exerting influence on the welding process, is under continual program control.

The concept of high-level software control, in which the user interacts with the equipment exclusively via the Windows-oriented graphical user interface (GUI), is used. The operation with GUI is made by using conventional standard tools: a keyboard and a mouse. The interface is intuitively conceivable (easy-to-understand) and doesn't require any specific skill. Each of the machine's subsystems is served by the appropriate window-based graphic tools with in- put data validation and safety locks to ensure the user and equipment protection.

Hierarchically, the control system is divided into two hardware and software levels, namely upper and lower. The upper level includes all means of communication with the user, including the GUI [5], means of creation and storage of specific welding programs (including collection of several welding subprograms with shared trajectory into one user program, for instance, tack run, welding run and cosmetic run), collection and storage of diagnostic data (including welding parameters), administration, etc. The lower level is engaged in the direct execution of all procedures under the instruction from the upper level.
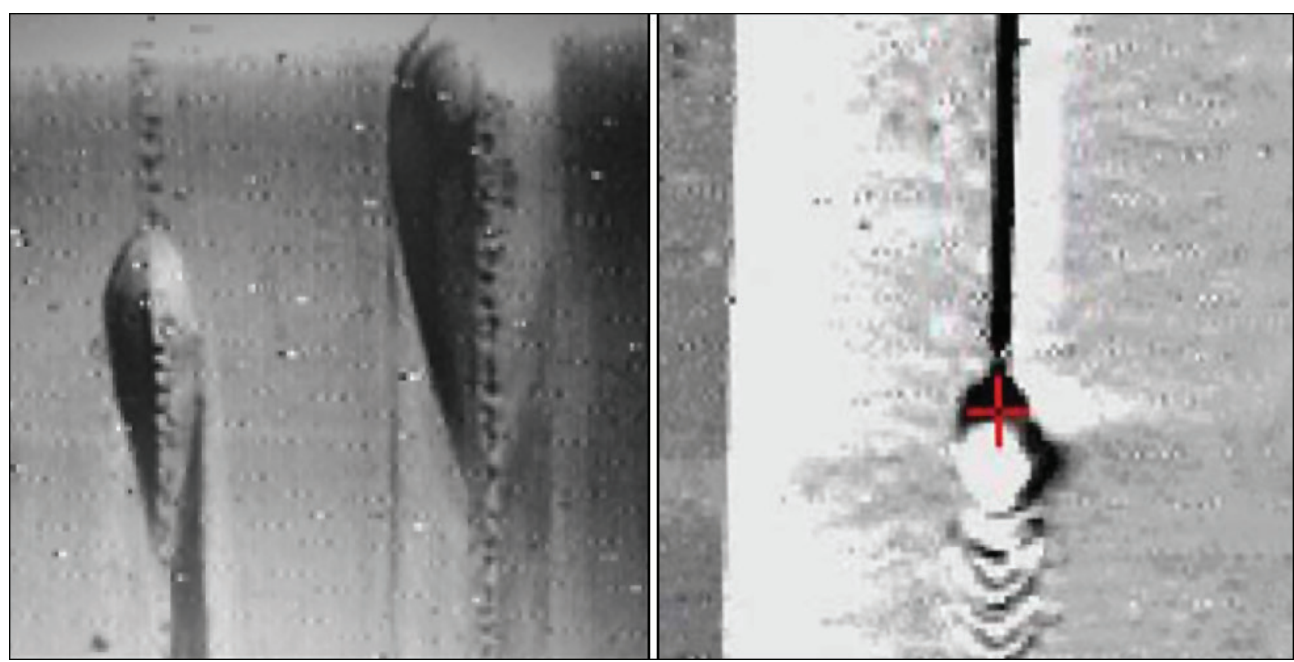

Figure 3. The secondary-emission image of welded surface 
At that the upper-level control program operates on the industrial computer Sinumerik PCU 50. The upper level interacts directly with the lower level elements, namely: the machine control panel (MCP), the main module NCU and connection module Basic PN, to which the mobile handheld terminal HT 2, used for the gun or weldment manual motion, is connected

Welding motion is under the CNC complete control both in the manual movement mode and at automatic welding mode. In the latter case, the text script of the prepared welding program is transmitted from the upper level to the NCU, where CNC makes a full calculation of the trajectory, proper interpolations, speeds and accelerations for each of the axes involved. CNC provides complete synchronization of all axes, both mechanical and virtual. As virtual axes, the channels of welding and focusing currents, as well as the channel of electron beam technological oscillation, are used [6]. At that the control assignments of these axes are taken from the DMP module of rapid analog outputs of the station ET 200M and converted into the CAN bus protocol (from which the high-voltage welding power supply is controlled).

Also the upper level interacts with the additional lower level element - the computer of the «RASTR-6» subsystem, which operates on the principles of a scanning electron microscope and makes it possible in real time to observe on upper-level program GUI the secondary-emission image of welded surface (Figure 3) before/after and during the welding process, precisely manually to aim the electron beam on any butt to be welded, as well as gives the data for operation of special automated algorithms of the weld butt «search» at both automatic teach-in (creation) of a new complicated curvilinear trajectory and correction of an existing trajectory immediately before welding of any serial product.

The PLC (Programmable Logic Controller) of NCU fulfills safe automatic control of vacuum system using digital and analog inputs/outputs of the station ET 200M.

Main technical parameters of KL-115 machine

Overall machine dimensions

(length $\times$ width $\times$ height), $\mathrm{mm} \mathrm{.} \mathrm{.} \mathrm{.} \mathrm{.} \mathrm{.} \mathrm{.} \mathrm{.} \mathrm{.} \mathrm{.} \mathrm{15960×10300×3740}$

Weight, tons . . . . . . . . . . . . . . . 48

Vacuum chamber internal size

(length $\times$ width $\times$ height), $\mathrm{mm}$. . . . . . . . . 4040×2950×2950

Working pressure in vacuum chamber, torr,

not worse than $\ldots \ldots \ldots \ldots \ldots \ldots \ldots \ldots \ldots \ldots .5 .10^{-4}$

Working pressure in EB gun, torr, not worse

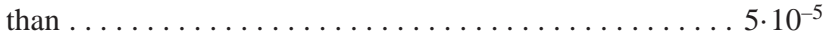

Pump-down time before working pressure in chamber

and EB gun is obtained, minutes, $\max \ldots \ldots \ldots \ldots \ldots 25$

EB gun movement (with positioning accuracy $\pm 0.1 \mathrm{~mm}$ )

stroke along coordinates $X, Y$

and $Z, m m \ldots \ldots \ldots \ldots \ldots$. . . . . . 3000, 1800 and 2000

EB gun linear movement speed, $\mathrm{mm} / \mathrm{s} \ldots \ldots \ldots \ldots$. $1.66-33.3$

EB gun rotation angle (with accuracy $0.1^{\circ}$ ) in $X-Y$ plane,

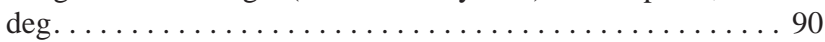

EB gun rotation angle (with accuracy $0,1^{\circ}$ ) in $X-Y$ plane,

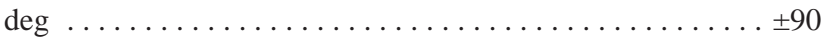

Electron beam gun and power supply: . . $60 \mathrm{~kW} / 60( \pm 0.06 \mathrm{kV})$

metal cathode life-time, $h \ldots \ldots \ldots \ldots \ldots \ldots$

beam deflection angle, $\operatorname{deg} \ldots \ldots \ldots \ldots \ldots \ldots \ldots . \ldots \ldots$

«RASTR-6» resolution upon observation, mm . . . . . . . 0.1

Equipped water chiller .................. Yes

Mains supply (according to German Standards

DIN EN 60 204-4.3) . . . . . . . . . 380, 50/60 Hz, 250 kVA

1. Nazarenko, O.K., Nesterenkov, V.M., Neporozhny, Yu.V. (2001) Design and electron beam welding of vacuum chambers. The Paton Welding J., 6, 40-42.

2. LaFlamme, G., Mac Williams, S., Rugh, J., Hendryx, R. (2006) Hybrid EBW process joining heavy-duty impellers. Welding J., 1, 44-47.

3. Myers, L., LaFlamme, G. (2000) Electron beam braze welding of compressor impellers. The Paton Welding J., 8, 53-57.

4. Paton, B.E., Nazarenko, O.K., Nesterenkov, V.M. et al. (2004) Computer control of electron beam welding with multi-coordinate displacements of the gun and workpiece. Ibid., 5, 2-5.

5. Nesterenkov, V.M., Khripko, K.S. (2017) Recent achievements of E.O. Paton Electric Welding Institute in development of equipment for electron beam welding. Zvaroc Professional, 2, 9-13.

6. Nazarenko, O.K., Nesterenkov, V.M., llyushenko, R.V. (2005) Weldability of aircraft aluminium alloys of great thickness in EBW. The Paton Welding J., 8, 25-31. 


\section{Calendar of November*}

NOVEMBER 1, 1917 Union Carbide \& Carbon Company was registered. In 1892 J. T. Morehead and T. Wilson, founders of Wilson Aluminium Company, performed first commercial melting of carbide. Further on J.T. Morehead transformed this company in Union Carbide Corporation, creating powerful industrial company on calcium carbide production, which is the main raw material for acetylene production.

NOVEMBER 2, 1942 Members of Soviet tank commission saw the samples of the new German tank «Panther». Tank hull was built from rolled surface-hardened armor plates of medium and low hardness, connected by «tonguing joint» and welded with double weld. Turret was set on armored basement welded of sheets of $80 \mathrm{~mm}$ thickness, thickness of turret basement is $100 \mathrm{~mm}$. «Panthers» in many respects were modernized samples of Soviet tank T-34. However, taking into account that they were assembled by manual arc welding and Soviet ones were assembled with the help of automatic high-speed welding Germany could not quickly and in sufficient amount supply «Panthers» and «Tigers» in the lines.

NOVEMBER 3, 1916 War ship Vendetta (D69), fleet destroyer of type $V$ of the Royal British and Australian Navy of the time of the Second World War, was laid. On October 17, 1917 it was included in the Royal British Navy. On October 11, 1933 it was transferred to the Royal Australian Navy. Fleet destroyer Vendetta was the first all-welded vessel built in Australia. Vendetta and other ships of this class were 390 feet $(120 \mathrm{~m})$ length and $2800 \mathrm{t}$ tonnage. The ship was constructed using electric arc welding.

NOVEMBER 4, 1953 Firstly the tests were carried out and then the traffic was opened on all-welded bridge in Kyiv of 1543 m length. Without waiting the complete end of construction of pilot welded bridges, the decision was made on start of manufacture and assembly of spans of the largest all-welded bridge over the Dnieper River. The leading role in designing, manufacture and assembly of spans was given to Electric Welding Institute and personally to E.O. Paton. The project of the bridge was developed by «Ukrproektstalkonstruktsiya» Institute. The bridge of 1543 $\mathrm{m}$ has 24 spans, four of them are navigable of $87 \mathrm{~m}$ height. The main scopes of works on welding of the main girders were carried out using automatic and semiautomatic machines of PWI development. The technological process of assembly and welding of main girders was performed by straight-line flow method.

NOVEMBER 6, 1936 Formal opening of Volodarsky Bridge - bridge over the Neva River in Saint-Petersburg. The project required pivot span in the middle of the bridge, side spans in accordance with the requirements of navigation could not already be every 100 meters. The pivot span of the bridge was double-leaf bascule system with stationary horizontal rotation axis with rigidly fixed counterbalances. Structure of the pivot span for the first time was made metallic and all-welded. For the time of bridge construction, the design works were started in 1931, application of electric welding in such a critical construction and in such scopes should be considered brave innovation.

NOVEMBER 7, 1938 Formal opening after reconstruction of Blagoveshchensky bridge (earlier also Nikolaevsky and Lieutenant Shmidt bridge), first permanent bridge over the Neva River in Saint-Petersburg. For economy of money and time it was decided to use the old bridge bearings, subjecting to reconstruction only their upper part. Due to design the new bridge was outstanding achievement of Soviet building engineering of the thirties. A series of significant improvements in bridge construction technique were implemented at its construction. Electric welding was used for joining the elements of span structure instead of rivets. Such method of joining of steel elements was for the first time used for manufacture of such a tremendous and critical structure.

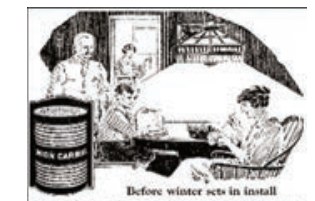

UNION CARBIDE GAS
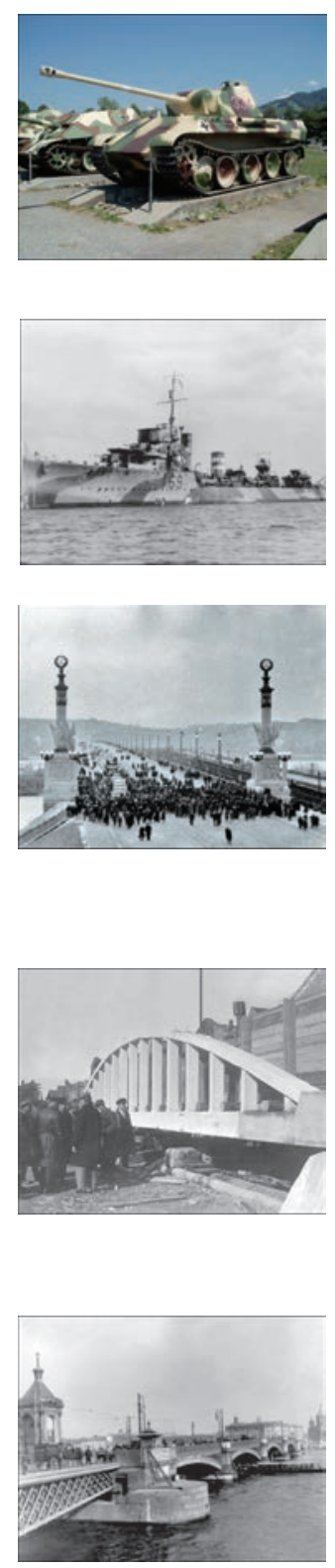

NOVEMBER 7, 1937 Birthday of N.M. Voropai (1937-2014), Dr. of Tech. Sci. representative of the Paton school.

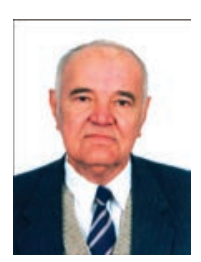
Worked on theoretical and experimental development of scientific fundamentals of physical and metallurgical processes in mechanized gas-shielded welding. He developed the methods of regulation of arc characteristics with consumable and non-consumable electrode, arc welding in atmosphere of high pressure, argon-arc and microplasma welding using different polarity current pulses, arc welding with activated wire, electric-plasma polishing of the surface of electrode wire.

\footnotetext{
*The material was prepared by the Steel Work Company (Kryvyi Rih, Ukraine) with the participation of the editorial board of the Journal. The Calendar is published every month, starting from the issue of «The Paton Welding Journal» No.1, 2019.
} 
NOVEMBER 11, 1976 Alexander Calder (1898-1976) died. He was American sculptor, which gained world-wide fame due to intricate figures of wires and so-called mobiles — kinetic sculptures, which is driven by electricity or wind. In 1926 he moved to Paris, where he joined the circles of surrealists and constructivists. At that time he found the new form of sculpture, i.e. figures from wire. These figures are the pictures in space endowed with humor and movability of puppets. Flexible material, from which they were made, allows easy change of figure pose. He was a well-known sculptor, which carried to perfection the art of development of sculptures by welding.

NOVEMBER 12, 1942 The record of assembly and welding of ship hull was set at Richmond Yard dockyard. It was necessary only four days for that. Due to replacement of riveted structure and rivet technology on welded structure and welding in ship construction allowed saving $500 \mathrm{t}$ of steel. Construction cycles dropped to 50 days. In order to decrease the time and reduce the manufacture costs, decrease residual stresses and deformations the scheme of «partition» of hulls for sections was developed. Each section was welded from separate sheets and elements of a set that allowed manufacturing the ship on a flow line in the workshop at several sites.
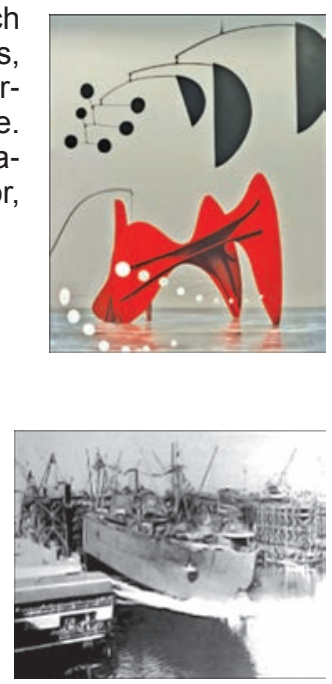

NOVEMBER 14, 1949 The first fly of seaplane Be-6, a multipurpose flying boat of development of marine aircraft construction CDB at aircraft factory No.31. The first variant of plane was carried out using welding, but it got unsatisfactory characteristic (presence of cracks in the structure). Later on in a new model Be-12 welding was used for parts of corrosion-resistant alloy AMg-6T. It provided economy of mass at each such part up to $8.8 \%$. Replacement of manufactured from casting and forgings large-sized parts of ship (lamps, manhole frames, strakes etc.) by welded ones provided significant saving of weight and increased corrosion resistance of the structure.

NOVEMBER 15, 1878 American inventor Thomas Edison established General Electric Company. Initially it was named Edison Electric Light and after joining in 1892 with Tomson-Houston Electric Company founded by another prominent American inventor E. Tomson got its modern name. Edison being aggrieved that his name escaped from the sign left the company. Ch. Coffin became its president, professor Edison was appointed a technical director. From the date of its establishment the company was a pioneer in many branches of welding science and technology, being the place of development of joining technologies. It became one of the main distributors of resistance welding in the USA in the beginning of its development.

NOVEMBER 16, 1931 The first fly of apparatus «Stal-2», Soviet short range passenger aircraft with one conventional engine of air cooling of development of DB of engineer Putilov (NII GVF). This was the first serial aircraft with all-welded structure of frame. The peculiarity of the aircraft was manufacture of welded frame of stainless steel of «Enerzh-6» grade. Skin of planes, tail unit and air-frame stern-post is linen, side parts of fuselage is plywood, front part of fuselage is dural.

NOVEMBER 17, 1972 The first fly of MiG-23BN, Soviet supersonic special bomber-fighter of the third generation. Its production requiring multiple complex and specific technological processes and fitting, was organized at Tushinsky machine-building plant (TMB), having known experience of work with steel structures and welding. Gained experience and welding technologies of structural steels were used in mastering the welded sections of fuselage MiG-23. TMB tried to implement manufacture of welded bays of MiG-23 from titanium, but technologically complex material did not give satisfactory results. Welding of tanks from VNS-2 at the end was mastered at «Znamya truda» plant.

NOVEMBER 18, 1939 British airplane carrier «Ark Royal» went hunting for German battle ship «Bismarck». For the first two years of the Second World War it participated in many naval operations of the Royal Fleet, where was distinguished in combat actions. One of the famous ships of that time. Welding was widely used in ship construction, namely $65 \%$ of hull structures were made using it, including transverse and longitudinal bulkheads, decks (except for flight and upper hangar decks), outer skin above the lower hangar deck, foreship. Due to welding weight of hull of airplane carrier was reduced by $500 \mathrm{t}$ that gave the possibility to rise armoring.

NOVEMBER 19, 1938 Birthday of N.P. Trigub (1938-2012), Dr. of Tech. Sci., representative of the Paton school. He

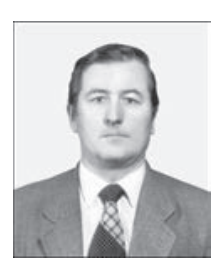
made significant contribution in development of domestic production of titanium ingots. He developed a technology of electron beam melting with cold hearth and batch supply of liquid metal in mould, electron-beam guns and units for production of ingots of $20 \mathrm{t}$ weight. Scientific-production center «Titan» and production of ingots of titanium and titanium alloys for industry was organized under his leadership.

NOVEMBER 20, 1996 Delta II Heavy, rocket of the second generation of carrier rockets of Delta family was launched in Mars side. It was designed and constructed by aircraft building Company McDonnell Douglas. The rockets of the second generation were called «heavy» since they were used for on-orbit delivery of heavy cargo. Application of friction stir welding made welds and joints of the rocket lighter, besides the structure was strong and carried tremendous loads during the fly. Friction stir welding was also used in manufacture of Delta IV rockets.

NOVEMBER 21, 1943 Tests of tank IS-2 took place in the field under Moscow. Armor hull of the tank (except for the front in machine parts) were welded from rolled armor plates of 90, 60, 30 and $20 \mathrm{~mm}$ thickness. From the middle of 1944 with the availability of rolled armor of high strength the front part started to be welded of $90 \mathrm{~mm}$ armor plates. Front parts with other were joined by welding. Streamlined turret represent itself armor casting of complex geometry, its edges of 90 $\mathrm{mm}$ thickness were located under angle to vertical line in order to increase shell ballistic strength. The frontal part of turret with fire slit for gun, formed with intersection of four spheres, was caste separate and welded with the rest parts of the turret.

NOVEMBER 22, 1922 Birthday of Eila Hiltunen (1922-2003), Finnish sculptor. The earlier works were made of marble and bronze, from the end of $1950^{\text {th }}$ started experimenting with casting and welding. In 1966 Hiltunen was awarded with the Higher State Honor of Finland for people of art, i.e. Pro Finlandia medal. One of the most famous works of Eila Hiltunen is a monument to composer Johan Sibelius in Helsinki. Reduction of the monument stands close to United Nations Headquarters in New York.
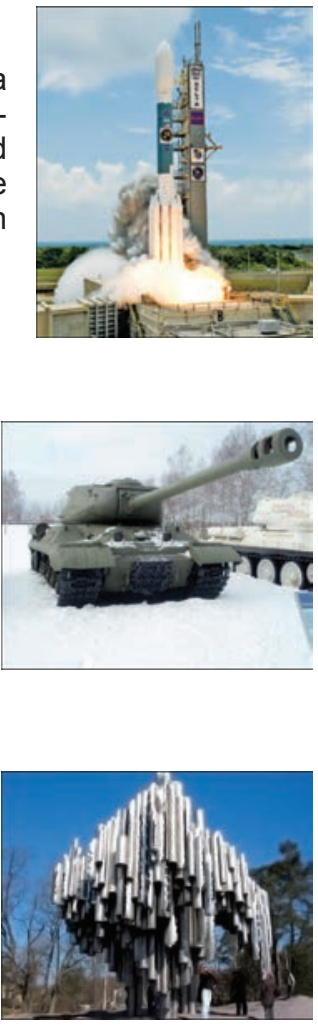

NOVEMBER 23, 1802 Russian scientist V.V. Petrov (1761-1834) discovered an electric arc the phenomenon, without which welding with electricity is impossible. The scientist connected to a powerful battery two small pieces of coal, touched by them each other and little bit drew apart. For the first it was sparks, then the gap between the coals was filled with blinding flame, which on form reminded arc-shaped bridge. That was a discovery of the electric arc discharge, the brightest for the next 100 years light source. Discovery by V.V. Petrov of electric arc attracted attention of the scientific community. A year before publishing of the book about Petrov's experiments in 1802 , the arc was mentioned in «Peterburgskie vedomosti».

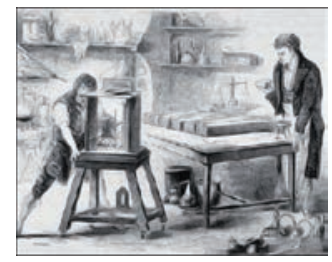

NOVEMBER 24, 1881 French engineer A. Meritins patented a device for welding of transferred arc consisting of holder with carbon electrode connected to positive pole, and cast iron plate connected to negative pole. The holder and plate were located in a chamber with porthole. Meritins used this device only for welding of lead plates (French patent No. 146010 dated November 24, 1881).

NOVEMBER 25, 1937 End of the World Fair of 1937 in Paris, at which the symbol of Soviet hall became a 24 meters sculptural group «Worker and Kolkhoz woman», made of stainless steel on Vera Mukhina design and dedicated to the achievements of socialist industrialization. In the Soviet Union it was the first large welded structure. Prof. P.N. Lvov, the first among the welders Cavalier of Lenin Order, put on hand and made huge sculptures without full-scale models. The elements of figures were tailored by a template and tapped out by model fragments from sheets of stainless steel, which were after that welded to parts of tubular carcass.
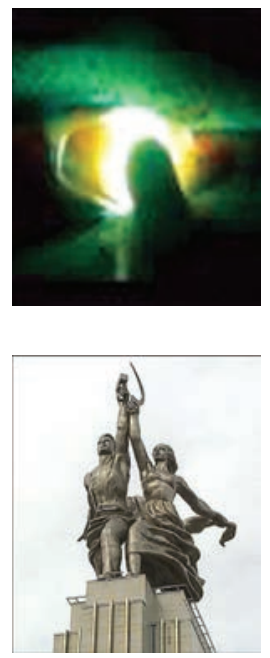


\section{CALENDAR OF NOVEMBER}

NOVEMBER 27, 1918 Birthday of B.E. Paton, an outstanding Ukrainian scientist in the field of welding, metallurgy

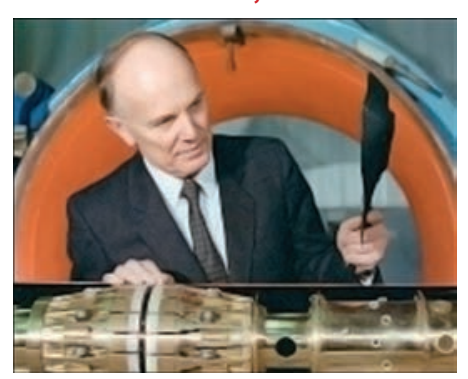
and technology of materials and materials science, prominent public figure and talented organizer of science, academician of the National Academy of Sciences of Ukraine, Academy of Sciences of the former USSR and Russian Academy of Sciences, President of the NAS of Ukraine, International Association of Academies of Sciences, director of the PWI, honoured personality of science and technology of the Ukrainian SSR, laureate of the Lenin Prize and State Prizes of the USSR and Ukraine, twice Hero of the Socialist Labour of the USSR, Hero of Ukraine. Boris Paton, together with his father E.O. Paton, established a world-known Paton scientific school.

NOVEMBER 28, 1907 Birthday of V.I. Dyatlov, a scientist, which for the first time patented a new principle of design

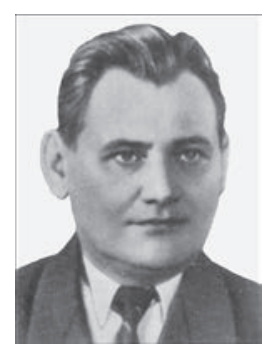
of arc automatic machines for electrode feeding with constant rate, which does not depend on arc voltage or any other factors. He in 1942 was the first person who paid attention on self-regulation of arc in consumable electrode welding, investigated this phenomenon and proposed to use it in other automatic machines. In a series of cases self-regulation of arc is so intensive that there is no need to apply sufficiently complex schemes of automatic arc regulation.

NOVEMBER 29, 1939 A day before beginning of the Soviet-Finland War, KV-1 tanks were sent to the battle front. The front part of turret with file port for a gun formed by intersection of four spheres were cast separately and welded with other turret armor parts. Turret of serial KV was manufactured in three variants, namely cast, welded with rectangular compartment and welded with rounded compartment. Thickness of armor in welded turrets was $75 \mathrm{~mm}$ and that of cast was $95 \mathrm{~mm}$ since cast armor was less strong. In 1941 welded turrets and tank side armor plates of some tanks were additionally reinforced, namely $25 \mathrm{~mm}$ armor shields were fixed on them using bolts, moreover an air gap was remained between the main armor and shield, i.e. this variant of $\mathrm{KV}-1$ virtually got spread armoring.

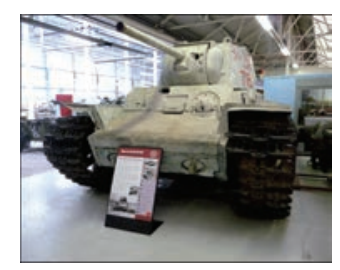

NOVEMBER 30, 1911 Beketov N.N. died (1827-1911). He was a Russian physical chemist, one of the founders of

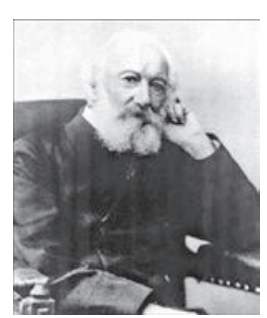
physical chemistry and chemical dynamics, laid the basis for a principle of aluminothermics. In 1859 he developed a method of metal production based on alumothermics, i.e. reduction of their oxides by aluminum. The scientist proved that a charge mixed of aluminum and iron oxide powders burns at temperature making several thousand degrees transforming in iron and slag. Instead of aluminum it was possible to use magnesium, and reduce from oxide not only iron, but also series of other metals (chromium, boron, titanium). This discovery recently found application in metallurgy for manufacture of carbon-free metals, ferro-alloys, foundry alloys and in the process of alumothermic welding. 